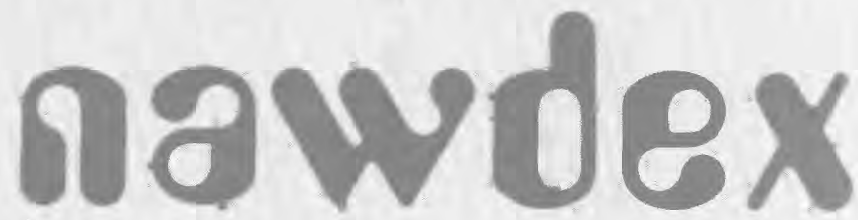

NATIONAL WATER DATA EXCHANGE

\title{
DEFINITIONS OF COMPONENTS OF THE MASTER WATER DATA INDEX MAINTAINED BY THE NATIONAL WATER DATA EXCHANGE
}

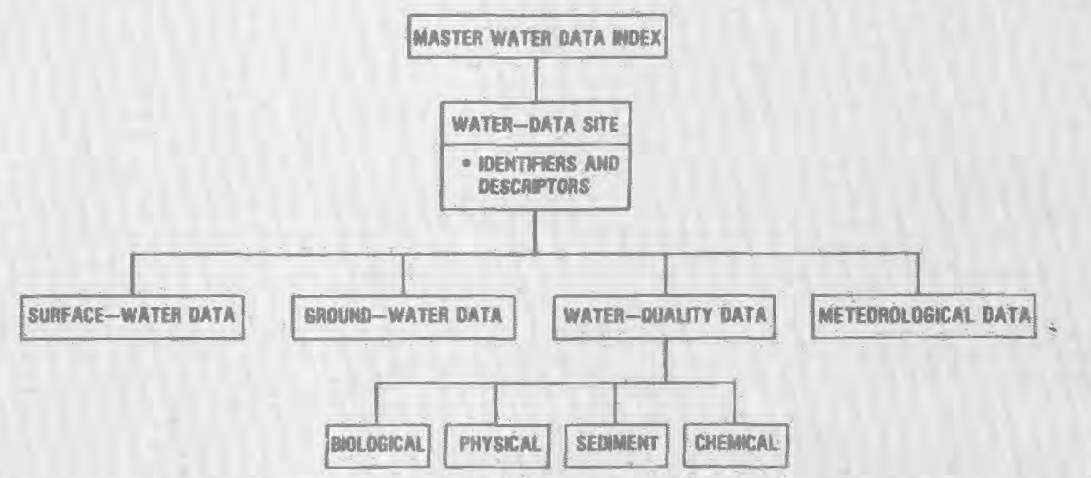

U.S. GEOLOGICAL SURVEY

Open-File Report 82-327 


\section{DEFNITIONS OF COMPONENTS OF THE MASTER WATER DATA INDEX MAINTAINED BY THE NATIONAL WATER DATA EXCHANGE}

By ROBERT A. PERRY and OWEN O. WILLIAMS

U.S. GEOLOGICAL SURVEY

Open-File Report 82-327

(Supersedes Open-File Report 78-183)

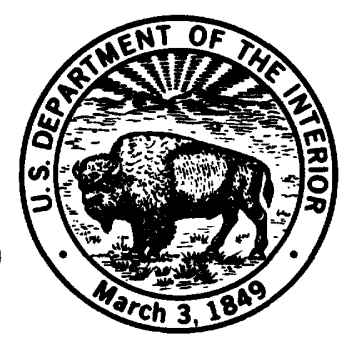




\section{UNITED STATES DEPARTMENT OF THE INTERIOR \\ JAMES G. WATT, Secretary}

GEOLOGICAL SURVEY

Dallas L. PECK, Director

For additional information write to:

Chief Hydrologist

U.S. Geological Survey, WRD

421 National Center

Reston, Virginia 22092 
The National Water Data Exchange (NAWDEX) is an interagency program to facilitate the exchange of water data and to promote the standardization of water-data-handling procedures. The participants in the NAWDEX program are those Federal, State, local governmental organizations, and private organizations that collect and use water data.

NAWDEX maintains a "Master Water Data Index" which is a computerized index of available water data. The Index contains information on sites for which water data are available, the location of these sites, the type of site, the datacollection organization, the types of data available, the major water-data parameters for which data are avallable, the frequency at which these parameters are measured, and the media in which the data are stored. The Master Water Data Index meets an Office of Management and Budget requirement in Circular A-67 that the Department of the Interior establish and maintain a catalog of information on water data.

This document defines the data components contained in the Master Water Data Index (MWDI); it is referred to as the MWDI Data Dictionary. Its purpose is to describe, in detail, the information in the MWDI:

Inquiries related to the Dictionary may be directed to:

Program Manager

National Water Data Exchange

U.S. Geological Survey

421 National Center

Reston, Virginia 22092 
, 
Preface--

Int roduct ion- 1

Overview of the Master Water Data Index- 2

Data-base description- 2

Data-base structure- 2

How to use this document- 4

Master Water Data Index component definitions- 7

Water-data site (component nos. $0-40,150,250,350,450$,

$550,650,750,1350)$

Surface-water data (component nos. 100-149)- 42

Ground-water data (component nos. 200-249) 80

Water-quality data (components nos. 300-355) 109

Biological (component nos. 400-464) 128

Physical (component nos. 500-546) 158

Sediment (component nos. 600-646)- 174

Chemical (component nos. 700-746) 190

Projects (component nos. 800-801) $219^{*}$

Networks (component nos. 900-901) 221

Site Funding (component nos. 990-992) 224

Funding (component nos. 1000-1044) 227

Other sources (component nos. 1100-1101) 234

Source information (component nos. 1200-1202) - 236

Meteorological (component nos. 1300-1349)- 239

Selected References- 263 


\section{ILLUSTRATIONS}

Figure 1. Hierarchical structure and contents of the Master Water Data Index data base-_-_-_-

Page

2. Format of a component description-

APPENDIXES

Appendix A. Data collection frequency codes- 267

B. Data storage codes- 268 


\title{
DEFINITIONS OF COMPONENTS OF THE MASTER WATER DATA INDEX MAINTAINED BY THE NATIONAL WATER DATA EXCHANGE
}

\section{By}

Robert A. Perry and Owen 0. Williams

\author{
INTRODUCTION
}

The Master Water Data Index (MWDI) is a computerized data base, developed and maintained by the National Water Data Exchange (NAWDEX) Program Office, which contains information about water-data collection sites of NAWDEX members and participants. It contains information on the identification and location of sites for which water data are available, the type of data-collection site, the organizations collecting data at each site, the current status of each site, the types of data available, the period of time for which data are available, the major water-data parameters for which data are available, the frequency at which these parameters are measured, and the media in which the data are available.

This document contains a definition and description of each component of the MWDI data base. For simplicity, it is referred to as a data dictionary. It is intended, primarily, to assist those persons using the MWDI in understanding and clarifying information obtained from the data base.

The MWDI is designed to be used independently, or in conjunction with, the Water Data Sources Directory (WDSD). The WDSD is also a computerized data base developed and maintained by the NAWDEX Program office. It contains information about organizations that are sources of water data; the major orientation of water-data activities conducted by these organizations; the names, addresses, and telephone numbers of offices within each organization from which water data may be obtained; the types of data held by each organization and the geographic locations where these data have been collected; and alternate sources of an organization's data. A few components are common in both data bases, thereby allowing retrieved information to be cross-referenced between them. For example, a retrleval may be made from the Master Water Data Index to identify all sites, within a geographic area of interest, for which water-quality data are available. A retrieval can then be made from the Water Data Sources Directory to determine the addresses from which data may be obtained from organizations operating the identified sites. A description of the Water Data Sources Directory is found in the publication entitled "Definition of Components of the Water Data Sources Directory Maintained by the National Water Data Exchange." 
OVERVIEW OF THE MASTER WATER DATA INDEX

Data Base Description

The Master Water Data Index (MWDI), contains the following general categories of information:

Station Identification

Unique identifiers

Operating organization

Type of site (stream, well, etc.)

Geographical identifiers

Physical identifiers

Station status (active, inactive)

Supplementary data available

Type of water data collected (surface water, ground water, water quality, meteorologica1)

Period of record

Record continuity

Data parameters collected

Frequency of data collection

Media on which data are stored

Purpose of activity

Status of activity

Data-Base Structure

The MWDI data base is managed and maintained through a generalized Data Base Management System called SYSTEM 20001/. The data in a SYSTEM 2000 Data Base are organized into a hierarchical structure as shown in figure 1 on page 269 . A11 the data about a single major item (in this case, a water data collection site operated by an organization) comprises a logical entry in the data base. In certain instances two or more organizations may be collecting different kinds of water data at the same physical site. Each organization will separately report its station activity at that site as a separate logical entry. Individual pieces of information, such as the drainage area of the station or the temperature of the water are data components. A group of components related to the same subject that may have multiple occurrences of data is called a schema record. Each single occurrence of a group of data values related to the same subject within a schema record is called a data record.

1/ SYSTEM 2000 is a registered trademark of Intel Corporation and its mention does not imply endorsement by the U.S. Geological Survey. 
Under the concept of the hierarchial structure, every data component "belongs to" a schema record and every schema record "belongs to" a higher level schema record (the logical entry is, itself, a schema record at the highest level, belonging to the data base). Thus, information about the temperature of water "belongs to" the set of information about the type of water data (water quality) collected; the type of water data information "belongs to" the collection site; and the collection site (the logical entry) is a schema record belonging, in turn, to the data base as a whole.

A fundamental aspect of the schema record is that it can occur once, many times, or not at all. Each logical entry contains all the information about an individual site, and because the logical entry is a schema record that can occur many times, there can be information about many sites in the data base. Similarly, for any particular logical entry (site) there can be more than one type of water data collected. Each "type of water data" schema record contains information on particular data parameters collected.

Figure 1 identifies the various schema records which have been defined for the MWDI data base. They are arranged in a logical tree structure representing their hierarchical relationships to each other. That is, all those schema records, defined by boxes, which appear below the single box located at the top of the figure are groups of related data components directly related to the description of the site. According to the situation at a particular site, any one of these lower-level schema records may occur once, several times, or not at all. The absence of a schema record may be the result of the lack of data, or applicability, to that particular site. For example, the schema record labeled "Surface Water Data" would not be appropriate with a site whose type was identified as "wel1."

An important aspect of the system is that logical entries can be of varying length, since, if a data record is not required, it is not stored and no space is reserved for it. If information that belongs in a nonexistent data record is added later, the data record is created and stored in any available space. 
This document contains a detailed explanation of each Master Water Data Index (MWDI) schema record and data component. It is organized in the same order as the MWDI data base, with descriptions of data components belonging to the same schema record being located together. Each page in this document describes one schema record or data component. A user searching for the description of a particular data component should use figure 1 to determine its schema record ( $S R$ ), then find the page number of that schema record in the table of contents. The description of the data component follows the description of the schema record.

At the top of each page, certain attributes of the data component defined are 1 isted to provide information generally needed only by data processing personnel for software development. These include IN SR, DATA TYPE, PICTURE, and LARGEST VALUE. A full definition of each of these attributes is found below. For the majority of users it will only be necessary to consider these attributes when producing a report or formulating a complex retrieval using the SYSTEM 2000 Immediate Access retrieval language. In other words, the majority of users need not be concerned with these attributes.

The attributes with which all users should be concerned are COMPONENT NAME, COMPONENT NUMBER, and KEY. COMPONENT NAME and COMPONENT NUMBER are simp1y labels for the component and may be used interchangeably by the user whenever referring to a component. The KEY attribute is an indicator of the relative expense and response time the user can expect when formulating a retrieval using the component in a conditional select clause. For most cases, using key components $\left(K E Y=Y e s\right.$ ) instead of non-key components ( $\left.K E Y=N_{0}\right)$, in specifying the selection criteria for a data base retrieva1, will result in faster response and lower expense. Additional information on the use of attributes may be obtained from the System 2000 Reference Manua1.

Figure 2 illustrates the format used to describe MWDI components. The following text contains an explanation of each part of the description.

IN SR - A number appears here, which is the number of the schema record (SR) to which the schema record or data component belongs. For example, the top level schema record, as shown in figure 1 , is schema record 0 . Data components 1 through 40, 150, 250,350,450,550,650,750, and 1350 belong to schema record 0 , as do schema records $100,200,300,800,900,990,1000$, 1100,1200 and 1300 . All data components that belong to the same schema record appear together in this document.

COMPONENT NAME - The unique name of the schema record or data component as used in the data base.

COMPONENT NUMBER - The unique number of the schema record or data component as used in the data base. 
NAWDEX

MASTER WATER DATA INDEX

DATA DICTIONARY

$\overline{\text { IN SR }}$

MANDATORY

KEY

DATA TYPE

PICTURE

LARGEST VALUE

Data Values

General Description

Figure 2.--Format of a component description. 
MANDATORY - Marked either "Yes" or "No." If "Yes," a value for the data component must be present in each data record. For example, data component 1 , NAWDEX ID, is mandatory because it is the unique identification code of the site and, therefore, must always be present. On the other hand, data component 115, COMPLETE FLOW is not mandatory because not every site has streamflow measurements and, therefore, the data component may be null (nonvalued).

KEY - Marked either "Yes" or "No." In SYSTEM 2000 , certain data components are designated by the designer of the data base as KEY to provide efficiencies in data retrieval. However, any data component, whether KEY or not, can be retrieved from the MWDI. This designation is not used for schema records.

DATA TYPE - Contains either CHAR, TEXT, INTEGER, DECIMAL, or DATE, depending on what type of data are stored for the component. CHAR and TEXT are used to store alphanumeric data (any character recognized by the computer), the difference being that TEXT retains leading and trailing blanks and multiple blanks between words, and CHAR does not. INTEGER and DECIMAL store whole numbers and decimal numbers, respectively, and DATE stores dates in the $\mathrm{MM} / \mathrm{DD} / \mathrm{YYYY}$ format. This notation is not applicable to schema records.

PICTURE - Describes the "storage capacity" of the data component, using $X(n)$ or $9(n)$ notation. Data components that are CHAR and TEXT have picture lengths of $X(n)$, where " $n$ " is the total number of characters. For example, $X(23)$ indicates that typically up to 23 characters are stored for the data component. $X$ indicates that only one character may be stored for the data component. INTEGER uses $9(n)$ to indicate the total number of digits that can be stored. For DECIMAL data components, $9(n) \cdot 9(n)$ indicates places to the left and right of the decimal point. DATE is always MM/DD/YYYY, where MM equals month, DD equals day, and YYYY equals year, and, therefore, PICTURE designation is unnecessary. Schema records do not have a PICTURE designation.

LARGEST VALUE - This is the largest value that is allowed for the data component. For example, the largest value of a component designated as PICTURE 9(4) may be 5075 because of editing standards placed on data input to the data base. For data components defined as CHAR or TEXT, the largest value is allowed to exceed the PICTURE size because of the SYSTEM 2000 "overflow" capability. An example of this is data component 7, STATION NAME, which is PICTURE X(30) but may contain names up to 48 characters long if necessary.

DATA VALUES - This is a narrative definition of the values that can be stored for a data component.

GENERAL DESCRIPTION - A narrative description of the type of data stored for a data component, its purpose, and the source or usefulness of the data. If If a coding scheme is used, the meaning of each code is explained. 
MASTER WATER DATA INDEX

COMPONENT DEFINITIONS 
$\frac{N / A}{\text { IN SR }}$

MANDATORY N/A
WATER DATA_SITE

COMPONENT NAME $\frac{0}{\text { COMPONENT NUMBER }}$

DATA TYPE

SR

PICTURE N/A

KEY N/A

LARGEST VALUE
N/A

This is the highest level schema record in the hierarchical structure of the data base and, therefore, represents the logical entry of a single water data collection site operated by an organization. It contains information on the identification, location, and type of site, and the organization that operates it. 
$\frac{0}{\text { IN SR }}$

MANDATORY Yes

PICTURE $X(20)$
NAWDEX ID

COMPONENT NAME

KEY Yes

DATA TYPE

Char
COMPONENT NUMBER

LARGEST VALUE

22 characters

Data Values - The NAWDEX Station Identification number can be up to 22 characters in length. The first 1-5 characters contain the NAWDEX Agency code (see component 4) and the remaining characters contain the Agency Station Number (see component 5). In the event no Agency Station Number exists for a site, the latitude-longitude of the site or a unique sequence number may be substi-. tuted. In the event duplicate Agency Station Numbers exist, a one- or two-digit sequence number may be appended to the end of the NAWDEX ID.

General Description - The NAWDEX ID is assigned by the NAWDEX Program Office and is the unique identifier of $\bar{a}$ logical entry in the data file. A logical entry is all of the information about a site that is being stored. A site is a hydrologic data collection site that is being operated by an individual organization. If more than one agency is collecting hydrologic data at the same physical site, there will be a separate logical entry for each agency. 
$\frac{0}{\text { IN SR }}$

MANDATORY Yes

PICTURE 9(6)
LATITUDE

COMPONENT NAME
2

COMPONENT NUMBER

KEY No

DATA TYPE Integer

LARGEST VALUE

900000

Data Values - This component (six digits) contains the latitudinal location of the site expressed in degrees, minutes, and seconds. For sites where seconds, and in some cases minutes, have not been submitted, zeros are stored in those portions of the value. Latitudinal locations north of the equator are positiveiy valued and those south of the equator are negatively valued.

General Description - The latitude is the angular distance north or south from the Earth's equator measured through 90 degrees. The length of a degree varies from 68.704 statute miles at the equator to 69.407 at the poles because of the flattened configuration of the Earth. The length of a second is approximately 100 feet. 
$\frac{0}{\text { IN SR }}$

MANDATORY Yes

PICTURE $9(7)$
LONGITUDE

COMPONENT NAME

KEY No

DATA TYPE Integer

Data Values - This component (seven digits) contains the most accurate available longitudinal location of the site expressed in degrees, minutes, and seconds. For sites where seconds and in some cases minutes, have not been submitted, zeros are stored in those portions of the value. Longitudinal locations west of the prime meridian are positively valued and those east of the prime meridian are negatively valued.

General Description - Longitude is the angular distance, measured in degrees, due east or west from the prime meridian that runs between the north and south poles and passes through Greenwich, England. The length of a degree varies from 69.65 statute miles at the Equator to zero miles at the poles. The length of a second is a little over 100 feet at the equator and about 78 feet at the 40 degree latitudinal parallel which passes through the approximate middle of the United States. 
$\frac{0}{I N S R}$

MANDATORY Yes
NAWDEX AGCY

COMPONENT NAME
4

COMPONENT NUMBER

PICTURE $X(5)$

KEY Yes
DATA TYPE Char

Data Values - The NAWDEX Agency code varies in length from three to five characters. For Federal organizations, it is US followed by a two or three character abbreviation of the organization's name. Values for non-Federal organizations whose activities are within a given State boundary have a two-character alphabetic State code followed by a NAWDEX-assigned sequence number. Alphabetic State codes are contained in the Federal Information Processing Standards (FIPS) Publication 5-1, dated June 15, 1970, entitled "States and Outlying Areas of the United States." Values for non-Federal organizations having activities at the multi-State or national level have a three to five character abbreviation of the organization name (the characters US will not appear in the first two character positions). The NAWDEX Agency code also appears in component 1 as the beginning part of the NAWDEX Identification number.

NAWDEX Agency codes are presented in the publication entitled "Identification Codes for Organizations Listed in Computerized Data Systems of the U.S. Geological Survey" by Edwards, M. D., and Myers, B. M., which may be obtained from the National Water Data Exchange, U.S. Geological Survey, 421 National Center, Reston, Virginia 22092

General Description - The NAWDEX Agency code is assigned by the NAWDEX Program Office and is the unique identifier for particlpating Federal and non-Federal organizations that actively collect and store water data. Non-Federal organizations include State, county, and municipal organizations as well as intergovernmental compacts, private organizations, universities, and any local organizations at other than county or municipal leve1. 
$\frac{0}{\text { IN SR }}$

MANDATORY No

PICTURE $\mathrm{X}(15)$
AGCY_STA_NO

COMPONENT NAME

KEY No

DATA TYPE

Text

Data Values - The Agency Station Number may consist of varying configurations of alphabetic characters and numbers depending upon the type of system used by the operating organization to distinguish among its sites. For example, the U. S. Geological Survey uses either an 8-digit downstream order number or a 15-digit number, which contains the station latitude in the first 6 characters and the station longitude in the next 7 characters followed by an arbitrary 2-digit sequence number.

General Description - The Agency Station Number is the code assigned and used by the participating organization that operates hydrologic data collection sites to uniquely identify the individual sites under its control. 
$\frac{0}{\mathrm{IN} \mathrm{SR}}$

MANDATORY No

PICTURE $\quad \mathrm{X}(30)$
STATION_NAME

COMPONENT NAME
7

COMPONENT NUMBER
KEY No

LARGEST VALUE
DATA TYPE

Char

48 characters

Data Values - The station name may contain up to 48 printable characters.

General Description - The station name is assigned by the participating organizations for the sites where it conducts water-data collection activities. It may contain both the name and location of the site. 
$\frac{0}{\text { IN SR }}$

MANDATORY No

PICTURE $X(2)$
NON_US_COUNTRY

COMPONENT NAME
71

COMPONENT NUMBER
KEY No
DATA TYPE Char

Data Values - This component contains a two-character alphabetic country code If, and only if, the site is physically located outside the United States; if the site is located within the United States, the component is not valued. Commonly used values are:

$$
\begin{aligned}
& M X=\text { Mexico } \\
& R P=\text { Republic of the Phillipine Islands } \\
& C A=\text { Canada }
\end{aligned}
$$

A complete 1ist of country codes is contained in the Federal Information Processing Standards (FIPS) publication 10-2, dated 1976, entitled "Countries, Dependencles, and Areas of Special Sovereignty."

General Description - The non-U.S. country code is valued for only those sites that Ile outside the borders of the United States and Its outlying areas. It bears no relationship to the location of the organization or office that is responsible for the operation of the site. 
$\frac{0}{\text { IN SR }}$

MANDATORY Yes

PICTURE 9(3)
STATE

COMPONENT NAME
8

COMPONENT NUMBER

DATA TYPE Integer

Data Values - This component contains a two-digit numeric code representing the State in which the site is physically located. Numeric codes for foreign installations will also appear, when applicable, as follows:

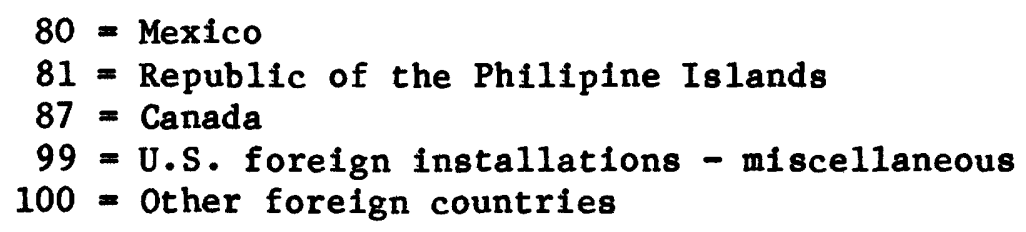

A complete 1ist of State codes is contained in the Federal Information Processing Standards (FIPS) Publication 5-1, dated June 15, 1970, entitled "States and Outlying Areas of the United States."

General Description - The STATE component is valued for those sites which are physically located within the United States. It bears no relationship to the organization or office that is responsible for the operation of the sites. 
$\frac{0}{\text { IN SR }}$

MANDATORY No

PICTURE 9(3)
COUNTY

COMPONENT NAME

KEY No

DATA TYPE

Integer

Data Values - This component contains a three-digit numeric code of the county or county equivalent in which the site is physically located. For sites not located in the conterminous U.S., Alaska, and Hawail, this component is not valued.

General Description - The value contained in this component must be for a county or county equivalent located in the State identified in component 8, STATE. A complete 1ist of county codes is contained in the Federal Information Processing Standards (FIPS) Publication 6-3, dated September 15, 1979, entitled "Counties and County Equivalents of States of the United States and the District of Columbia."

Note: Codes used to value this component include independent city codes for the states of Maryland, Missouri, Nevada, and Virginia, and division codes for the state of Alaska. 
$\frac{0}{\text { IN SR }}$

MANDATORY No

PICTURE $\quad X(8)$
HYDROL_UNIT

COMPONENT NAME

KEY Yes

LARGEST VALUE

DATA TYPE

Char

8 characters
10

COMPONENT NUMBER

Data Values - This component contains an eight-digit numeric code identifying the site's location with reference to the areal definitions shown on the USGS State Hydrologic Unit Maps. The format is (RRSSAACC) where:

$R R$ is the 2-digit code for the regional area defined in (1) below SS is the 2-digit code for the subregional area defined in (2) below $\mathrm{AA}$ is the 2-digit code for the accounting unit area defined in (3) below CC is the 2-digit code for the cataloging unit area defined in (4) below

General Description - Hydrologic unit codes are given in the U.S. Geological Survey map series "State Hydrologic Unit Maps." The series provides a uniform, nationally consistent set of maps showing drainage, culture, hydrography, and hydrologic boundaries of: (1) WRC (Water Resources Counci1) Regions, (2) WRC (Water Resources Counci1) Subregions, (3) National Water Data Network Accounting Units, and (4) Cataloging Units of the Catalog of Information on Water Data maintained by the Office of Water Data Coordination (OWDC). 
$\frac{0}{\text { IN SR }}$

MANDATORY No

PICTURE 9(3)
CONG_DIST

COMPONENT NAME

KEY No

DATA TYPE

Integer

LARGEST VALUE

2 digits

Data Values - This component contains the two-digit code of the U.S. Congressional District in which the station is physically located.

General Description - Congressional District boundaries are specified in the laws and(or) court orders establishing districts within the various States based upon population census. They are identified and defined in the latest "Congressional Directory" which may be obtained from the Superintendent of Documents, U.S. Government Printing Office, Washington, D.C. 20402. 
$\frac{0}{\text { IN SR }}$
SITE_TYPE

COMPONENT NAME
12

COMPONENT NUMBER
MANDATORY Yes

PICTURE $\mathrm{X}(2)$
KEY Yes

DATA TYPE

Char
2 characters

Data Values - This component contains a two-character alphabetic code that describes the type of water body subject to hydrologic data collection activities performed at the site, or the type of data collected at the site.

General Description:

Code

Meaning

CN Canal - An artificial waterway designed for navigation or for transporting water for municipal water supply, land irrigation, or drainage (see Drain below).

CP Outcrop - That part of a geologic formation or structure that appears at the surface of the Earth; also, bedrock that is covered only by surficial deposits such as alluvium.

DR Drain - A small artificial watercourse designed to drain swampy areas or irrigated lands. Theoretically, it is actually a small canal, but it is referred to as a "drain" in many localities.

ES Estuarine Zone or Estuary - The term "estuarine zone" means an environmental system consisting of an estuary and those transitional areas which which are consistently influenced or affected by water from an estuary such as, but not limited to, salt marshes, coastal and intertidal areas, bays, harbors, lagoons, inshore water, and channels. The term "estuary" means that part of a river or stream, or other body of water having unimpaired connection with the open sea, where the sea water is measurably diluted with fresh water derived from land drainage. The term includes estuary-type areas of the Great Lakes. 
EX Excavation - A pit, cavity, hole or other uncovered cutting produced by the process of removing soil and/or rock materials from one location and transporting them to another.

GW Well - An artificial excavation that derives some water from the interstices of the rocks or soil which it penetrates, and from which water can be withdrawn.

LK Lake, reservoir - An inland body of standing water, an expanded part of a river, or an impoundment formed by a dam.

ME Meteorological - A site where measurements are made to describe the scientific phenomena related to the atmosphere such as temperature, solar radiation, winds, quantity of precipitation, quantity of precipitation, and quality of precipitation.

OC Ocean - A site located in any of the world's oceans.

OT Other - Other types of sites where hydrologically related data, not categorized above or below, are collected.

PD Pond - Pond dug to intercept the water table or the potentiometric surface and serve as a water supply.

SB Subsidence - A site where data are obtained on the lowering of the elevation of the land surface, resulting from the compaction of sediments composing an aquifer system, due to the withdrawal of subsurface fluids.

$\mathrm{SH}$ Sinkhole - A hollow into which surface water flows to join an underground drainage system, produced by the solution of underlying material such as limestone, salt, etc. or by collapse of underlying caves.

SP Spring - A place where water flows from a rock or soil upon the land surface or into a body of water.

SM Soil Moisture (soil water) - A site where phenomena on soil moisture are measured. Soil moisture is the water diffused in the soil immediately below the land surface (zone of aeration), from which water is discharged by transpiration in plants or by evaporation from the soil.

SS Specific Source - An artificial conduit or other conveyance where pollutants are discharged (from factories, sewage treatment plants, etc.) into a water body or aquifer.

SW Stream - A body of water flowing in a natural channel as distinct from a canal (see Canal on previous page).

TN Tunnel - Tunnel, shaft, or mine from which ground water is obtained. 
$\frac{0}{\text { IN SR }}$
MANDATORY No

PICTURE $9(3)$

PICIURE
BAS IN DESCRP

COMPONENT NAME
13

COMPONENT NUMBER
KEY No
DATA TYPE Integer

Data Values - The Basin Descriptor component may contain up to three numeric codes. It is used to classify conditions in the drainage area of the data collection site. Code " 3 " (Urban) and code "4" (Natural) are mutually exclusive; one or the other will always be present but both will never be present in the same component.

\begin{tabular}{cl} 
Code & Meaning \\
\hline 1 & Regulation \\
2 & Diversion \\
3 & Urban \\
4 & Natura1
\end{tabular}

General Description - A Basin Descriptor is a general term used to describe man's effect on the hydrologic characteristics of a drainage basin or an aquifer.

Regulation - The artificial manipulation of the flow of a stream. The term does not apply to ground-water sites.

Diversion - The taking of significant quantities of water from a stream or other body of water into a canal, pipe, or other conduit. This term applies to ground-water stations when pumping is significant.

Urban - The situation where streamflow patterns at a site are affected significantly by urban development. The effect is considered to be significant when approximately 20-25 percent or more of the drainage area is covered by a dense road grid (indicating the presence of impermeable surfaces of roads, parking lots, and building roofs). The term is also applied to the setting in which a ground-water site is situated, but it is based upon a macroscopic scale and not restricted just to the immediate vicinity of the site.

Natural - The opposite of "Urban". 
$\frac{0}{\text { IN SR }}$

MANDATORY No

PICTURE $9(9)$
WDSD OFC CODE

COMPONENT NAME
17

COMPONENT NUMBER
KEY Yes

LARGEST VALUE
DATA TYPE

Integer

Data Values - This component contains from one to nine numeric digits to identify a particular office of the organization, as recorded in the NAWDEX Water Data Sources Directory (WDSD) data base, which is responsible for the data collection activities performed at the site. The code assignment is unique, by organization, and represents the relationship of a particular office to the parent organization. This component corresponds to component 102 OFC CODE in the WDSD data base.

The office code is comprised of the 2-digit FIPS state code, the 5-digit FIPS place code and a 2-digit sequence number for offices within same organization and place or city.

General Description - The WDSD code is assigned by the NAWDEX Program Of fice and used by NAWDEX support software to retrieve addresses of operating offices from the NAWDEX WDSD data base. 
$\frac{0}{\text { IN SR }}$

MANDATORY No

PICTURE $9(7) \cdot 9(2)$
DRAIN_AREA

COMPONENT NAME
19

COMPONENT NUMBER
KEY No

LARGEST VALUE
DATA TYPE

Decimal

Data Values - This component contains the value of the site's drainage area in square miles. The component allows values specified to the hundredths of a square mile for small drainage areas, and values seven digits to the left of the decimal point for large drainage areas. The component is not valued for ground water stations.

General Description - The drainage area of the stream at the specific location of the site is that area, measured in a horizontal plane, enclosed by a topographic divide from which direct surface runoff from precipitation normally drains by gravity into the stream above the site; it includes all closed basins, or noncontributing areas, within the total drainage area. 
$\frac{0}{\text { IN SR }}$

MANDA TORY No

PICTURE X(1)
NC AREA

COMPONENT NAME

KEY No
20

COMPONENT NUMBER

DATA TYPE

Char

Data Values - This component is valued with an " $N$ " if the contributing drainage area is equal to the total drainage area, or valued with a " $Y$ " when the contributing drainage is less than the total drainage area. The " $Y$ " value, therefore, signifies the existence of a noncontributing area in the drainage area referred to in component 19.

-

General Description - A noncontributing drainage area situation can occur when part of the drainage area consists of highly porous soll of depressions in the land surface that either allows all runoff to enter the ground-water zone or traps the water in ponds, lakes, or swamps, etc., so that precipitation does not contribute to runoff. Noncontributive conditions are rarely caused by manmade structures and then only when there is total diversion of runoff (including floodflows) from the drainage area. 
$\frac{0}{\text { IN SR }}$

MANDA TORY Yes

PICTURE N/A
LAST_UPDATE

COMPONENT NAME

KEY No
21

COMPONENT NUMBER

DATA TYPE Date

LARGEST VALUE

Data Values - This component contains the month, day, and year of the last date $\overline{(M M / D D / Y Y Y Y)}$ that an update of any type was processed against the station's logical entry. This date is generated by the computer at the time a transaction is performed against the data base.

General Description - An update is defined as any computer transaction that adds, deletes, or changes data values in the MWDI data base. 
$\frac{0}{\mathrm{IN} \mathrm{SR}}$

MANDATORY Yes

PICTURE $9(5)$
STATE COUNTY

COMPONENT NAME
22

COMPONENT NUMBER

DATA TYPE

Integer

Data Values - This component contains a concatenation (SSCCC) of the 2-digit numeric state code and the 3-digit numeric county code of the State and county in which the site is physically located.

General Description - These codes also appear in component numbers 8(STATE) and 9(COUNTY) but are repeated here in a combined format to provide computer search strategy efficiencies for retrievals involving specific States and counties. 
$\frac{0}{\text { IN SR }}$

MANDATORY NO

PICTURE X(1)
PRIMARY USE

COMPONENT NAME
34

COMPONENT NUMBER

DATA TYPE

Char

LARGEST VALUE

1 character

Data Values - This component contains a 1-character code which indicates principal use of water from the site. If water from the site is used for more than one purpose, circle the principal use here and enter the subordinate uses in the following two fields. The codes and their meanings are:
A - air conditioning
B - bottling
C - commercial
D - dewatering
E - power generation
F - fire protection
$\mathrm{H}$ - domestic

I - irrigation

$\mathrm{J}$ - industrial (cooling)

$\mathrm{K}$ - mining

$M$ - medicinal

$\mathrm{N}$ - industrial

$P$ - public supply

Q - aquacul ture

$$
\begin{aligned}
& \text { R - recreation } \\
& \text { S - stock supply } \\
& \text { T - institutional } \\
& \text { U - unused } \\
& \text { Y - desalination } \\
& \text { Z - other }
\end{aligned}
$$

General Description:

Air conditioning (A) refers to water supply used solely or principally for heating or cooling a building. Water used to cool industrial machinery belongs in the industrial category, not in the air-conditioning category.

Bottling (B) refers to the storage of water in bottles and use of the water for potable purposes (see Medicinal).

Commercial (C) use refers to use by a business establishment that does not fabricate or produce a product. Filling stations and motels are examples of commercial establishments. If some product is manufactured, assembled; or otherwise fabricated, use of water for that plant should be considered industrial even though the water is not used directly in the product or in the manufacturing of the product. 
Dewatering (D) means that water is pumped to drain a construction or mining site, or to lower the water table for agricultural purposes. In this respect, it differs from a drainage well that is used to drain surface water underground. If the main purpose for which the water is withdrawn is to provide drainage, dewatering should be indicated even though the water may be discharged into an irrigation ditch and subsequently used to irrigate land.

Power generation (E) refers to use of water for generation of any type
of power.

Fire protection (F) refers to the principal use of the water and should be indicated if the site was constructed principally for this purpose even though the water may be used at times to supplement an industrial or defense supply, irrigate a golf course, fill a swimming pool, or for other use.

Domestic $(H)$ use is water used to supply household needs, principally

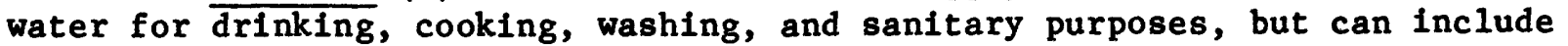
watering a lawn and caring for a few pets. Most domestic wells will be at suburban or farm homes, but wells supplying small quantities of water for one-classroom schools, turnpike gates, and for similar installations, should also be in the domestic category.

Irrigation (I) refers to the use of water to irrigate cultivated plants including grass. Most irrigation sites will supply water for farm crops, but the category should include wells used to water school, industrial plant, cemetery, or golf course grounds if more than a small amount of water is pumped and that is the sole use of the water.

trial cooling.

Industrial (cooling) (J) refers to a water supply used solely for indusMining (K) refers to a water supply used solely for mining purposes.

Medicinal (M) refers to water purported to have therapeutic value. Water may be used for bathing and/or drinking. If use of water is mainly because of its claimed therapeutic value, use this category even though the water is bottled.

Industrial (N) use is water used within a plant that manufactures or fabricates a product. The water may or may not be incorporated into the product being manufactured. Industrial water may be used to cool machinery, to provide sanitary facilities for employees, to air-condition the plant, and to irrigate the ground at the plant.

Public Supply (P) use is water that is pumped and distributed to several homes. Such supplies may be owned by a municipality or community, a water district, or a private concern. In most States, public supplies are regulated by departments of health which enforce minimum safety and sanitary requirements. If the system supplies five or more homes, it should be considered a public 
supply; for four or fewer, classify use as domestic. Water supplies for trailers or summer camps with five or more living units should be in this category, but motels and hotels are classified as commercial. Most public supply systems also furnish water for a variety of other uses, such as industrial, institutional, and commercial.

such as fish farms.

Aquaculture (Q) refers to a water supply used solely for aquaculture,

Recreation (R) refers to water discharged into pools, or channels which are dammed downstream to form pools, for swimming, boating, fishing, ice rinks, and other recreational uses.

Stock Supply (S) refers to the watering of livestock.

Institutional (T) refers to water used in the maintenance and operation of institutions such as large schools, universities, hospitals, rest homes, or similar installations. Owners of institutions may be individuals, corporations, churches, or governmental units.

Unused (U) means water is not being removed from the site for one of the purposes described above. A test hole, oll or gas well, recharge, drainage, observation, or waste-disposal well will be in this category. Do not use this classification for an irrigation, domestic, stock, or other well during "off season" or temporary periods of nonuse. The use of water from a newly constructed site should be considered as the use for which it is intended even though it may not yet be in use when inventoried.

Desalination $(Y)$ refers to water used in a desalting process whereby dissolved solids are removed to make water potable or suitable for other uses. Enter the type of use of the desalinated water in the next column, Secondary Water Use. categories.

Other (Z) refers to miscellaneous uses not included in the listed 
$\frac{0}{\text { IN SR }}$

PICTURE $\mathrm{X}(1)$
WRD ACCT

COMPONENT NAME
35

COMPONENT NUMBER
MANDATORY No

KEY No

LARGEST VALUE
DATA TYPE Char

Data Values - If the site is identified as a USGS site, then this component contains a "Y" if the USGS provides funding for the operation of the site or a " $N$ " if the USGS does not provide funding.

General Description - The USGS maintains data for some sites for which the collection of data was not funded by the USGS. These sites will not have a C1000 (SITE FUNDING) data record existing and component 901 (NETWORK CODE) of a C900 (NETWORKS ) data record will contain "COOP". Those sites which receive some funding from the USGS will have at least one $\mathrm{C} 1000$ data record and will not have a $\mathrm{C} 901$ containing "COOP". This component will be valued only for sites identified as USGS sites. 
$\frac{0}{\text { IN SR }}$

DOWNSTREAM ORDER NO

36

COMPONENT NUMBER

MANDATORY No

KEY No

DATA TYPE

Integer

PICTURE 9(15)

LARGEST VALUE

$999,999,999,999,999$

Data Values - This component contains a 15-digit sequence number for surface- . water sites. It is used as a sort-key to arrange sites in downstream order.

General Description - The downstream order number is assigned to each site by the NAWDEX Program office. 
$\frac{0}{\text { IN SR }}$

PICTURE X(4)
OTHER_DATA

COMPONENT NAME
COMPONENT NUMBER
MANDATORY No
KEY No

LARGEST VALUE
DATA TYPE Char

Data Values - The Other Data component provides for the entry of up to six onedigit numeric codes to indicate the avallability of supplementary or special purpose data for a station:

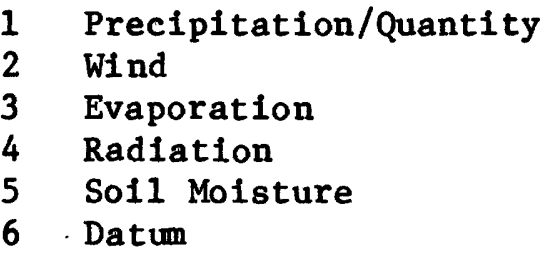

General Descriptions:

Precipitation/Quantity - The discharge of water, in liquid or solid state, out of the atmosphere. Precipitation includes rainfall, snow, hail, and sleet. For the purposes of this data file, precipitation data collection refers specifically to the quantity of water that is precipitated (usually expressed in inches).

Wind - Alr in natural motion parallel to the surface of the Earth. Data parameters commonly measured are velocity (miles per hour) and/or direction in degrees from true north (clockwise).

Evaporation - The process by which water is changed from the liquid or the solid state into the vapor state. In hydrology, evaporation is vaporization that takes place at a temperature below the boiling point. It is usually measured with evaporation pans.

Radiation (solar) - The process in which energy (as waves or particles) is emitted from the Sun, transmitted through space and absorbed by the Earth. The rate of solar radiation is measured with a variety of instruments. A general method is to convert the Sun's radiation into heat, which can be accurately measured.

Soil Moisture (soil water) - The water diffused in the soil immediately below the land surface (zone of aeration), from which water is discharged by the transpiration in plants or by evaporation from the soil.

Datum - Any level surface, line, or point used as a reference in measuring elevations. For the purpose of the MWDI, datum refers to station datum that has been referenced to mean sea level. 
$\frac{0}{\text { IN SR }}$

MANDA TORY No

PICTURE $X(1)$
SW_ACTIVE

COMPONENT NAME
150

COMPONENT NUMBER

DATA TYPE

Char

LARGEST VALUE

1 character

Data Values - This component contains a value that signifies whether or not surface water parameters (in the 100 schema record) are actively being collected at the site. The existence of a " $Y$ " means that one or more surface water parameters are actively being collected and an " $N$ " means that although one or more parameters have been collected in the past, none are presently being collected.

General Description - The Surface Water Active component provides computer search strategy efficiencies for retrievals concerned exclusively with active or inactive surface-water stations. 
$\frac{0}{\text { IN SR }}$

MANDA TORY No

PICTURE $\mathrm{X}(1)$
GW ACTIVE

COMPONENT NAME
250

COMPONENT NUMBER

KEY Yes

DATA TYPE

Char

Data Values - This component contains a value that signifies whether or not ground-water parameters (in the 200 schema record) are actively being collected at the site. The existence of a "Y" means that one or more ground-water parameters are actively being collected and an " $N$ " means that although one or more parameters have been collected in the past, none are presently being collected.

General Description - The Ground Water Active component provides computer search strategy efficencies for retrievals concerned exclusively with active or inactive ground-water stations. 
Char

PICTURE

Data Values - This component contains a value that signifies whether or not water-quality parameters (300-700 schema records) are actively being collected at the site. The existence of a "Y" means that one or more water-quality parameters are actively being collected and an " $\mathrm{N}$ " means that although one or more parameters have been collected in the past, none are presently being collected.

General Description - The Quality of Water Active component provides computer search strategy efficiencies for retrievals concerned exclusively with active or inactive water quality stations. 
Data Values - This component contains a value that signifies whether or not biological parameters are actively being collected at the site. The existence of a " $\mathrm{Y}$ " means that one or more biological parameters are actively being collected. An " $N$ " value means that although one or more parameters have been collected in the past, none are presently being collected.

General Description - The Biological Active component provides computer search strategy efficiencies for retrievals concerned exclusively with active or inactive biological sites. 
$\frac{0}{\text { IN SR }}$

MANDATORY

No

PICTURE $\mathrm{X}(1)$
PHY ACTIVE

COMPONENT NAME

KEY Yes

DATA TYPE

Char

COMPONENT NUMBER

LARGEST VALUE

1 character

Data Values - This component contains a value that signifies whether or not water quality physical parameters are actively being collected at the site. The existence of a " $\mathrm{Y}$ " means that one or more physical parameters are actively being collected. An " $N$ " value means that although one or more parameters have been collected in the past, none are presently being collected.

General Description - The water quality physical parameters activity component provides computer search strategy efficiencies for retrievals concerned exclusively with active or inactive physical parameter data-collection sites. 
$\frac{0}{\text { IN SR }}$

MANDATORY No

PICTURE $\mathrm{X}(1)$
SED ACTIVE

COMPONENT NAME

KEY Yes

LARGEST VALUE

Data Values - This component contains a retrieval key that signifies whether or not sediment parameters are actively being collected at the site. The existence of a " $Y$ " means that one or more sediment parameters are actively being collected. An " $N$ " value means that although one or more parameters have been collected in the past, none are presently being collected.

General Description - The Sediment Active component provides computer search strategy efficiencies for retrievals concerned exclusively with active or inactive chemical quality sites. 
$\frac{0}{\text { IN SR }}$

MANDA TORY No

PICTURE X(1)
CHM ACTIVE COMPONENT NAME
750

COMPONENT NUMBER
KEY Yes
DATA TYPE

Char

Data Values - This component contains a retrieval key that signifies whether or not chemical water quality parameters are actively being collected at the site. The existence of a " $\mathrm{Y}$ " means that one or more chemical parameters are actively being collected. An " $N$ " value means that although one or more parameters have been collected in the past, none are presently being collected.

General Description - The Chemical Active component provides computer search strategy efficiencies for retrievals concerned exclusively with active or inactive chemical quality sites. 
$\frac{0}{I N S R}$

MANDATORY No
PICTURE X(1)
MET_ACTIVE

COMPONENT NAME
1350

COMPONENT NUMBER
KEY Yes

LARGEST VALUE
DATA TYPE

Char

Data Values - This component contains a value that signifies whether or not meteorological parameters (in the 1300 schema record) are actively being collected at the site. The existence of a " $\mathrm{Y}$ " means that one or more meteorological parameters are actively being collected and an "N" means that although one or more parameters have been collected in the past, none are presently being collected.

General Description. - The Meteorological Active component provides computer search strategy efficiencies for retrievals concerned exclusively with active or inactive meteorological stations. 
$\frac{0}{\text { IN SR }}$

MANDATORY N/A

PICTURE N/A
SURFACE WTR

COMPONENT NAME
100

COMPONENT NUMBER
KEY N/A

DATA TYPE SR

A schema record containing data values that indicate the types of surface-water data collection activities performed, the years in which these activities took place, and the media in which surface-water data for the sites are available: 
$\frac{100}{\text { IN SR }}$

MANDATORY No

PICTURE $9(4)$
SW BEGIN YR

COMPONENT NAME
101

COMPONENT NUMBER

DATA TYPE

Integer

KEY No

Data Values - The Surface Water Data Collection Begin Year component contains a 4-digit numeric value identifying the year that surface-water data were first collected at the site, for example 1910.

General Description - This component identifies the calendar year in which the acquisition of surface-water data first began at a site, regardless of the types of surface-water data that were collected. This date will never change even though surface-water data collection may be deactivated and reactivated several times during a site's history. 
100

$\overline{\text { IN SR }}$
SW_END_YR

COMPONENT NAME
102

COMPONENT NUMBER
MANDATORY No

PICTURE 9(4)
KEY No

LARGEST VALUE
DATA TYPE

Integer

Data Values - The Surface Water Data Collection End Year component contains a 4digit numeric value identifying the year that all surface-water data collection activities were ceased at the site. If the organization is currently collecting any surface-water data at the site, this component is not valued.

General Description - This component identifies the calendar year in which all surface-water data collection activity at the site was discontinued. If at a later date, the collection of any of the surface-water parameters is resumed, the former end date is deleted. 
MANDATORY NO

KEY No

DATA TYPE

Char

PICTURE X(1)

LARGEST VALUE

$\mathbf{Y}$

Data Values - The Surface Water Interrupted component contains a value of " $Y$ " If the collection of all surface-water parameters has been discontinued (for more than one year) and later resumed one or more times in the history of the site. If surface water data colleciton has not been discontinued at any time, the component is not valued.

General Description - The presence of a value of "Y" for this component indicates one or more interruptions in the period of record of surface water data acquisition during the period beginning with SW BEGIN YR (component 101) through the present time (if currently active), or ending with SW END_YR (component 102). 
100

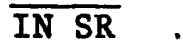

MANDA TORY NO

PICTURE X(5)
SW OWDC NO

COMPONENT NAME

KEY No

LARGEST VALUE

DATA TYPE

Char
104

COMPONENT NUMBER

Data Values - The Surface Water OWDC Number component contains a 5-character alpha-numeric code.

General Description - A unique identification number assigned by the U.S. Geological Survey's office of Water Data Coordination (OWDC) to each site in the "Part A-Streamflow and Stage" section of the "Catalog of Information on Water Data." 
$\frac{100}{\text { IN SR }}$

MANDATORY No

PICTURE 9(13)
SW_OWDC_SEQ

COMPONENT NAME

KEY No

DATA TYPE

Integer

107
COMPONENT NUMBER

LARGEST VALUE 13 digits

Data Values - The Surface Water OWDC Sequence Number consists of 13 numeric

General Description - A 13-digit downstream order number is assigned by the U.S. Geological Survey's Office of Water Data Coordination (OWDC) to each site in the "Part A - Streamflow and Stage" section of the "Catalog of Information on Water Data." It is used as a sort key to arrange sites in downstream order. 
100

$\overline{\text { IN SR }}$

MANDATORY No
COMPLETE_STAGE

COMPONENT NAME
110

COMPONENT NUMBER
PICTURE $\mathrm{X}(1)$

$\underline{x(1)}$
KEY No

DATA TYPE

Char

Data Values - A 1-character code in this component indicates the frequency with which stage observations or instrument recorded stage determinations are made at the site. This component is not valued for partial record sites (see next paragraph). See appendix A for frequency codes.

General Description - The stage of a stream or lake is the height of the water surface above an established datum plane. The water-surface elevation referred to some arbitrary or predetermined gage datum is called the gage height. The terms may be used interchangeably when, as in this particular instance, they are used to describe data-collection activity at a site. Records of stage at a site are obtained by systematic observations of a nonrecording gage or from data automatically registered by a water-stage-recording instrument. This component pertains only to those sites where a complete record (full range) of stage is being determined. Partial record sites where stage determinations are purposely limited to only those above or below a predetermined gage height are separately accounted for in components 111 (PEAK_STATE) and 112 (LOW_STAGE). 
$\frac{100}{\text { IN SR }}$

MANDA TORY No

PICTURE $\mathrm{X}(1)$

Data Values - The Peak Stage component, if applicable, will be valued with a 1-character code as follows:

Code

Meaning

1

Year round - Peak stage sensing devices are operated, and determinations are made on a year round basis.

2 Seasonal - Peak stage sensing devices are operated, and determinations are made only during certain portions of the year.

E Eliminated activity - Peak stage data collection, on a year round or seasonal basis, has been conducted in the past but has since been discontinued. Also applies if the site previously measured peak stage only, or peak stage and low stage only, but now measures complete stage.

Nul1 A null value signifies that there has been no peak stage only, or peak stage and low stage only, activity in the history of the site.

General Description - This component pertains primarily to those sites where less than a complete record (full range) of stage is being determined. It is predominantly a type of partial record site where stage determinations are iimited to a predetermined range in stage. This component and component number 110 (COMPLETE STAGE) may both be valued if peak stages are discretely available in addition to complete stages. 
Data Values - The Low Stage component, if applicable, will be valued with a 1-character code as follows:

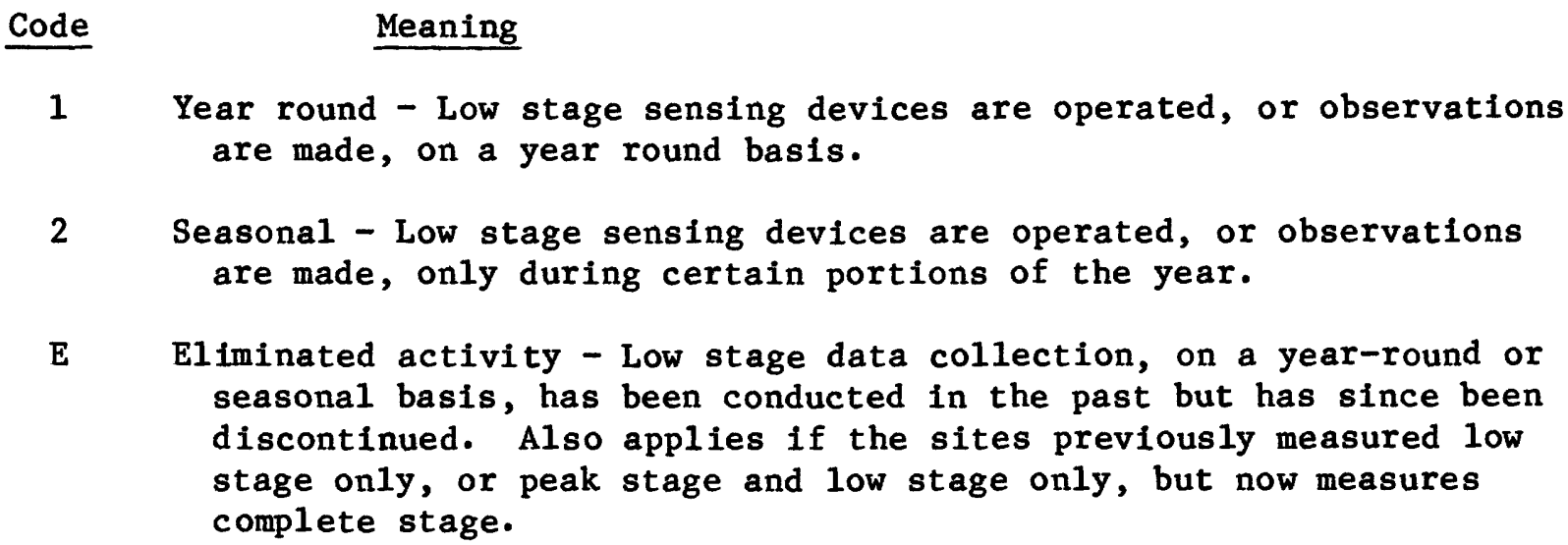

Nul1 A null value signifies that there has been no low stage only, or peak stage and low stage only, activity in the history of the site.

General Description - This component pertains primarily to those sites where less than a complete record (full range) of stage is determined. It is predominantly a type of partial-record site where stage determinations are limited to a predetermined range in stage. This component and component number 110 (COMPLETE STAGE) may both be valued if low stage is discretely available in addition to complete stage. 
Data Values - This component contains a 1-character code indicating the type(s) of storage media (document, computer readable, etc.) on which the data values for stage are stored and avallable to potential users of the data. See appendix $B$ for Data Storage codes and also see component number 110 (COMPLETE_STAGE) for the definition of stage.

General Description - Organizations collect hydrologic data and record and store the information on a variety of storage media ranging from original fleld notes to computer storage devices. Media is used as a general term encompassing all means of storing and disseminating the data. 
Data Values - The Complete Flow component provides for the entry of a 1-character code as follows:

\section{Codes}

Year Round

$\underline{\text { Seasonal }}$

2

1

1

2
4

E
Meaning

Daily - Mean daily flow figures are determined either on a year-round basis or only during certain portions of a year, as indicated by the code entered.

Monthly - Monthly totals and mean monthly flow figures are determined either on a year-round basis or only during certain portions of the year, as indicated by the code entered.

Eliminated activity - Complete flow figures have been determined in the past, but have since been discontinued.

General Description - Surface water flow is the discharge that occurs in any natural or artificial surface channel or course. Discharge is the volume of water (or more broadly, total fluid) that passes a given point within a given period of time.

Complete Flow means that flow (discharge) figures are determined based upon a complete record (full range) of stage, as opposed to partial record flow where figures pertain only to a predetermined limited range in stage. Partial record flow sites are separately accounted for in components 116 (PEAK FLOW) and 117 (LOW_FLOW). 
Data Values - The Peak Flow component, if applicable, is valued with a 1-character code as follows:

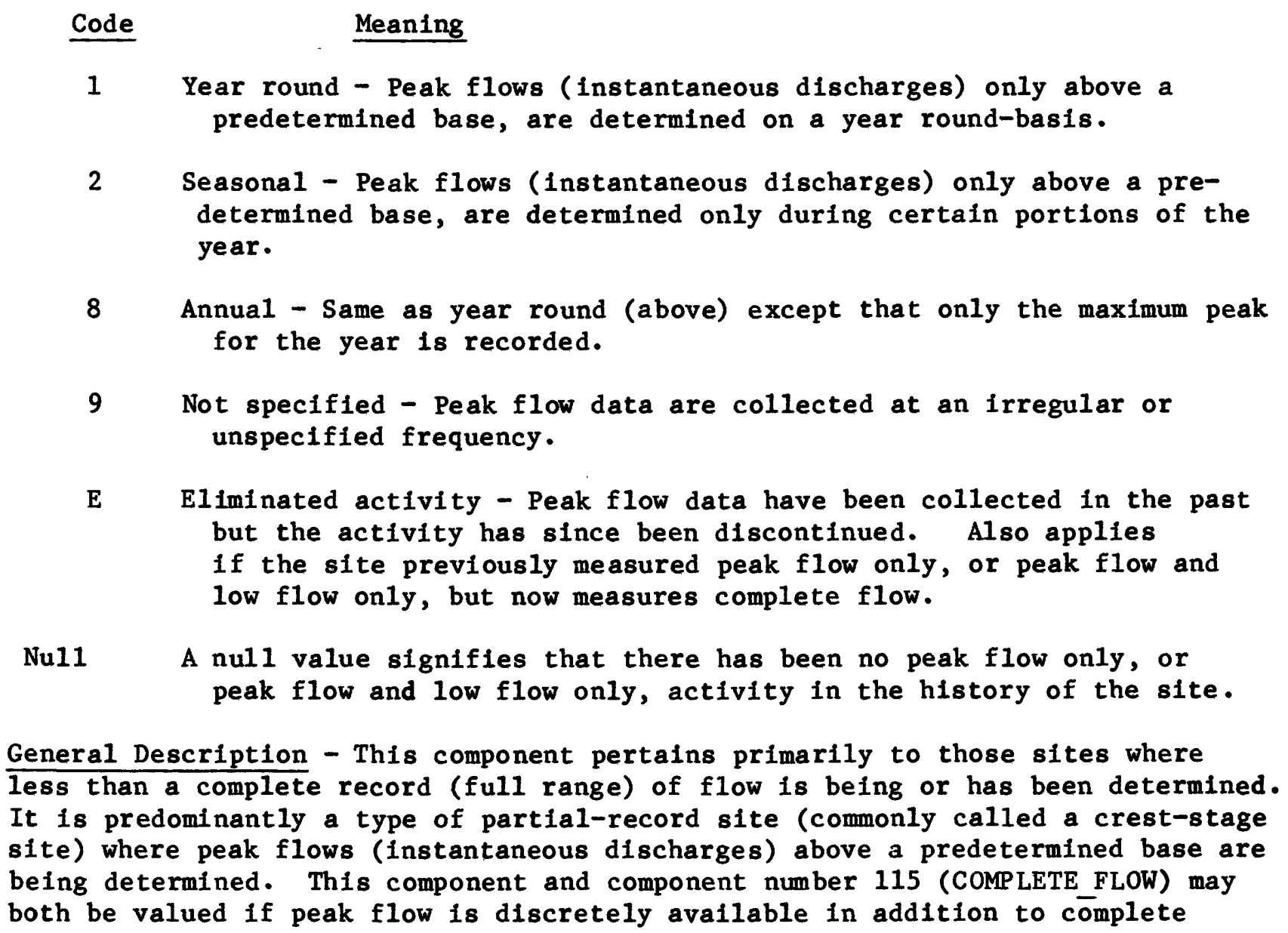

Nu11 A nul1 value signifles that there has been no peak flow only, or peak flow and low flow only, activity in the history of the site.

General Description - This component pertains primarily to those sites where less than a complete record (full range) of flow is being or has been determined. It is predominantly a type of partial-record site (commonly called a crest-stage site) where peak flows (instantaneous discharges) above a predetermined base are being determined. This component and component number 115 (COMPLETE FLOW) may both be valued if peak flow is discretely avallable in addition to complete flow. 
$\frac{100}{\text { IN SR }}$

MANDA TORY No

PICTURE X(1)
LOW FLOW

COMPONENT NAME
117 .

COMPONENT NUMBER
KEY No

DATA TYPE

Char

Data Values - The Low Flow component, if applicable, is valued with a 1-character code as follows:

\begin{tabular}{|c|c|}
\hline Code & MeanIng \\
\hline 1 & $\begin{array}{l}\text { Year round - Low-flow determinations (machine recorded or observed) } \\
\text { are made on a year-round basis. }\end{array}$ \\
\hline 2 & $\begin{array}{l}\text { Seasonal - Low-flow determinations (machine recorded or observed) } \\
\text { are made only during certain portions of the year. }\end{array}$ \\
\hline 9 & $\begin{array}{l}\text { Not specified - Low-flow data are collected at an irregular or } \\
\text { unspecified frequency. }\end{array}$ \\
\hline $\mathbf{E}$ & $\begin{array}{l}\text { Eliminated activity - Low-flow data have been collected in the past } \\
\text { but the activity has since been discontinued. Also applies if } \\
\text { the site previously measured low flow only, or peak flow and low } \\
\text { flow only, but now measures complete flow. }\end{array}$ \\
\hline Null & $\begin{array}{l}\text { A null value signifies that there has been no low flow only, or peak } \\
\text { flow and low flow only, activity in the history of the site. }\end{array}$ \\
\hline
\end{tabular}


$\frac{100}{\text { IN SR }}$

MANDATORY No

PICTURE X(1)
No
MISC FLOW MEAS

COMPONENT NAME
119

COMPONENT NUMBER
KEY No

LARGEST VALUE
DATA TYPE

Char

Data-Values - The Miscellaneous Flow Measurements component, if applicable, is valued with a 1-character alphabetic code that describes the frequency with which the measurements are made. See appendix A for frequency codes.

General Description - Field discharge measurements are made periodically at sites other than those classified as partial-record or complete-record gaging sites. The sites are called miscellaneous sites and the measurements are made during times of drought or flood to give better areal coverage to these events. 
100

$\overline{\text { IN SR }}$

MANDA TORY No

PICTURE $\mathrm{X}(1)$
FLOW MED

COMPONENT NAME
121

COMPONENT NUMBER

DATA TYPE

Char

KEY No

LARGEST VALUE
1 character

Data Values - This component contains a 1-character code for the type(s) of storage media (document, computer readable, etc.) on which the data values for flow are stored and available to potential users of the data. See appen$\mathrm{d}$ Ix $\mathrm{B}$ for data storage codes and also see component number 115 (COMPLETE_FLOW) for the definition of flow.

General Description - Organizations collect hydrologic data and record and store the information on a variety of storage media ranging from original field notes to computer storage devices. Media is used as a general term encompassing all means of storing and disseminating the data. 
Char

Data Values - A 1-character frequency code indicates the time intervals at which reservoir or lake volumetric measurements are computed as follows:

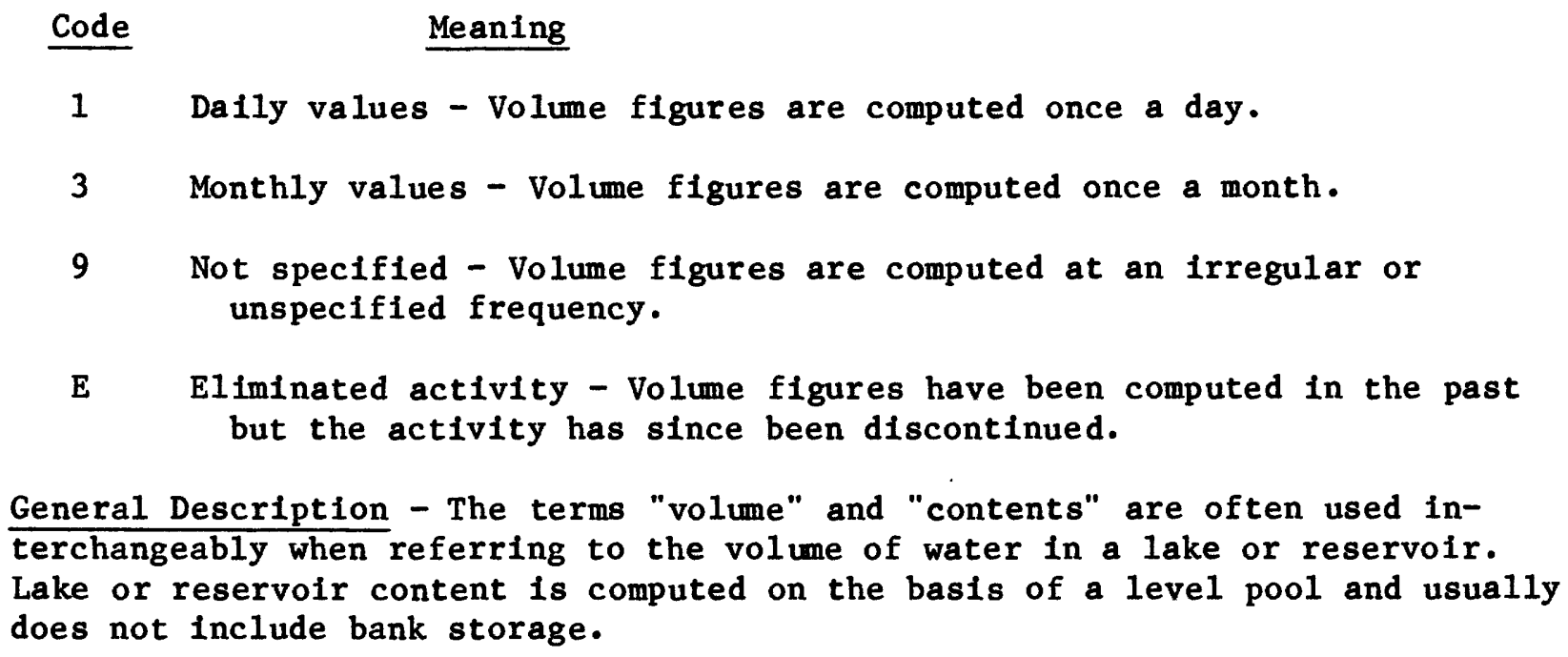

General Description - The terms "volume" and "contents" are often used interchangeably when referring to the volume of water in a lake or reservoir. Lake or reservoir content is computed on the basis of a level pool and usually does not include bank storage. 
Data Values - A 1-character frequency code indicates the time intervals at which changes in reservoir or lake volume (contents) are computed as follows:

Code $\quad$ Meaning

1 Daily values - Changes in volume figures are computed once a day.

3 Monthly values - Changes in volume figures are computed once a month.

9 Not specified - Changes in volume figures are computed at an irregular or unspecified frequency.

E Eliminated activity - Changes in volume figures have been computed in the past but the activity has since been discontinued.

General Description - Change in volume (contents) computations are made for reservoirs and lakes where the total volume of the water body is not known. They are also often made, where the total volume is known, for the purpose of acquiring more definitive information. The figures reflect the difference (plus or minus) from a previously computed volume. See component 124 (VOLUME) for the general definition of volume. 
MANDA TORY NO

PICTURE $\mathrm{X}(1)$
KEY No

LARGEST VALUE
DATA TYPE

Char

Data Values - This component contains a 1-character code indicating the type(s) of storage media (document, computer readable, etc.) on which the data values for volume are stored and can be made available to potential users of the data. See appendix $B$ for data storage codes and also see component number 114 (VOLUME) for the definition of volume.

General Description - Organizations collect hydrologic data and record and store the information on a variety of storage media ranging from original field notes to computer storage devices. Media is used as a general term encompassing all means of storing and disseminating the data. 
$\frac{100}{\text { IN SR }}$

MANDA TORY NO

PICTURE X(1)

LARGEST VALUE
SW UNIT FLOW

COMPONENT NAME
127

COMPONENT NUMBER
KEY No

DATA TYPE

Char

Data Values - The Unit Flow component, if applicable, is valued with a 1-character code as follows:

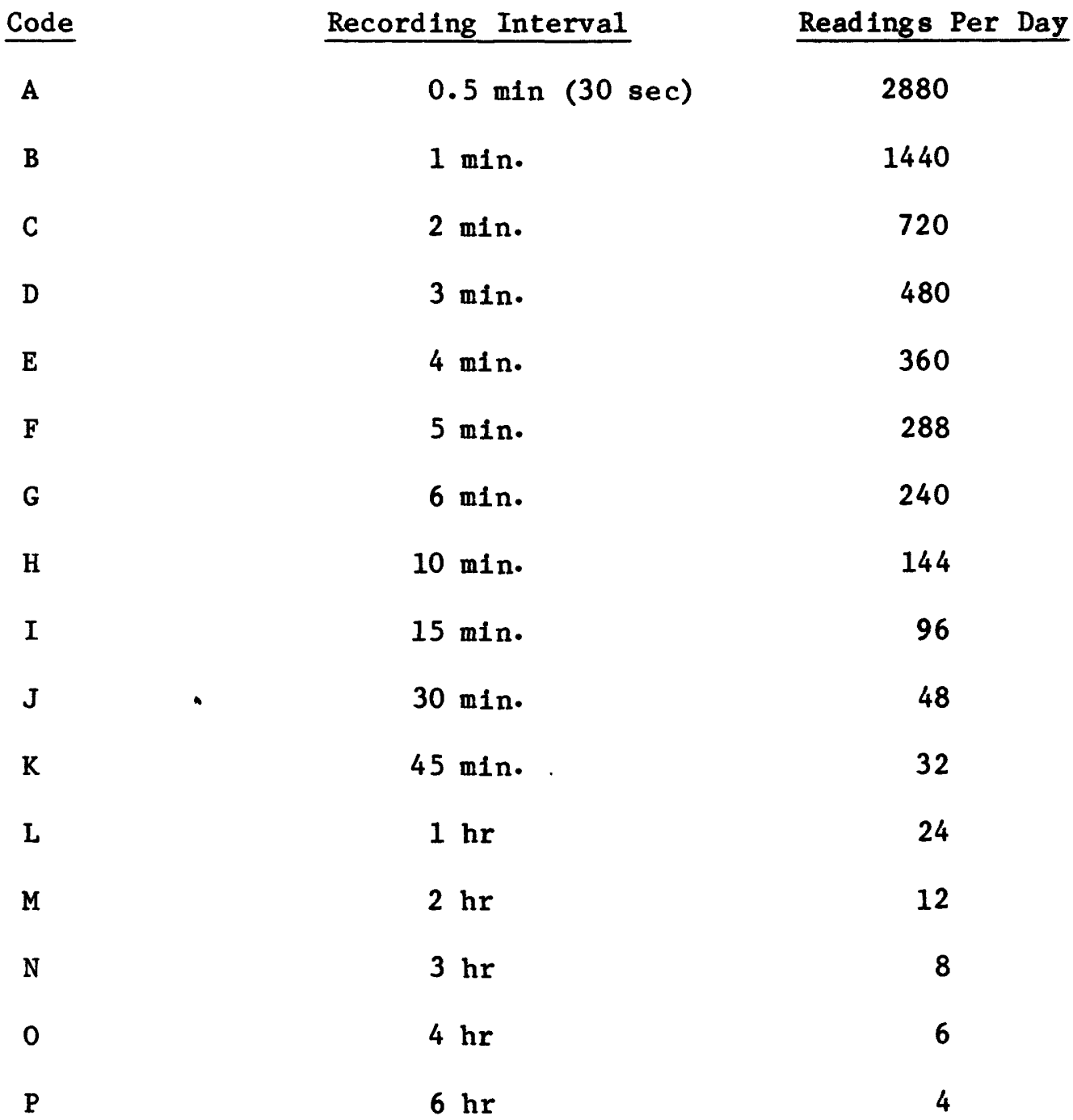




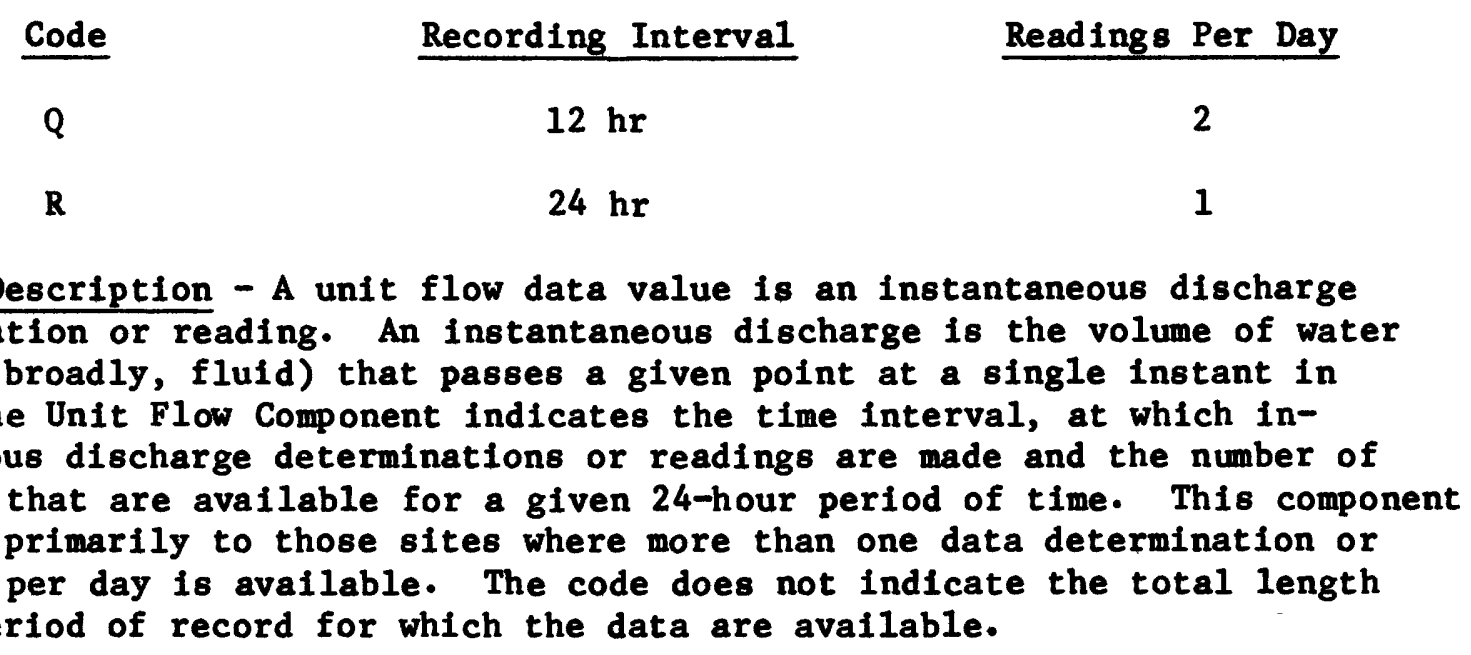


$\frac{100}{\text { IN SR }}$

MANDATORY No

PICTURE $\mathrm{X}(1)$
SW UNIT STAGE

COMPONENT NAME
128

COMPONENT NUMBER
KEY No

LARGEST VALUE
DATA TYPE

Char

Data Values - The unit stage component, if applicable, is valued with a 1-character code as follows:

Code

A

B

C

D

F

G

$\mathrm{H}$

I

$\mathrm{J}$

$\mathrm{K}$

$\mathbf{L}$

M

N

0

$\mathbf{P}$
Recording Interval

$0.5 \mathrm{~min}(30 \mathrm{sec})$

1 min.

$2 \min$.

3 min.

4 min.

$5 \mathrm{~min}$.

$6 \mathrm{~min}$.

10 min.

15 min.

30 min.

45 min.

$1 \mathrm{hr}$

$2 \mathrm{hr}$

$3 \mathrm{hr}$

$4 \mathrm{hr}$
1 character
Readings Per Day

2880

1440

720

480

360

288

240

144

96

48

32

24

12

8

6 


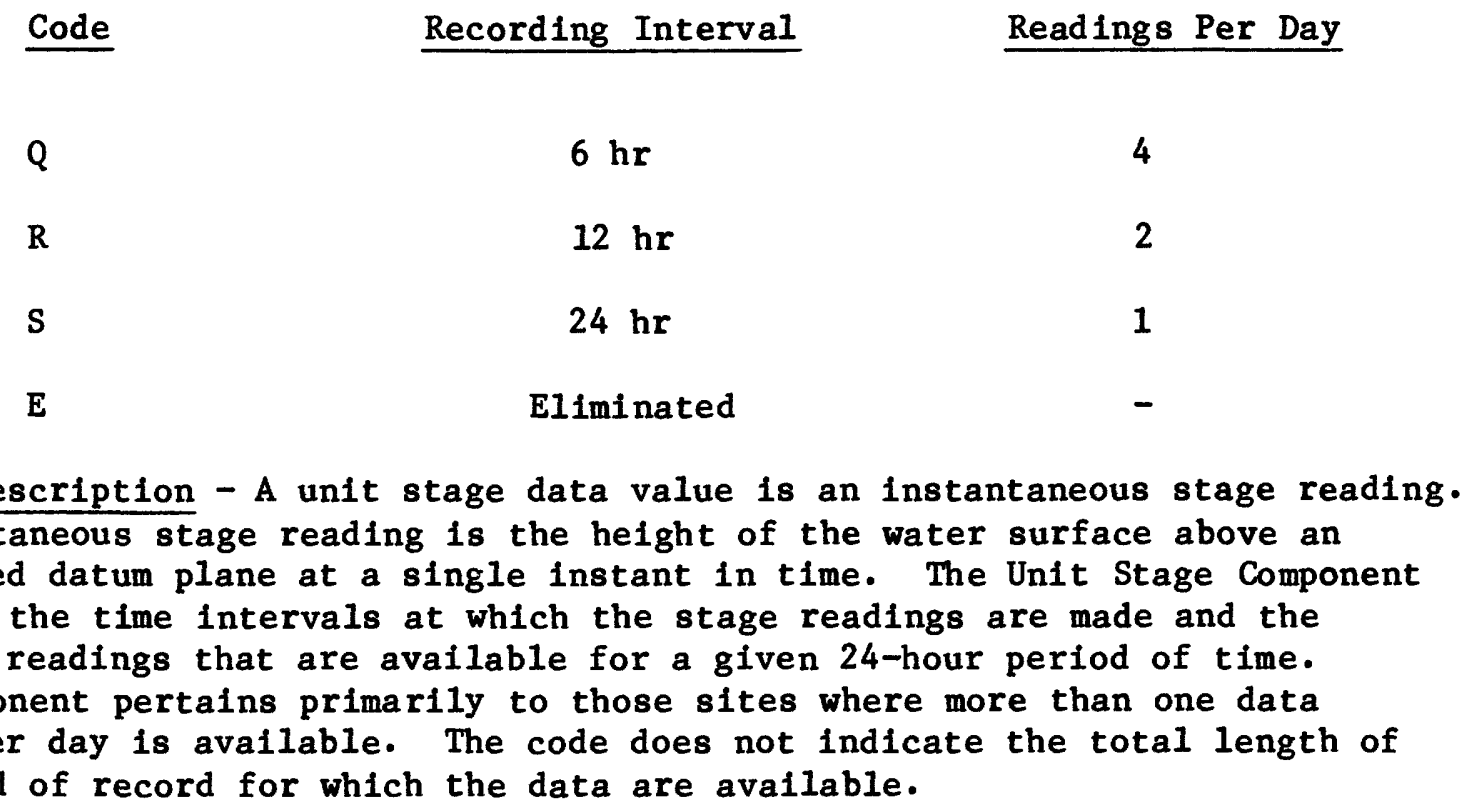


100

$\overline{\text { IN SR }}$

MANDATORY No

PICTURE X(1)
SW UNIT VOLUME

COMPONENT NAME
129

COMPONENT NUMBER
TO
KEY No

DATA TYPE

Char
1 character

Data Values - The Unit Volume component, if applicable, is valued with a 1-character code as follows:

\begin{tabular}{|c|c|c|}
\hline Code & Recording Interval & Readings Per Day \\
\hline $\mathbf{A}$ & $0.5 \mathrm{~min}(30 \mathrm{sec})$ & 2880 \\
\hline B & $1 \mathrm{~min}$. & 1440 \\
\hline C & $2 \mathrm{~min}$. & 720 \\
\hline D & $3 \mathrm{~min}$. & 480 \\
\hline $\mathbf{F}$ & $4 \mathrm{~min}$. & 360 \\
\hline G & $5 \mathrm{~min}$. & 288 \\
\hline H & $6 \mathrm{~min}$. & 240 \\
\hline I & $10 \mathrm{~min}$. & 144 \\
\hline $\mathrm{J}$ & 15 min. & 96 \\
\hline $\mathbf{K}$ & $30 \mathrm{~min}$. & 48 \\
\hline $\mathbf{L}$ & $45 \mathrm{~min}$. & 32 \\
\hline M & $1 \mathrm{hr}$ & 24 \\
\hline $\mathrm{N}$ & $2 \mathrm{hr}$ & 12 \\
\hline 0 & $3 \mathrm{hr}$ & 8 \\
\hline $\mathbf{P}$ & $4 \mathrm{hr}$ & 6 \\
\hline
\end{tabular}




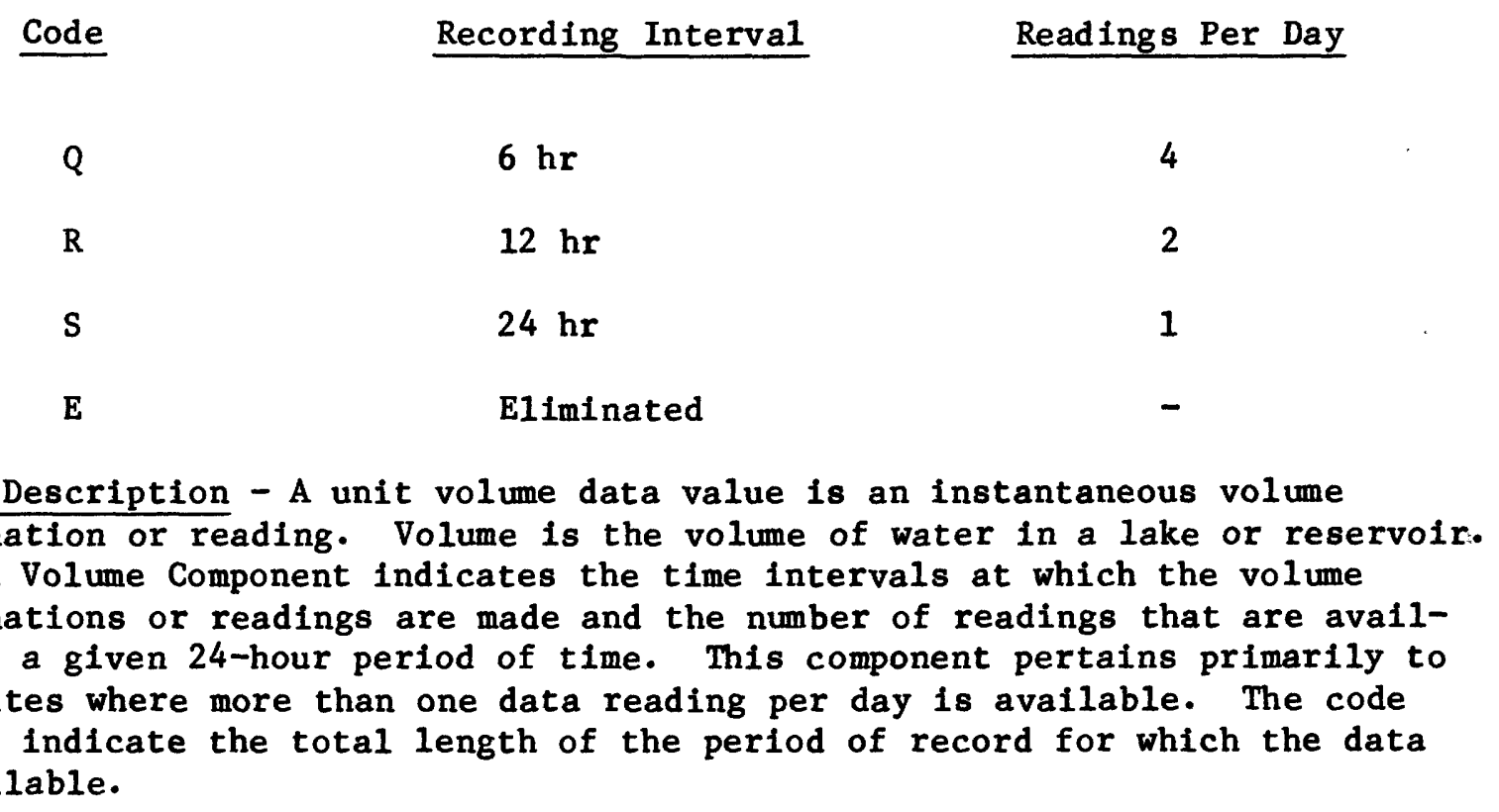

General Description - A unit volume data value is an instantaneous volume determination or reading. Volume is the volume of water in a lake or reservoir. The Unit Volume Component indicates the time intervals at which the volume determinations or readings are made and the number of readings that are available for a given 24-hour period of time. This component pertains primarily to those sites where more than one data reading per day is available. The code does not indicate the total length of the period of record for which the data are available. 
100

$\overline{\text { IN SR }}$

MANDA TORY No

PICTURE X(1)
SW_RECMD_MTHDS

COMPONENT NAME

KEY No

DATA TYPE Char
COMPONENT NUMBER

LARGEST VALUE

Data Values - The Surface Water Recommended Methods component is valued with a "Y" if the C100 data record describes data collected according to recommended methods. If not the component is valued with a "N".

General Description - In 1977, the Office of Water Data Coodination published the National Handbook of Recommended Methods for Water Data Acquisition. Another reference for recommended methods is the USGS's Techniques of Water-Resources Investigations (TWRI). 
$\frac{100}{\text { IN SR }}$

MANDATORY No
PICTURE X(6)

PICTURE X(6)
SW OTHER

COMPONENT NAME
140

COMPONENT NUMBER
KEY No

LARGEST VALUE
DATA TYPE

Char

Data Values - The Other Surface Water component contains any combination of 1-character codes needed to indicate supplementary surface water related data available, as follows:

Code $\quad$ Meaning

1 QW, recurring - Systematic water quality data collection takes place at the site.

2 QW, nonrecurring - A one-time-only water-quality data measurement is available.

3 Flood hydrograph - Certain sites are equipped with special-purpose stage recorders that become activated when the stage exceeds a chosen base stage. A continuous record of stage and discharge with respect to time is produced, but only for the periods when the water elevation exceeds the chosen base. This record is called a flood hydrograph.

Sediment data - Data on fluvial sediment are collected at the site. See component 600 for definition of sediment.

5 Cross section - A two-dimensional representation of the profile of the flood plain land surface along a plane at right angles to a stream.

6 Flow duration - A computed relationship that shows the percentage of time that specified daily discharges were equaled or exceeded in a stated number of complete years.

7 Flood frequency - A relationship showing the probability that floods of a certain magnitude are equaled or exceeded in any year; or a similar relationship between flood magnitude and frequency of ex- 
8 Coefficient of roughness - This is the "resistance to flow" variable used in hydraulic equations to determine peak discharges in natural channels by indirect methods. The factors that exert the greatest influence upon the coefficient of roughness are the character of the bed material, cross-section irregularities, depth of flow, vegetation, and alignment of the channel.

9 Time of travel - This refers to the rate of movement of water, or waterborne materials, through the reach of stream channel for steady or gradually varied flow conditions. These studies are conducted by dye tracing methods where dye is injected at some location on a stream and detected at other locations downstream.

A Flood plain maps - These maps either define areas inundated by specific floods of record, or show areas potentially covered by floods of selected frequencies (for example 10, 50, 100, or 500 year recurrence intervals).

B Tides - Records of tidal stage collected at ocean gages or gages located in estuarine zones.

C Surface inflow-outflow - Data related to stored water in lakes and reservoirs where inflow to and outflow from the water body is computed for the purpose of regulation or research.

General Description - Special purpose surface-water data or other tyes of surface water related information are often collected at or in the near vincinity of a site, in addition to, or instead of, the normal stage-discharge determinations. 
Data Values - The Surface Water Telemetry code is a 1-digit numeric code identifying, if applicable, the type of telemetry system in use at the sites:

Code $\quad$ Meaning

1 Telemeter-land line - A telemetry system that uses electrical current conducting wires (telephone, etc.) to transmit data from a site to a distant receiving site.

2 Telemeter-radio network - A telemetry system that uses terrestrial line of sight radios (wireless transmission of electric impulses) to transmit data from a site to a distant receiving site.

3 Landsat - A satelifte telemetry system used to relay data two or more times daily from in situ sensors.

4 GOES (Geostationary Operational Environmental Satellite) - A sate1lite telemetry system used to relay data, normally once every 3 hours, from in situ sensors.

5 DARC (Device for Automatic Remote Data Collection) - A telemetry system interface used to enter in situ sensor data into a landline, line of sight radio, or satellite telemetry system.

6 Other - Other telemetry systems.

7 Two or more of the above telemetry systems are in use.

8 Telemetry equipment used but type not specified.

General Description - A telemeter is an electrical apparatus for measuring quantity (e.g. stage data) and transmitting the value to a distant receiving site, and there indicating or recording the quantity measured. The Surface Water Telemetry component indentifies the type of system or equipment being used to transmit surface-water information (primarily stage data) from the data collecting site to a central receiving site. 
Data Values - This component contains the year and month ( $Y Y / M M$ ) in which the C100 data record was last updated. This date is generated by the computer. General Description - An update is defined as any transaction that adds, deletes, or changes data values in the MWDI data base. 
100

$\overline{\text { IN SR }}$

MANDATORY No

PICTURE X(4)
SW_PURPOSE

COMPONENT NAME
145

COMPONENT NUMBER

DATA TYPE

Char

LARGEST VALUE

4 character

Data Values - Up to four codes may be entered to denote the purpose(s)

(classification) of a surface water site as follows:

Code $\quad \underline{\text { Meaning }}$

B Benchmark - Sites measuring natural phenomena in areas where man's activity has essentially no effect. These sites would be expected to continue at least as long as natural conditions exist.

H Long-term hydrologic - Sites intended for the development of general hydrologic knowledge and/or trends having local as well as transfer value to other points.

R Research or special study - Sites identified with research projects or special studies, including modeling, as part of a specific plan for developing specialized water information. These sites would be operated during the period of the research project or special study.

A Areal analysis - Sites to provide data for the hydrologic definition of an area or basin. These sites would generally be expected to be in operation until satisfactory area definition is achieved.

S Assessment - Sites operated for the specific purpose of national accounting, or determining trends, or general hydrologic planning.

F Forecasting - Sites to provide data for the purpose of forecasting hazardous or critical conditions.

L Compact or legal - Sites providing data used for surveillance or recordkeeping to fulfill legal requirements or compacts.

C Current operation - Sites providing information necessary for the management and operation of hydrologic projects, water supplies, pollution abatement, waste disposal, etc. These sites would be operated as long as the specific need exists. 
General Description - A site classification scheme devised and used internally by the U.S. Geological Survey to identify the purpose(s) being served by the collection of hydrologic data at the site. 
100

IN SR

MANDATORY

No

KEY

No

DATA TYPE

Char

PICTURE $\mathrm{X}(1)$

LARGEST VALUE

1 character

Data Values - The Surface Water Recorder Type component is valued with a

1-character code to indicate the type of recorder used to collect the water data.

Code Meaning

A Digital Recorder - Records data at intervals throughout the day by storing the values on paper tape or magnetic recording devices.

B Graphic Recorder - Supplies a continuous trace of parameter value with respect to time on a chart.

C Crest-Stage Gage - is a device for obtaining the elevation of the flood crest of streams.

General Description - A recorder is an automatic (self-acting or self-regulating) device that registers and stores data values without human intervention. Telemetry equipment, which is used to transmit data to points distant from the data collection site, is separately accounted for in component 143 (SW TELEMETRY). 
$\frac{100}{\text { IN SR }}$

MANDATORY No
SW_RECORDER FREQ

COMPONENT NAME
148

COMPONENT NUMBER

PICTURE X(1)

KEY No

LARGEST VALUE
DATA TYPE Char

Data Values - This component contains a 1-character code to indicate the frequency at which data are being recorded at a site.

Code

A

B

C

D

E

F

G

H

I

J

K

L

M

N
Recording Interval

$0.5 \mathrm{~min}(30 \mathrm{sec})$

1 min.

2 min.

$3 \mathrm{~min}$.

$4 \mathrm{~min}$.

5 min.

$6 \mathrm{~min}$.

$10 \mathrm{~min}$.

15 min.

$30 \mathrm{~min}$.

45 min.

$1 \mathrm{hr}$

$2 \mathrm{hr}$

$3 \mathrm{hr}$
Readings Per Day

2880

1440

720

480

360

288

240

144

96

48

32

24

12

8 


\begin{tabular}{|c|c|c|}
\hline Code & Recording Interval & Readings Per Day \\
\hline 0 & $4 \mathrm{hr}$ & 6 \\
\hline $\mathbf{P}$ & $6 \mathrm{hr}$ & 4 \\
\hline$Q$ & $12 \mathrm{hr}$ & 2 \\
\hline $\mathbf{R}$ & $24 \mathrm{hr}$ & 1 \\
\hline s & Continuous & - \\
\hline $\mathrm{T}$ & Periodic & - \\
\hline
\end{tabular}


$\frac{100}{\text { IN SR }}$

MANDA TORY No

PICTURE $\mathrm{X}(1)$
SW_PN_CODE

COMPONENT NAME

KEY No

LARGEST VALUE
149

COMPONENT NUMBER

DATA TYPE Char

Data Values - For sites which are in the planning stage, the Surface Water Planned or Needed component contains a 1-character code as follows:

B Plan to establish - The establishment of a new site is planned.

$R \quad$ Plan to reestablish - The reestablishment of a discontinued site is planned

D Plan to discontinue - An active site is planned to be discontinued

C Plan to change - A change in the parameter types or frequency of data collection at an active site is planned.

1 Need to establish - There is a need to establish a new site.

2 Need to reestablish - There is a need to reestablish a discontinued site.

3 Need to discontinue - There is a need to discontinue an active site.

4 Need to change - A change in the parameter types or frequency of data collection at an active site is needed.

General Description - The office of Water Data Coordination (OWDC) is responsible for coordinating Federal agency needs and plans for long-term site activities for obtaining data on stage, flow, and quality of surface waters and quality of ground water. "Planned" activities are those for which funds have been budgeted. "Needed" activities are those that are planned but do not yet have funds budgeted for them. 
$\frac{100}{\text { IN SR }}$

MANDATORY N/A

PICTURE N/A
SW MODIF IERS

COMPONENT NAME
170

COMPONENT NUMBER
KEY N/A

DATA TYPE SR

LARGEST VALUE

N/A

A schema record containing codes that indicate the external file that contains the data indexed in the C100 data record. The MWDI indexes data from the Envi ronmental Protection Agency's Storage and Retrieval (STORET) System, the U.S. Geological Survey's National Water Data Storage and Retreival System (WATSTORE), and the Texas Natural Resources Information System (TNRIS) by means of software interfaces. Multiple occurrences of C170 may exist for each $\mathrm{C} 100$ data record having data indexed from more than one external

file. 
$\frac{170}{\text { IN SR }}$

MANDATORY No

PICTURE X(4)
SW POINTER

COMPONENT NAME

KEY No

DATA TYPE

Char
171

COMPONENT NUMBER

Data Values - This component contains a 4-character code that indicates an external file from which data have been indexed in the $\mathrm{C} 100$ schema record. The codes, assigned at the time of interfacing, are described below:

Code

STOR

TNRS

WATD

WATG

WATP

WATS
Description

Data have been indexed from EPA's STORET.

Data have been indexed from the Texas Natural Resources Information System (TNRIS).

Data have been indexed from the USGS's WATSTORE Daily Values File.

Data have been indexed from the WATSTORE Ground-water Site Inventory (GWSI) data base.

Data have been indexed from the WATSTORE Peak Flow file.

Data have been indexed from the WATSTORE data base but the exact file is unknown.

General Description - Surface-water data indexed at the time of interfacing with the major water data bases have the Surface Water Pointer component (C171) automatically set and stored to indicate the appropriate major water data base. Use of this component simplifies the retrieval of data from the appropriate data base. 
170

IN SR

PICTURE $\mathrm{X}(1)$

MANDATORY No

SW MOD FILE

COMPONENT NAME
172

COMPONENT NUMBER

KEY No

DATA TYPE

Char

Data Values - This component contains a 1-character code to indicate the WATSTORE Groundwater Site Inventory (GWSI) data base subset from which the data were indexed.

$\begin{array}{cl}\text { Code } & \text { Subset } \\ \text { N } & \text { Northeast Region } \\ \mathrm{S} & \text { Southeast Region } \\ \mathrm{C} & \text { Central Region } \\ \mathrm{W} & \text { Western Region }\end{array}$

General Description - This component is set automatically to one of the above codes to indicate the GWSI subset in which the data resides at the time of interfacing with the GWSI. 
$\frac{0}{\text { IN SR }}$

MANDATORY

N/A
GROUND WATER

COMPONENT NAME
200

COMPONENT NUMBER

PICTURE N/A

KEY N/A

DATA TYPE

SR

LARGEST VALUE

N/A

A schema record containing data values that indicate the types of groundwater data collection activities performed, the years in which these activities took place, and the media on which ground-water data for the sites are available. 
200

IN SR

MANDATORY

No

PICTURE
GW BEGIN YR

COMPONENT NAME
201

COMPONENT NUMBER

KEY

No

DATA TYPE

Integer

LARGEST VALUE

current year

Data Values - The Ground Water Data Collection Begin Year component contains a 4-digit numeric value that identifies the year during which ground-water data were first collected at the site, for instance 1910.

General Description - This component identifies the calendar year in which the acquisition of ground-water data was first begun at a site, regardless of the types of ground-water data that were collected. This date will never change even though ground water collection may be deactivated and reactivated several times during a site's history. 
200

IN SR

MANDA TORY No
GW_END_YR

COMPONENT NAME
202

COMPONENT NUMBER

PICTURE

DATA TYPE

Integer

Data Values - The Ground Water Data Collection End Year component contains a 4-digit numeric value which identifies the year that all ground-water data collection activities were ceased at the site. If the organization is currently collecting any ground-water data at the site, this component is not valued.

General Description - This component identifies the calendar year in which all ground-water data collection activity at a site was discontinued. If at a later date, the collection of any of the ground-water parameters is resumed, the former end date is deleted. 
200

IN SR

MANDA TORY

No

PICTURE

$\mathrm{X}(1)$
GW INTERRUPTED

COMPONENT NAME
203

COMPONENT NUMBER

-

KEY

No

DATA TYPE

Char

Data Values - The Ground Water Interrupted component contains a value of "Y" if the collection of all ground-water parameters has been discontinued (for more than one year) and later resumed one or more times in the history of the site. If ground-water data collection has not been discontinued at any time, the component is not valued.

General Description - The presence of a value of " $\mathrm{Y}$ " for this component indicates one or more interruptions in the period of record of ground-water acquisition during the period beginning with GW BEGIN YR (component 201) through the present time (if currently active), or ending wit $\bar{h}$ GW_END_YR (component 202). 
200

IN SR

MANDATORY

No

KE

No

LARGEST VALUE

DATA TYPE

Char

PICTURE $\quad \mathrm{X}(5)$

GW_OWDC_NO

COMPONENT NAME

COMPONENT NUMBER

204

Data Values - The Ground Water OWDC Number component contains a five-character, alpha-numeric code.

General Description - A unique Identification number assigned by the U.S. Geological Survey's Office of Water Data Coordination (OWDC) to each site in the "Part C - Quality of Ground Water" section of the "Catalog of Information on Water Data". 
200

$\overline{\text { IN SR }}$

MANDATORY

No
PRIN AQUIFER

COMPONENT NAME
208

COMPONENT NUMBER

PICTURE $\mathrm{X}(8)$

KEY No

LARGEST VALUE
DATA TYPE

Char

Data Values - The Principal Aquifer component contains the Geologic Unit code (up to eight alpha-numeric characters) for the aquifer supplying water to the well. For Geologic Unit codes see appendix $F$ of the WATSTORE User's Guide, U.S. Geological Survey Open File Report 75-426, August 1975.

General Description - An aquifer is a formation, group of formations, or part of a formation that contains sufficient saturated permeable material to yield significant quantities of water to wells and springs. If a well taps more than one aquifer, the principal aquifer will be the one that yields the greatest amount of water. 
200

IN SR

MANDA TORY No

PICTURE X(1)
AQUIFER TYPE

COMPONENT NAME
209

COMPONENT NUMBER

KEY No

DATA TYPE

Char

LARGEST VALUE

1 character

Data Values - The component contains a 1-character alphabetic code that best describes the type(s) of aquifer(s) supplying water to the well as follows:

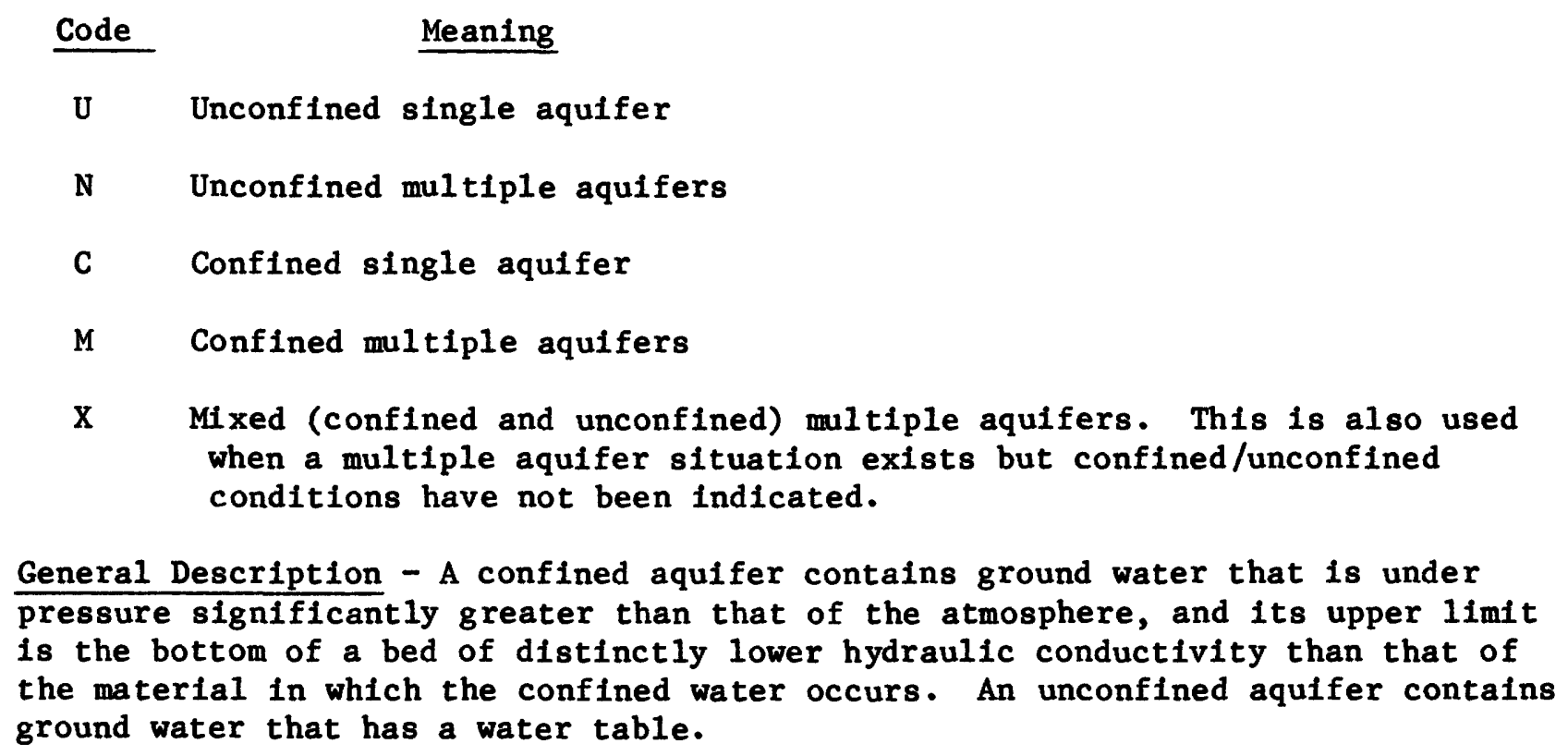

General Description - A confined aquifer contains ground water that is under pressure significantly greater than that of the atmosphere, and its upper limit is the bottom of a bed of distinctly lower hydraulic conductivity than that of the material in which the confined water occurs. An unconfined aquifer contains ground water that has a water table. 
200

IN SR

MANDA TORY

No

PICTURE

$X(1)$
LEVEL FREQ

COMPONENT NAME
210

COMPONENT NUMBER

DATA TYPE

Char

KEY No

LARGEST VALUE

1 character

Data Values - A 1-character alphabetic code in this component indicates the frequency with which well water level measurements or instrument recorded water level determination are made. See appendix A for frequency codes.

General Description - The water level of a well is the distance to the water surface below a reference datum. Water level measurements are expressed in feet with reference to either mean sea level or land-surface datum. Mean sea level is the datum plane on which the network of precise levels is based; land-surface datum is a datum plane that is approximately at land surface at each well. The altitude of the land-surface datum with repect to mean sea level is often known. 
$\frac{200}{\text { IN SR }}$

MANDA TORY No

PICTURE $\mathrm{X}(1)$
LEVE L_MED

COMPONENT NAME
211

COMPONENT NUMBER

DATA TYPE Char

KEY No

LARGEST VALUE
1 character

Data Values - This component contains a 1-character code indicating the type( 8 ) of storage media (document, computer readable, etc.) on which the data values for well water levels are stored and available to potential users of the data. See appendix $B$ for data storage codes and also see component number 210

(LEVEL FREQ) for the definition of level.

General Description - Organizations collect hydrologic data and record and store the information on a variety of storage media ranging from original field notes to computer storage devices. Media is used as a general term encompassing all means of storing and desseminating the data. 
200

$\overline{\text { IN SR }}$

MANDATORY

No

KEY No
212

DISCHRG FREQ

COMPONENT NAME
COMPONENT NUMBER

DATA TYPE Char

Data Values - A 1-character alphabetic code in this component indicates the frequency with which well discharge measurements are made. See appendix A for frequency codes.

General Description - The discharge from a well is either the natural flow from a well or that produced by pumping. Discharge is the volume of water (or more broadly, total fluid) that passes a given point within a given period of time, usually expressed in gallons per minute. 
200

IN SR

MANDA TORY No

PICTURE X(1)
DICHRG_MED

COMPONENT NAME

KEY No

LARGEST VALUE

1 character

Data Values - This component contains a 1-character code indicating the type(s) of storage media (document, computer readable, etc.) on which the data values for well discharge are stored and available to potential users of the data. See appendix $B$ for data storage codes and also see component number 212 (DISCHRG FREQ) for the definition of discharge.

General Description - Organizations collect hydrologic data and record and store the information on a variety of storage media ranging from original field notes to computer storage devices. Media is used a a general term encompassing all means of storing and disseminating the data. 
200

IN SR

PICTURE X(1)

MANDATORY No

SUBSIDE FREQ

COMPONENT NAME
214

COMPONENT NUMBER

KEY No

DATA TYPE Char

Data Values - A 1-character alphabetic code in this component indicates the frequency with which subsidence data are collected. See appendix A for frequency codes.

General Description - Subsidence is the lowering of the land surface, resulting from the compaction of sediments composing an aquifer system when subsurface fluids are withdrawn. 
200

IN SR

MANDA TORY No

$\mathrm{KE}$
SUBSIDE_MED

COMPONENT NAME
215

COMPONENT NUMBER

PICTURE $\mathrm{X}(1)$

Data Values - This component contains a 1-character code indicating the type(s) of storage media (document, computer readable, etc.) on which the data values for subsidence are stored and available to potential users of the data. See appendix $B$ for data storage codes and also see component number 214 (SUBSIDE FREQ) for the definition of subsidence.

General Description - Organizations collect hydrologic data and record and store the information on a variety of storage media ranging from original field notes to computer storage devices. Media is used as a general term encompassing all means of storing and disseminating the data. 
$\frac{200}{\text { IN SR }}$

MANDATORY No

KE

Y No
WELL DEPTH

COMPONENT NAME

PICTURE 9(5)

DATA TYPE Integer

Data Values - This component contains the depth (up to five digits) of the well In feet.

General Description - The greatest depth below land surface at which water can enter the well will be reported. For screened or perforated wells, the depth to the bottom of the screen or to the lowest perforations will be reported. For open-hole or open-end wells, the total depth will be reported. 
$\frac{200}{\text { IN SR }}$

MANDA TORY

No

$X(1)$
GW_RECMD_MTHDS

COMPONENT NAME

KEY No

DATA TYPE

Char

LARGEST VALUE

1 character

Data Values - The Ground-Water Recommended-Methods Component is valued with a "Y" if the $\mathrm{C} 200$ data record describes data collected according to recommended methods. If not, the component is valued with a " $\mathrm{N}$ ".

General Description - In 1977, the office of Water Data Coordination published the National Handbook of Recommended Methods for Water Data Acquisition. Another reference for recommended methods is the USGS's Techniques of Water-Resources Investigations (TWRI). 
$\frac{200}{\text { IN SR }}$

MANDATORY No
GW_OTHER

COMPONENT NAME
240

COMPONENT NUMBER

PICTURE $x(6)$

KEY No

DATA TYPE

Char

LARGEST VALUE

$\mathrm{ABC} 123456789$

Data Values - The Other Ground Water component will contain any combination of 1-character codes needed to indicate supplementary ground water related data available as follows:

Code Meaning

1 Total annual pumpage or flow - The total volume of water withdrawn from a well in a year's time, usually expressed in acre-feet or millions of gallons.

2 Depth of well - The total depth to which the hole was drilled even though it may have been plugged back in completing the well.

3 Casing record - Information on well casing material, diameter, and length.

4 Screen record - Information about openings that permit water to enter the well, including perforations and uncased sections of the aquifer.

5 Driller s log - Description by the driller of the geologic materials penetrated from the land surface to the greatest depth of the well.

6 Geologic Log - Same as code "5" except that the description is made by a geologist.

7 Instrument $\log$ - Measurements of physical phenomena about the well or natural phenomena in the earth surrounding the well, or responses of the earth material around the well to induced stimuli such as radiation, electric current, or induced magnetic field.

8 Hydraulic conductivity - The rate at which water moves through aquifer material under a unit hydraulic gradient, expressed as volume per unit time per unit cross section ( $\mathrm{ft}^{3} / \mathrm{day} / \mathrm{ft}^{2}$ or $\mathrm{M}^{3} / \mathrm{day} / \mathrm{M}^{2}$ ) reduced to feet per day or meters per day.

9 Transmissivity - The rate at which water moves through the aquifer expressed as volume per unit time per unit width ( $\mathrm{ft}^{3} / \mathrm{day} / \mathrm{ft}$ or $\mathrm{m}^{3}$ / day/M) reduced to $\left(\mathrm{ft}^{2} / \mathrm{day}\right.$ or $\mathrm{M}^{2} / \mathrm{day}$ ). Note that transmissivity is 
a property of a vertical strip of the aquifer and is the product of hydraulic conductivity of the material and the saturated thickness of the aquifer.

A Storage coefficient - The volume of water an aquifer releases from or takes into storage unit surface area of the aquifer per unit change in head.

B Construction - Information about the construction of the we11 such as: the means of drilling, hole diameter, date drilled, driller name, type of finish (screening, perforations), and type of casing.

C Lift - The means by which water is removed from the well such as type of pump.

D Discharge-drawdown - The difference between the static water level and a property of a vertical strip of the aquifer and is the product of the water level during the largest sustainable discharge rate.

General Description - Supplementary ground-water data or related information about the station. 
$\frac{200}{\text { IN SR }}$

MANDATORY No

PICTURE X(4)
MAJOR VAR

COMPONENT NAME
242

COMPONENT NUMBER

Key No

DATA TYPE

Char

LARGEST VALUE 1234567

Data Values - The Causes of Major Variances in Observed Data component may contain up to seven 1-digit numerical codes as follows:

Code Meaning

1 Pumping - The artificial removal of water from an aquifer.

2 Evapotranspiration - Water withdrawn from a land area by evaporation from water surfaces and moist soll and by plant transpiration.

3 Changes in stream or lake stage - The transfer of water to and from ground water and surface-water bodies.

4 Recharge from soll moisture - The downward percolation from the unsaturated zone (soil moisture or soll water) to the saturated zone of an aquifer.

5 Infiltration - The infusion of water into an aquifer from surface-water sources such as spreading ponds, storage lagoons, disposal pits, etc.

6 Natural dissolution - The dissolving of minerals ( such as limestone) resident in the aquifer.

7 Injection of fluids - Deep well artificial recharge of fluids into an aquifer.

General Description - This component identifies the artificial and natural phenomena that cause variations and fluctuations in the movement and amount of fluid in an aquifer. 
200

IN SR

MANDATORY No
GW TELEMETRY

COMPONENT NAME
243

COMPONENT NUMBER

PICTURE $9(1)$

DATA TYPE Integer

Data Values - The Ground Water Telemetry code is a 1-digit numeric code identifying, if applicable, the type of telemetry system in use at the site:
Code
Meaning
1
Telemeter-land lines - A telemetry system that uses electrical current conducting wires (telephone, etc.) to transmit data from a site to a distant receiving site.
2
Telemeter-radio network - A telemetry system that uses terrestrial line-of-sight radios (wireless transmission of electric impulses) transmit data from a site to a distant recelving site.
3 Landsat - A satellite telemetry system used to relay data two or more times daily from in situ sensors.
4 GOES (Geostationary Operational Environmental Satellite) - A sat- ellite telemetry system used to relay data, normally every 3 hours, from in situ sensors.
5 DARDC (Device for Automatic Remote Data Collection) - A telemetry system interface used to enter in situ sensor data into a landine, line of sight radio, or satellite telemetry system.
6 Other - Other telemetry systems.
7 Two or more of the above telemetry systems are in use.
8 Telemetry equipment used but type not specified.
General Description - A telemeter is an electrical apparatus for measuring quantity (e.g. water-level data) and transmitting the value to a distant receiving site, and there indicating or recording the quantity measured. The Ground Water Telemetry component identifies the type of system or equipment being used to transmit ground-water information from the data collection site to a central receiving site. 
200

IN SR

MANDA TORY

Yes

PICTURE $9(4)$
GW_LST_UPDATE

COMPONENT NAME
244

COMPONENT NUMBER
DATA TYPE Integer

Data Values - This component contains the year and the month (YY/MM) the C200 data record was last updated. This date is generated by the computer.

General Description - An update is defined as any transaction that adds, changes, or deletes data values in the MWDI data base. 
$\frac{200}{\text { IN SR }}$

MANDATORY

No

$\mathrm{X}(4)$

PICTURE
GW PURPOSE

COMPONENT NAME
245

COMPONENT NUMBER

$\mathrm{X}(4)$

KEY No

DATA TYPE Integer

ABCFHLRS

Data Values - Up to four codes may be entered to denote the purpose(s)

(classification) of a ground-water site as follows:

Code Meaning

B Benchmark - Sites measuring natural phenomena in areas where man's activity has essentially no effect. These sites would be expected to continue at least as long as natural conditions exist.

$\mathrm{H} \quad$ Long-term hydrologic - Sites intended for the development of general hydrologic knowledge and/or trends having local as well as transfer value to other points.

R Research or special study - Sites identifled with research projects or special studies, including modeling, as part of a specific plan for developing specialized water information. These sites would be operated during the period of the research project or special study.

A Areal analysis - Sites to provide data for the hydrologic definition of an area or basin. These sites would generally be expected to be in operation until satisfactory areal definition is achieved.

S Assessment - Sites operated for the specific purpose of national accounting, determining trends, or general hydrologic planning.

F Forecasting - Sites to provide data for the purpose of forecasting hazardous or critical conditions.

L Compact or legal - Sites providing data used for survelllance or recordkeeping to fulfill legal requirements or compacts. 
C Current operation - Sites providing information necessary for the management and operation of hydrologic projects, water supplies, pollution abatement, waste disposal, etc. These sites would be operated as long as the specific need exists

General Description - A site classification schema devised and used internally by the U.S. Geological Survey to identify the purpose served by collection of hydrologic data at the site. 
MANDA TORY

No

KEY No

DATA TYPE

Char

PICTURE

$\mathrm{X}(1)$

LARGEST VALUE

1 character

Data Values - The Ground-Water-Recorder-Type component is valued with a 1-character code to indicate the type of recorder used to collect the water data.

Code

Meaning

A Digital Recorder - Records data at intervals throughout the day by storing the values on paper tape or magnetic recording device.

B Graphic Recorder - Supplies a continuous trace of parameter value with respect to time on a chart.

General Description - A recorder is an automatic (self-acting or self-regulating) device that registers and stores data values without human intervention. Telemetry equipment, which is used to transmit data to points distant from the data collection site, is separately accounted for in component 243 (GW_TELEMETRY). 
200

IN SR

MANDATORY No

KEY

No
248

COMPONENT NUMBER

PICTURE $\mathrm{X}(1)$

LARGEST VALUE

1 character

Data Values - This component contains a 1-character code to indicate the frequency at which data are being recorded at a site.

Code

A

B

C

D

E

F

G

H

I

J

K

L

M

N
Recording Interval

$0.5 \mathrm{~min}(30 \mathrm{sec})$

1 min.

2 min.

3 min.

4 min.

5 min.

6 min.

10 min.

15 min.

30 min.

45 min.

$1 \mathrm{hr}$

$2 \mathrm{hr}$

$3 \mathrm{hr}$
Readings Per Day

2880

1440

720

480

360

288

240

144

96

48

32

24

12

8 


\begin{tabular}{|c|c|c|}
\hline Code & Recording Interval & Read Ings Per Day \\
\hline 0 & $4 \mathrm{hr}$ & 6 \\
\hline $\mathbf{P}$ & $6 \mathrm{hr}$ & 4 \\
\hline Q & $12 \mathrm{hr}$ & 2 \\
\hline $\mathbf{R}$ & $24 \mathrm{hr}$ & 1 \\
\hline $\mathbf{s}$ & Continuous & - \\
\hline $\mathbf{T}$ & Periodic & - \\
\hline
\end{tabular}


MANDA TORY

No

KEY No

DATA TYPE Char

PICTURE $\quad \mathrm{X}(1)$

LARGEST VALUE

1 character

Data Values - For stations which are in the planning stage, the Ground Water Planned or Needed component will contain a 1-character code as follows:

Code $\quad$ Meaning

B Plan to establish - The establishment of a new site is planned.

$R \quad P l a n$ to reestablish - The reestablishment of a discontinued site is planned.

D Plan to discontinue - An active site is planned to be discontinued.

C Plan to change - A change in the parameter types or frequency of data collection at an active site is planned.

1 Need to establish - There is a need for the establishment of a new site.

2 Need to reestablish - There is a need for the reestablishment of a discontinued site.

3 Need to discontinue - There is a need for discontinuing an active site.

4 Need to change - A change in the parameter types or frequency of data collection at an active site is needed.

General Description - The Office of Water Data Coordination (OWDC) is responsible for coordinating Federal agency needs and plans for long-term site activities for obtaining data on stage, flow, quality of surface waters, and quality of ground waters. "Planned" activities are those for which funds have been budgeted. "Needed" activities are those that are planned but do not yet have funds budgeted for them. 
$\frac{200}{\text { IN SR }}$

MANDA TORY

N/A

PICTURE N/A
GW_MODIF IERS

COMPONENT NAME
270

COMPONENT NUMBER

KEY N/A

DATA TYPE SR

LARGEST VALUE

N/A

A schema record containing codes that indicate the external file that contains the data indexed in the $\mathrm{C} 200$ data record. The MWDI indexes data in the Environmental Protection Agency's Storage and Retrieval (STORET) System, the U.S. Geological Survey's National Water Data Storage and Retrieval System (WATSTORE), and the Texas Natural Resources Information System (TNRIS) by means of software interfaces. Multiple occurrences of C270 may exist for each $\mathrm{C} 200$ data record having data indexed from more than one external file. 
$\frac{270}{\text { IN SR }}$

MANDATORY NO
GW POINTER

COMPONENT NAME
271

COMPONENT NUMBER

PICTURE $\mathrm{X}(4)$

KEY NO

DATA TYPE

Char

Data Values - This component contains a 4-character code that indicates an external file from which data have been indexed in the C200 schema record. The codes, assigned at time of interfacing, are described below:

$\begin{array}{ll}\text { Code } & \text { Description } \\ \text { STOR } & \text { Data have been indexed from EPA's STORET. } \\ \text { TNRS } & \begin{array}{l}\text { Data have been indexed from the Texas Natural } \\ \text { Resources Information System (TNRIS) }\end{array} \\ \text { WATD } & \begin{array}{l}\text { Data have been indexed from USGS's WATSTORE } \\ \text { Daily Values File. }\end{array} \\ \text { WATG } & \begin{array}{l}\text { Data have been indexed from the WATSTORE } \\ \text { Ground-water Site Inventory File (GWSI) data base. }\end{array} \\ \text { WATP } & \begin{array}{l}\text { Data have been indexed from the WATSTORE } \\ \text { Peak Flow File. }\end{array} \\ \text { WATS } & \begin{array}{l}\text { Data have been indexed from the WATSTORE } \\ \text { data base but exact file unknown. }\end{array}\end{array}$

General Description - Ground-water data indexed at the time of interfacing with the major water data bases have the Ground Water Pointer component (C271) automatically set and stored to indicate the appropriate major water data bases. Use of this component simplifies the retrieval of data from the appropriate data base. 
270

IN SR

GW_MOD_FILE

COMPONENT NAME

MANDA TORY NO

KEY

No

DATA TYPE

Char

PICTURE $X(1)$

LARGEST VALUE 1 character

Data Values - This component contains a 1-character code to indicate the WATSTORE Ground-Water-Site-Inventory (GWI) data base subset from which the data were indexed.

$\begin{array}{cl}\text { Code } & \text { Subset } \\ \text { N } & \text { Northeast Region } \\ \text { S } & \text { Southeast Region } \\ \text { C } & \text { Central Region } \\ \text { W } & \text { Western Region }\end{array}$

General Description - This component is set automatically to one of the above codes to indicate the GWSI subset in which the data resided at the time of interfacing with the GWSI. 
$\frac{0}{\text { IN SR }}$

MANDATORY N/A

PICTURE

N/A
QUALITY_WTR

COMPONENT NAME
300

COMPONENT NUMBER

DATA TYPE SR

KEY No

LARGEST VALUE

N/A

A schema record containing data values indicating the types of water-quality data collection activities performed, the years in which these activities took place, and the media on which water-quality data for the sites are available. 
$\frac{300}{\text { IN SR }}$

MANDA TORY

Yes
OW BEGIN YR

COMPONENT NAME
301

COMPONENT NUMBER

PICTURE 9(4)

KEY No

DATA TYPE Integer

Data Values - The Quality of Water Data Collection Begin Year component contains a 4-digit numeric value identifying the year that water-quality data were first collected at the site, for example, 1910.

General Description - This component identifies the calendar year in which the acquisition of water quality data was first begun at a site, regardless of the types of water quality data that were collected. This date will never change even though water quality data collection may be deactivated and reactivated several times during a site's history. 
300

$\overline{\text { IN SR }}$

MANDATORY

No

$9(4)$
QW_END_YR

COMPONENT NAME

KEY No

DATA TYPE Integer

Data Values - The Quality of Water Data Collection End Year component contains a 4-digit numeric value identifying the year that all water quality data collection activities were ceased at the site. If the organization is currently collecting any water quality data at the site, this component is not valued.

General Description - This component identifies the calendar year in which all water quality data collection activity at a site was discontinued. If, at a later date, the collection of any of the water quality parameters is resumed, the former end date is deleted. 
300

$\overline{\text { IN SR }}$

MANDATORY No

KEY No
303

COMPONENT NUMBER
QW INTERRUPTED

COMPONENT NAME

DATA TYPE

Char

LARGEST VALUE

1 character

PICTURE $\mathrm{X}(1)$

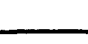

Data Values - The Quality of Water Interrupted component contains a value of "Y" if the collection of water quality parameters has been discontinued (for more than one year) and later resumed one or more times in the history of the site. If water quality data collection has not been discontinued at any time, the component is not valued.

General Description - The presence of a value of " $Y$ " for this component indicates one or more interruptions in the period of record of water quality data acquisition during the period beginning with QW BEGIN YR (component 301) through the present time (if currently active), or ending with QW_END_YR (component 302). 
$\frac{300}{\text { IN SR }}$

MANDATORY

No

$x(5)$

PICTURE
QW_OWDC NO

COMPONENT NAME
304

COMPONENT NUMBER

KEY

No

DATA TYPE Char

$x(5)$

LARGEST VALUE

5 characters

Data Values - The Quality of Water OWDC Number component contains a 5-character alpha-numeric code.

General Description - A unique identification number assigned by the U.S. Geological Survey's Office of Water Data Coordination (OWDC) to each station in the "Part B - Quality of Surface Water" and to each station in the "Part C - Quality of Ground Water" sections of the "Catalog of Information on Water Data." 
$\frac{300}{\text { IN SR }}$

$\frac{\text { QW_OWDC_SEQ }}{\text { COMPONENT NAME }}$

$\frac{307}{\text { COMPONENT NUMBER }}$

MANDA TORY No

KEY

DATA TYPE

Integer

PICTURE

9(13)

LARGEST VALUE

13 digits

Data Values - The Quality of Water OWDC Sequence Number consists of 13 numeric digits.

General Description - A 13-digit downstream order number assigned by the U.S. Geological Survey's Office of Water Data Coordination (OWDC) to each site in the "Part B - Quality of Surface Water" section of the "Catalog of Informatron on Water Data." It is used as a sort key to arrange sites in downstream order.

114 
300

$\overline{\text { IN SR }}$

MANDATORY

No

KEY

No

RECMD MTHDS

COMPONENT NAME

330

COMPONENT NUMBER

DATA TYPE Char

PICTURE $\quad \mathrm{X}(1)$

LARGEST VALUE

1 character

(1)

TEST

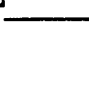

Data Values - The Quality of Water Recommended Methods component is valued with a "Y" if the $\mathrm{C} 300$ data record describes data collected according to recommended methods.

General Description - In 1977, the Office of Water Data Coordination published the National Handbook of Recommended Methods for Water Data Acquisition. Another reference for recommended methods is the USGS's Techniques of Water-Resources Investigations (TWRI). 
$\frac{300}{\text { IN SR }}$

MANDATORY No
QW TELEMETRY

COMPONENT NAME $\frac{1343}{\text { COMPONENT NUMBER }}$

DATA TYPE Integer

PICTURE

Data Values - The Quality of Water Telemetry code is a 1-digit numeric code identifying, if applicable, the type of telemetry system in use at the station site:

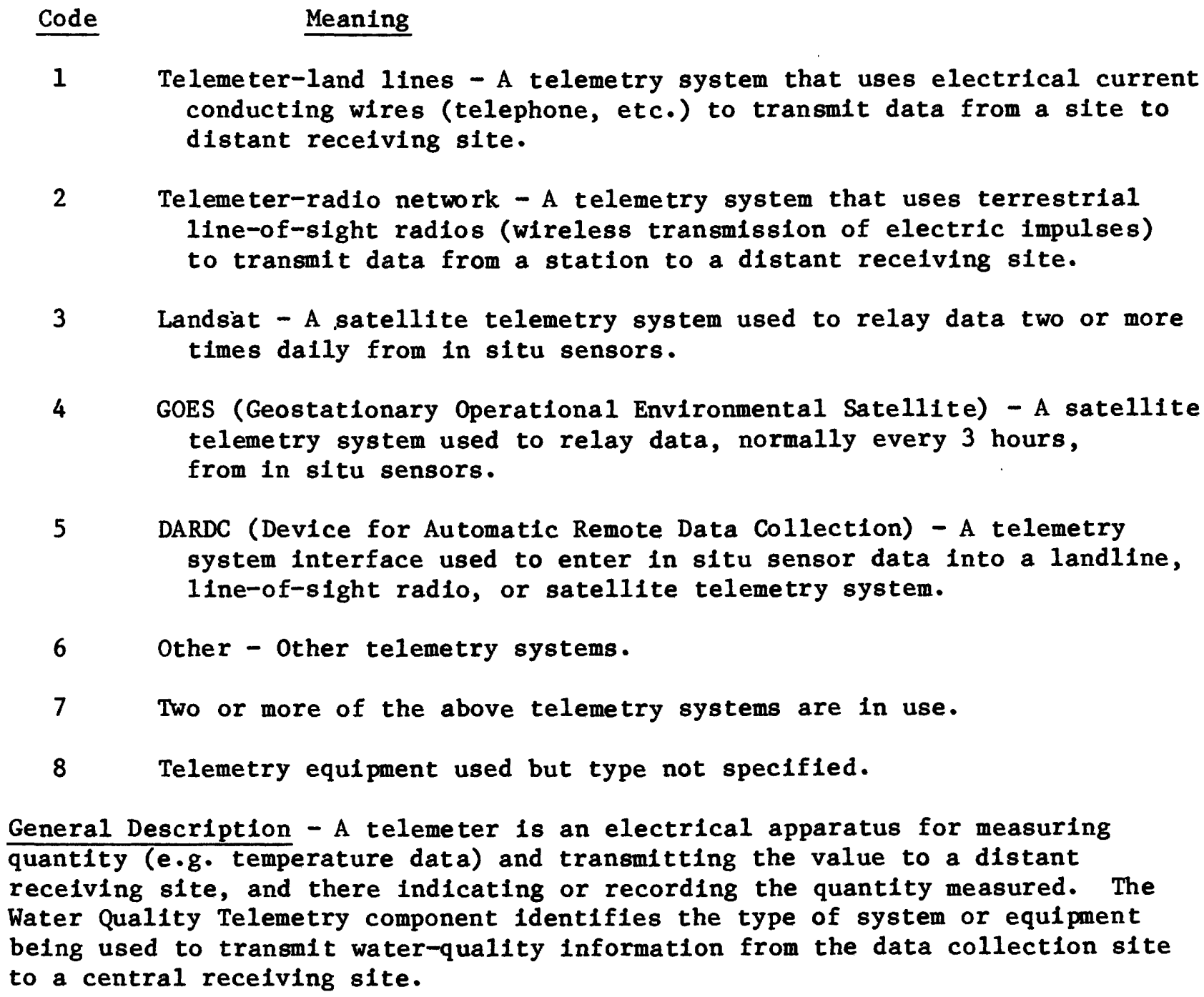
conducting wires (telephone, etc.) to transmit data from a site to distant receiving site.

2 Telemeter-radio network - A telemetry system that uses terrestrial line-of-sight radios (wireless transmission of electric impulses) to transmit data from a station to a distant recelving site.

3 Landsat - A satellite telemetry system used to relay data two or more times daily from in situ sensors.

4 GOES (Geostationary Operational Environmental Satellite) - A satellite telemetry system used to relay data, normally every 3 hours, from in situ sensors.

5 DARDC (Device for Automatic Remote Data Collection) - A telemetry system interface used to enter in situ sensor data into a landine, line-of-sight radio, or satellite telemetry system.

$6 \quad$ Other - Other telemetry systems.

7 Two or more of the above telemetry systems are in use.

8 Telemetry equipment used but type not specified.

General Description - A telemeter is an electrical apparatus for measuring quantity (e.g. temperature data) and transmitting the value to a distant receiving site, and there indicating or recording the quantity measured. The Water Quality Telemetry component identifies the type of system or equipment being used to transmit water-quality information from the data collection site to a central receiving site. 
$\frac{300}{\text { IN SR }}$

MANDA TORY

Yes

PICTURE

9(4)
QW_LST_UPDATE

COMPONENT NAME
344

COMPONENT NUMBER

DATA TYPE Integer
KEY No

LARGEST VALUE

Current YYMM

Data Values - This component contains the year and month ( $Y Y / M M$ ) in which the c300 data record was last updated. This date is generated by the computer.

General Description - An update is defined as any transaction that adds, changes, or deletes data values in the MWDI data base. 
300

IN SR

MANDATORY No

PICTURE $\mathrm{X}(4)$
QW PURPOSE

COMPONENT NAME
345

COMPONENT NUMBER
KEY No

DATA TYPE Char

Data Values - Up to four codes may be entered to denote the purpose(s) (classification) of a water-quality site as follows.

Code Meaning

B Benchmark - Sites measuring natural phenomena in areas where man's activity has essentialiy no effect. These sites would be expected to continue at least as long as natural conditions exist.

H Long-term hydrologic - Sites intended for the development of general hydrologic knowledge and(or) trends having local as well as transfer value to other points.

R Research or special study - Sites identified with research projects or special studies, including modeling, as part of a specific plan for developing specialized water information. These sites would be operated during the period of the research project or special study.

A Areal analysis - Sites to provide data for the hydrologic definition of an area or basin. These sites would generally be expected to be in operation until satisfactory areal definition is achieved.

S Assessment - Sites operated for the specific purpose of national accounting, determining trends, or general hydrologic planning.

F Forecasting - Sites to provide data for the purpose of forecasting hazardous or critical conditions.

L Compact or legal - Sites providing data used for survelllance or recordkeeping to fulfill legal requirements or compacts. 
C Current operation - Sites providing information necessary for the management and operation of hydrologic projects, water supplies, pollution abatement, waste disposal, etc. These sites would be operated as long as the specific need exists.

General Description - A site classification scheme devised and used internally by the U.S. Geological Survey to identify the purpose being served by the collection of hydrologic data at the site. 
300

IN SR

MANDA TORY

No

$\mathrm{KEY}$

No
347

COMPONENT NUMBER

DATA TYPE Char

1 character

PICTURE $\mathrm{X}(1)$

LARGEST VALUE

Data Values - The Quality of Water Recorder Type component is valued with a

1-character code to indicate the type of recorder used to collect the water data.

\begin{tabular}{|c|c|}
\hline Code & Meaning \\
\hline A & $\begin{array}{l}\text { Digital Recorder - Records data at intervals } \\
\text { throughout the day by storing the values on } \\
\text { paper tape or magnetic recording device. }\end{array}$ \\
\hline B & $\begin{array}{l}\text { Graphic Recorder - Supplies a continuous trace } \\
\text { of parameter value with respect to time on a } \\
\text { chart. }\end{array}$ \\
\hline
\end{tabular}

General Description - A recorder is an automatic (self-acting or self-regulating) device that registers and stores data values without human intervention. Telemetry equipment, which is used to transmit data to points distant from the data collection site, is separately accounted for in component 343 (QW TELEMETRY). 
QW RECORDER FREQ

COMPONENT NAME $\frac{348}{\text { COMPONENT NUMBER }}$

DATA TYPE Char

PICTURE

Data Values - This component contains a 1-character code to indicate the frequency at which data are being recorded at site.

\begin{tabular}{|c|c|c|}
\hline Code & Recording Interval & Readings Per Day \\
\hline A & $0.5 \mathrm{~min}(30 \mathrm{sec})$ & 2880 \\
\hline B & 1 min. & 1440 \\
\hline C & 2 min. & 720 \\
\hline D & 3 min. & 480 \\
\hline$E$ & 4 min. & 360 \\
\hline $\mathbf{F}$ & 5 min. & 288 \\
\hline G & $6 \mathrm{~min}$. & 240 \\
\hline $\mathrm{H}$ & 10 min. & 144 \\
\hline I & 15 min. & 96 \\
\hline $\mathbf{J}$ & 30 min. & 48 \\
\hline $\mathrm{K}$ & $45 \mathrm{~min}$. & 32 \\
\hline L & $1 \mathrm{hr}$ & 24 \\
\hline M & $2 \mathrm{hr}$ & 12 \\
\hline $\mathrm{N}$ & $3 \mathrm{hr}$ & 8 \\
\hline 0 & $4 \mathrm{hr}$ & 6 \\
\hline
\end{tabular}




\begin{tabular}{|c|c|c|}
\hline Code & Recording Interval & Readings Per Day \\
\hline $\mathbf{P}$ & $6 \mathrm{hr}$ & 4 \\
\hline Q & $12 \mathrm{hr}$ & 2 \\
\hline $\mathbf{R}$ & $24 \mathrm{hr}$ & 1 \\
\hline $\mathrm{S}$ & Continuous & - \\
\hline $\mathrm{T}$ & Periodic & - \\
\hline
\end{tabular}


300

$\overline{\text { IN SR }}$

MANDA TORY No

PICTURE $\mathrm{X}(1)$
QW_PN_CODE

COMPONENT NAME
349

COMPONENT NUMBER

KEY No

DATA TYPE Char

LARGEST VALUE

1 character

Data Values - For stations which are in the planning stage, the Quality of . Water Planned or Needed component will contain a 1-character code as follows:

Code $\quad \underline{\text { Meaning }}$

B Plan to establish - The establishment of a new site is planned.

$\mathrm{R} \quad$ Plan to reestablish - The reestablishment of a discontinued site is planned.

D Plan to discontinue - An active site is planned to be discontinued.

C Plan to change - A change in the parameter types or frequency of data collection at an active site is planned.

1 Need to establish - There is a need for the establishment of a new site.

2 Need to reestablish - There is a need for the reestablishment of a discontinued site.

3 Need to discontinue - There is a need for discontinuing an active site.

4 Need to change - A change in the parameter types or frequency of data collection at an active site is needed.

General Description - The office of Water Data Coordination (OWDC) is responsible for coordinating Federal agency needs and plans for long-term site activities for obtaining data on stage, flow, quality of surface waters, and quality of ground waters. "Planned" activities are those for which funds have been budgeted. "Needed" activities are those that are planned but do not yet have funds budgeted for them. 
$\frac{300}{I N ~ S R}$

MANDATORY

No

PICTURE $9(7)$
STORET_POINTER

COMPONENT NAME
355

COMPONENT NUMBER

LARGEST VALUE

9,999,999

Data Values - This component contains the STORET computer address to locate the data for the site in the STORET file.

General Description - The STORET pointer is stored in the MWDI data base to facilitate the future development of automated retrieval procedures between the two data systems. The pointer has no application in nonautomated uses of STORET. 
A schema record containing codes that indicate the external file that contains the data indexed in the C300 data record. The MWDI indexes data in the Environmental Protection Agency's Storage and Retrieval (STORET) system, the U.S. Geological Survey's National Water Data Storage and Retrieval System (WATSTORE), and the Texas Natural Resources Information System (TNRIS) by means of software interfaces. Multiple occurrences of $\mathrm{C} 370$ may exist for each C300 data record having data indexed from more than one external file. 
$\frac{370}{\text { IN SR }}$

MANDATORY

No

PICTURE $X(4)$
QW POINTER

COMPONENT NAME
371

COMPONENT NUMBER

DATA TYPE Char

KEY No

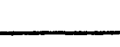

Data Values - This component contains a 4-character code that indicates an external file from which data have been indexed in the $\mathrm{C} 300$ schema record. The codes, assigned at time of interfacing, are described below:

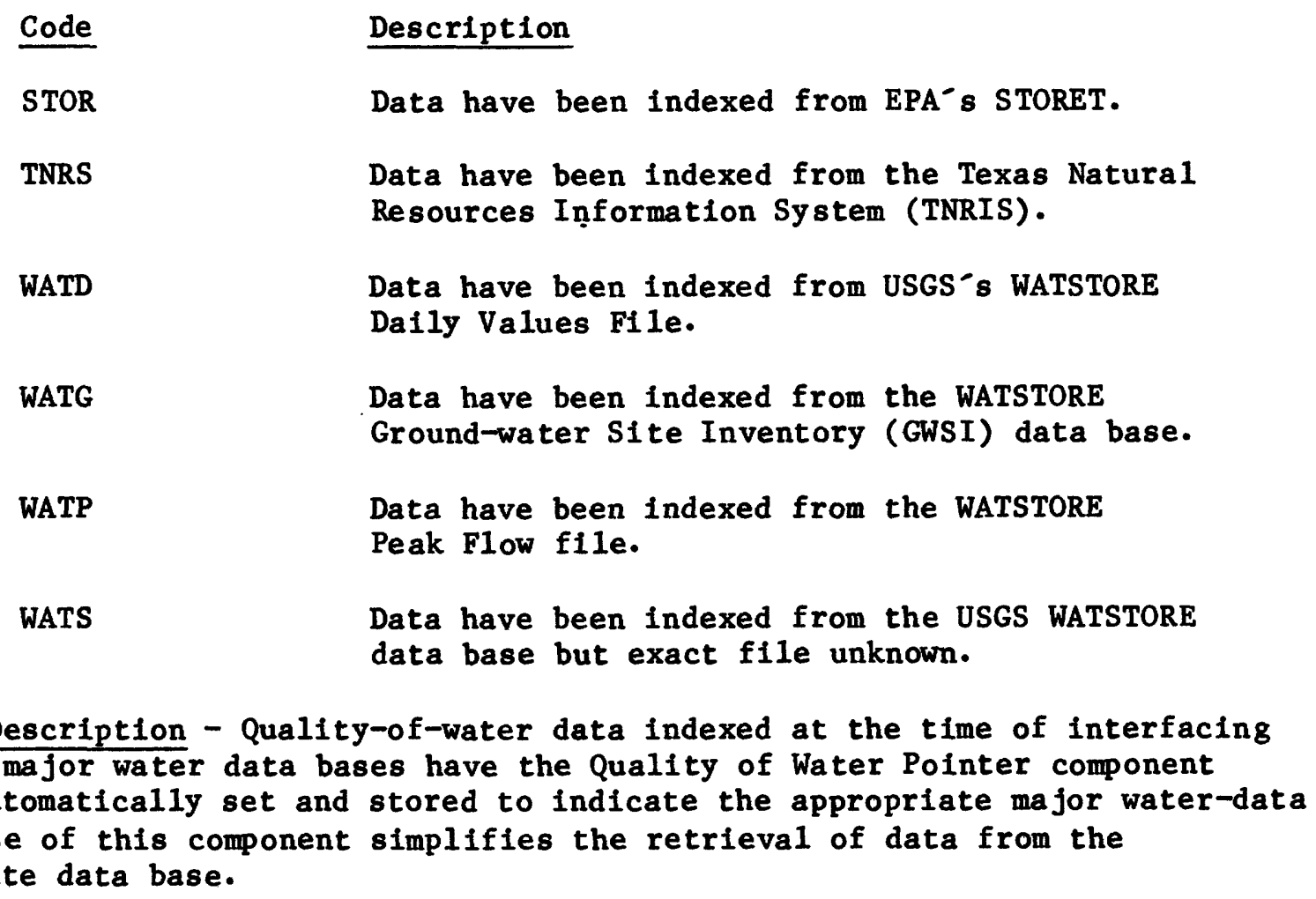

General Description - Quality-of-water data indexed at the time of interfacing with the major water data bases have the Quality of Water Pointer component (C371) automatically set and stored to indicate the appropriate major water-data base. Use of this component simplifies the retrieval of data from the appropriate data base. 
$\frac{370}{\text { IN SR }}$

MANDATORY

No

KEY

No
372

COMPONENT NUMBER
QW_MOD_FILE

COMPONENT NAME

DATA TYPE Char

Data Values - This component contains a 1-character code to indicate the WATSTORE Ground Water Site Inventory (GWSI) base subset from which the data were indexed.

$\begin{array}{ll}\text { Code } & \text { Subset } \\ \text { N } & \text { Northeast Region } \\ \text { S } & \text { Southeast Region } \\ \text { C } & \text { Central Region } \\ \text { W } & \text { Western Region }\end{array}$

General Description - This component is set automatically to one of the above codes to Indicate the GWSI subset in which the data reside at the time of interfacing with the GWSI. 
300

$\overline{\text { IN SR }}$

MANDATORY

N/A

N/A

PICTURE
B IOLOGICAL_QW

COMPONENT NAME
400

COMPONENT NUMBER

KEY N/A

DATA TYPE

SR

A schema record containing data values indicating the type of biological data (relating to living organisms in water) collection activities performed, the frequency at which the observations and/or determinations are made, and the media on which biological data for the site is available.

Components 401 through 453 deal specifically with the population, that is, the community structure found in aquatic habitats (what kinds of organisms and how many of each are present).

Components 455 through 469 are concerned with general measurements of the biological community's functions (see component 454 BIOLOGIC_QW2 for further definitions). 
400

$\overline{\text { IN SR }}$

MANDATORY No

PICTURE $\mathrm{X}(1)$
ENTERIC BACT

COMPONENT NAME
401

COMPONENT NUMBER

DATA TYPE Char
KEY No

LARGEST VALUE

Data Values - A 1-character alphabetic code in this component indicates the frequency with which a sample of the parameter is collected. See appendix A for frequency codes.

General Description - Enteric bacteria are those which originate in the intestines of warm-blooded animals. 
MANDA TORY

No

KEY No

DATA TYPE

Char

PICTURE

Data Values - A 1-character alphabetic code in this component indicates the frequency with which a sample of the parameter is collected. See appendix A for frequency codes.

General Description - Native bacteria, for the purpose of this data base, are those which are indigenous to a natural water body. 
$\frac{400}{\text { IN SR }}$

MANDATORY

No

PICTURE $\mathrm{X}(1)$
PHYTOPLANKTON

COMPONENT NAME
403

COMPONENT NUMBER

LARGEST VALUE

1 character

Data Values - A 1-character alphabetic code in this component indicates the frequency with which a sample of the parameter is collected. See appendix A for frequency codes.

General Description - Phytoplankton are the suspended or floating plant organisms which drift passively with water currents. Examples of phytoplankton are diatoms and blue-green algae. 
MANDA TORY

No

KEY

No

DATA TYPE

Char

PICTURE

Data Values - A 1-character alphabetic code in this component indicates the frequency with which a sample of the parameter is collected. See appendix A for frequency codes.

General Description - Zooplankton are the suspended or floating animal organisms which drift passively with water currents. Examples of zooplankton are protozoans, entomostracans, and various larvae. 
MANDA TORY

No

KEY No

DATA TYPE

Char

PICTURE

Data Values - A 1-character alphabetic code in this component indicates the frequency with which a sample of the parameter is collected. See appendix A for frequency codes.

General Description - Periphyton are the community of microorganisms that are attached to or live upon submerged surfaces. 
$\frac{400}{\text { IN } S R}$

$\overline{\mathrm{IN} \text { SR }}$
MACROPHYTON

COMPONENT NAME
406

COMPONENT NUMBER

MANDATORY No

KEY No

DATA TYPE Char

PICTURE $\quad \mathrm{X}(1)$

LARGEST VALUE

1 character

Data Values - A 1-character alphabetic code in this component indicates the frequency with which a sample of the parameter is collected. See appendix A for frequency codes.

General Description - Macrophytes are large aquatic plants that can be seen without magnification, including mosses and seed plants. 
400

$\overline{\text { IN SR }}$

MANDATORY

No

KE

MICROINVERTS

COMPONENT NAME
407

COMPONENT NUMBER

PICTURE $\mathrm{X}(1)$

LARGEST VALUE

1 character

Data Values - A 1-character alphabetic code in this component indicates the frequency with which a sample of the parameter is collected. See appendix A for frequency codes.

General Description - Small animals (without backbones) that will pass through a U.S. Standard $\$ 30$ sieve ( 0.595 millimeter mesh opening) are classified as microinvertebrates, according to the American Public Health Association publication entitled, "Standard Methods For The Examination of Water and Waste Water" (1975). The U.S. Geological Survey, however, has recently provisionally adopted the use of the U.S. Standard $\$ 70$ sieve ( 0.210 millimeter mesh opening) for this purpose. No universal mesh opening standard has been agreed to, but most organizations use mesh opening sizes which fall within the range of the \#30 to \#70 sieve sizes. 
$\frac{400}{\text { IN SR }}$

PICTURE $\quad \mathrm{X}(1)$
MACROINVERTS

COMPONENT NAME
408

COMPONENT NUMBER
MANDATORY No

KEY

No
DATA TYPE

Char

Data Values - A 1-character alphabetic code in this component indicates the frequency with which a sample of the parameter is collected. See appendix A for frequency codes.

General Description - Animals (without backbones) that will not pass through a U.S. Standard $\$ 30$ sieve ( 0.595 millimeter mesh opening) are classified as macroinvertebrates, according to the American Public Health Association publication entitled, "Standard Methods for the Examination of Water and Waste Water" (1975). The U.S. Geological Survey, however, has recently provisionally adopted the use of the U.S. Standard \#70 sieve ( 0.210 millimeter mesh opening) for this purpose. No universal mesh opening standard has been agreed to, but most organizations use mesh opening sizes which fall within the range of the \#30 to \#70 sieve sizes. 
400

$\overline{\text { IN SR }}$

MANDA TORY No

KEY

No

ERTEBRATES

COMPONENT NAME

409

COMPONENT NUMBER

DATA TYPE Char

PICTURE $\quad \mathrm{X}(1)$

LARGEST VALUE

1 character

Data Values - A 1-character alphabetic code in this component indicates the frequency with which a sample of the parameter is collected. See appendix A for frequency codes.

General Description - A vertebrate is an animal with a backbone enclosing a nerve cord; aquatic examples include fishes and amphibians. 
400

$\overline{\text { IN SR }}$

MANDATORY

No

KEY

No

FUNGI

COMPONENT NAME

410

COMPONENT NUMBER

PICTURE $\quad \mathrm{X}(1)$

LARGEST VALUE 1 character

Data Values - A 1-character alphabetic code in this component indicates the frequency with which a sample of the parameter is collected. See appendix A for frequency codes.

General Description - Fungi are plants lacking chlorophyll including molds, yeasts, mildews, rusts, and mushrooms. They derive their nourishment directly from other organisms (parasitic fungi) or from dead organic matter (saprophytic fungi). 
$\frac{400}{\text { IN SR }}$

MANDATORY No

KEY No
411

VIRUSES

COMPONENT NAME

PICTURE $\quad \mathrm{X}(1)$

LARGEST VALUE

1 character

DATA TYPE Char

Data Values - A 1-character alphabetic code in this component indicates the frequency with which a sample of the parameter is collected. See appendix A for frequency codes.

General Description - A class of ultramicroscopic, filterable, infectious agents, chiefly protein in composition, which are typically inert except when in contact with certain living cells. 
400

IN SR
BIO RECMD MTHDS

COMPONENT NAME
430

COMPONENT NUMBER

MANDATORY

No

KEY

No

DATA TYPE

Char

PICTURE X(1)

LARGEST VALUE

1 character

Data Values - The Biological Recommended Methods component is valued with a "Y" if the C400 data record describes data collected according to recommended methods. If not, the component is valued with an " $\mathrm{N}$ ".

General Description - In 1977, the Office of Water Data Coordination published the National Handbook of Recommended Methods for Water Data Acquisition. Another reference for recommended methods is the USGS's Techniques of WaterResources Investigations (TWRI). 
400

IN SR
BIO_BEGIN_YR

COMPONENT NAME
440

COMPONENT NUMBER

MANDATORY

No

KEY

No

DATA TYPE

Char

PICTURE $\mathrm{X}(1)$

LARGEST VALUE

1 character

Data Values - The Biological Data Collection Begin Year component contains a 4-digit numeric value identifying the year that biological data were first collected.

General Description - This component identifies the calendar year in which the acquisition of biological data first began at a site regardless of the types of biological data that were collected. This date will never change even though biological data collection may be deactivated and reactivated several times during a site's history. 
$\frac{454}{\text { IN SR }}$

PICTURE 9(4)
BIO END YR

COMPONENT NAME
441

COMPONENT NUMBER
MANDATORY No

KE

No

DATA TYPE Integer

Data Values - The Biological Data Collection End Year component contains a 4-digit numeric value identifying the year that all biological data collection activities were ceased at the site. If the organization is currently collecting data at the site, this component is not valued.

General Description - This component identifies the calendar year in which all biological data collection activities at the site were discontinued. If at a later date, the collection of any of the biological parameters is resumed, the former end date is deleted. 
400

$\overline{\text { IN SR }}$

MANDATORY Yes

KEY

No

DATA TYPE Integer

PICTURE $9(4)$

444

\section{LARGEST VALUE Current YYMM}

COMPONENT NUMBER

Data Values - This component contains the year and the month ( $Y Y / M M)$ in which the 6400 data record was last updated. This date is generated by the computer.

General Description - An update is defined as any transaction that adds, deletes, or changes data values in the MWDI data base. 
$\frac{400}{\text { IN SR }}$

MANDA TORY

No
BIOLOGICAL QW

COMPONENT NAME
446

COMPONENT NUMBER

PICTURE $\quad \mathrm{X}(1)$

KEY No

DATA TYPE Char

Data Values - This component contains a 1-character code indicating the type(s) of storage media (document, computer readable, etc.) on which the biological data are stored and available to potential users of the data. See appendix $B$ for data storage codes and also see component number 400 (BIOLOGICAL) for the definition of biological.

General Description - Organizations collect hydrologic data and record and store the information on a variety of storage media ranging from original field notes to computer storage devices. Media is used as a general term encompassing all means of storing and disseminating the data. 
$\frac{400}{\text { IN SR }}$

BIOLOGICAL QW2

COMPONENT NAME $\frac{454}{\text { COMPONENT NUMBER }}$

DATA TYPE

SR

PICTURE N/A

KEY N/A

MANDATORY N/A

LARGEST VALUE N/A

Further biological analyses used in the interpretation of water quality.

Components 455-458 are concerned with community metabolism, which is the rate at which the life processes of the organisms of a community take place, that is, growth, reproduction, and assimilation.

Components 459-461 are concerned with bioassays, which involve the use of living organisms to test the effect of a given substance.

Components 462-464 are concerned with tissue analysis, which is the examination of dead organisms to detect the presence or influence of substances or physical damage. 
$\frac{454}{\text { IN SR }}$

MANDATORY No

KEY

No

PRIMARY_PRDCTVTY

COMPONENT NAME
COMPONENT NUMBER

PICTURE $\quad \mathrm{X}(1)$

LARGEST VALUE

1 character

Data Values - A 1-character alphabetic code in this component indicates the frequency with which determinations are made. See appendix A for frequency codes.

General Description - Primary productivity is the rate at which organic matter is produced by the photosynthetic and chemosynthetic activity of autotrophic organisms (chiefly green plants) using inorganic material as a carbon source and sunlight as an energy source. 
454

IN SR

456

COMPONENT NUMBER

MANDATORY No

PICTURE $\quad \mathrm{X}(1)$
KEY No

DATA TYPE Char

Data Values - A 1-character alphabetic code in this component indicates the frequency with which determinations are made. See appendix A for frequency codes.

General Description - Secondary productivity is the rate at which organic matter is produced by the heterotrophic organisms of a community. 
MANDATORY

No

KEY

No

DATA TYPE

Char

PICTURE $\quad \mathrm{X}(1)$

LARGEST VALUE

1 character

Data Values - A 1-character alphabetic code in this component indicates the frequency with which determinations are made. See appendix A for frequency codes.

General Description - Chemosynthetic activity is the synthesis of organic matter from mineral substances with the aid of chemical energy. 
MANDATORY

No

KEY

No

DATA TYPE Char

PICTURE

Data Values - A 1-character alphabetic code in this component indicates the frequency with which determinations are made. See appendix A for frequency codes.

General Description - Biostimulatory tests determine the reaction of an organism to a given substance or set of conditions, for example, cold, heat, and excessive nutrients. Algae growth potential is an example of this type of test. 
$\frac{454}{\text { IN SR }}$

MANDATORY NO

KEY

No
460

TOXICITY TEST

COMPONENT NAME

PICTURE $\quad \mathrm{X}(1)$

LARGEST VALUE

1 character

DATA TYPE Char

Data Values - A 1-character alphabetic code in this component indicates the frequency with which determinations are made. See appendix A for frequency codes.

General Description - Toxicity tests determine the potency of a toxic substance by measuring the intensity of a biological response. 
MANDATORY

No

KEY

No

DATA TYPE Char

PICTURE $\quad \mathrm{X}(1)$

LARGEST VALUE

1 character

Data Values - A 1-character alphabetic code in this component indicates the frequency with which determinations are made. See appendix $A$ for frequency codes.

General Description - Other bioassay tests refer to those not covered in components 459 (BIOSTIMULATORY TEST) and 460 (TOXICITY TEST), and may include, for example, the measurement of low-level response systēms, such as heart rate. 
$\frac{454}{\text { IN SR }}$

MANDA TORY No

KEY

No
462

COMPONENT NUMBER

PICTURE $\quad \mathrm{X}(1)$

LARGEST VALUE

1 character

DATA TYPE Char

Data Values - A 1-character alphabetic code in this component indicates the frequency with which determinations are made. See appendix A for frequency codes.

General Description - Chemical analysis of tissue involves the measurements of the types and/or amounts of chemical substances present in the tissue of an organism. 
$\frac{454}{\text { IN SR }}$

MANDA TORY No

KEY

No
HISTOPATH_ANALYSIS

COMPONENT NAME
463

COMPONENT NUMBER

PICTURE $\quad \mathrm{X}(1)$

LARGEST VALUE

1 character

DATA TYPE Char

Data Values - A 1-character alphabetic code in this component indicates the frequency with which determinations are made. See appendix $A$ for frequency codes.

General Description - Histopathological analysis involves the determination of changes in an organism's tissue structure as a result of some physical (for example, parasitism) or chemical (for example toxic substances) activity. 
$\frac{454}{\text { IN SR }}$

OTHER TISSUE ANALYSIS

COMPONENT NAME
464

COMPONENT NUMBER

MANDA TORY

No

KEY

No

DATA TYPE

Char

PICTURE $\quad \mathrm{X}(1)$

LARGEST VALUE

1 character

Data Values - A 1-character alphabetic code in this component indicates the frequency with which determinations are made. See appendix A for frequency codes.

General Description - Other tissue analyses of organisms refer to those not covered in components 462 (CHM TISSUE ANALYSIS) and 463 (HISTOPATH ANALYSIS), and may involve, for example, determinations in flavor impairment or fish flesh. 
400

$\overline{\text { IN SR }}$

MANDATORY

N/A

N/A

PICTURE
BIO_MODIF IERS

COMPONENT NAME
470

COMPONENT NUMBER

KEY N/A

DATA TYPE SR

LARGEST VALUE N/A

A schema record containing codes that indicate the external file that contains the data indexed in the 6400 data record. The MWDI indexes data from the Environmental Protection Agency's Storage and Retrieval (STORET) System, the U.S. Geological Survey's National Water Data Storage and Retrieval System (WATSTORE), and the Texas Natural Resources Information System (TNRIS) by means of software interfaces. Multiple occurrences of $\mathrm{C} 470$ may exist for each $\mathrm{C} 400$ data record having data indexed from more than one external file. 
470

IN SR

MANDATORY

No

PICTURE $\quad X(4)$
BIO POINTER

COMPONENT NAME
471

COMPONENT NUMBER

KEY

No

DATA TYPE

Char

LARGEST VALUE 4 characters

Data Values - This component contains a 4-character code that indicates an external file from which data have been indexed in the 6400 schema record. The codes assigned at time of interfacing are described below:

Code

STOR

TNRS

WATD

WATG

WATP

WATS
Description

Data have been indexed from EPA's STORET.

Data have been indexed from the Texas Natural Resources Information System (TNRIS).

Data have been indexed from the WATSTORE Dally Values.

Data have been indexed from the WATSTORE Ground-water Site Inventory (GWSI) data base.

Data have been indexed from the WATSTORE Peak Flow file.

Data have been indexed from the WATSTORE data base but exact file unknown.

General Description - Biological data indexed at the time of interfacing with the major water data bases have the Biological Pointer component (C471) automatically set and stored to indicate the appropriate major water data base. Use of this component simplifies the retrieval of data from the appropriate data base. 
470

IN SR

MANDATORY

No

KEY

No
472

COMPONENT NUMBER

PICTURE $\mathrm{X}(1)$

BIO MOD FILE

COMPONENT NAME

DATA TYPE Char

LARGEST VALUE 1 character

Data Values - This component contains a 1-character code to indicate the WATSTORE Ground Water Site Inventory (GWSI) data base subset from which the data were indexed.

Code

N

S

C

W
Subset

Northeast Region

Southeast Region

Central Region

Western Region

General Description - This component is set automatically to one of the above codes to indicate the GWSI subset in which the data resides at the time of interfacing with the GWI. 
MANDA TORY N/A

KEY N/A

DATA TYPE

SR

PICTURE N/A

LARGEST VALUE

N/A

A schema record containing data values which indicate the types of physical waterquality data collection activities performed, the frequency at which the observations and/or determinations are made, and the media on which physical water quality data for the site is available.

Physical water quality parameters are those which pertain to the measurement of the physical properties (temperature, turbidity, color, etc.) of water, as distinguished from the concentrations of chemical or biological components. 
500

IN SR

MANDATORY No

KEY

No

DATA TYPE

Char
TEMPERATURE

COMPONENT NAME
501

COMPONENT NUMBER

PICTURE $\quad \mathrm{X}(1)$

1 character

Data Values - A 1-character alphabetic code in this component indicates the frequency with which observed or instrument-recorded temperature data are collected. See appendix A for frequency codes.

General Description - Temperature is a measure of the intensity aspect of heat energy present in a water body. It influences the aquatic environment and affects the aquatic biota, the concentrations of dissolved gases, and the distribution of chemical solutes (dissolved substances). 
MANDATORY No

KEY No

DATA TYPE Char

PICTURE $\mathrm{X}(1)$

LARGEST VALUE

1 character

Data Values - A 1-character alphabetic code in this component indicates the frequency with which specific conductance determinations are made. See appendix $A$ for frequency codes.

General Description - Specific conductance is a measure of the ability of water to conduct an electrical current and is expressed in micromhos per centimeter at $25^{\circ} \mathrm{C}$. 
$\frac{500}{\mathrm{IN} \mathrm{SR}}$

MANDA TORY No

KEY

No

TURBIDITY

COMPONENT NAME
503

COMPONENT NUMBER

PICTURE $\quad \mathrm{X}(1)$

LARGEST VALUE

1 character

DATA TYPE Char

Data Values - A 1-character alphabetic code in this component indicates the frequency with which turbidity determinations are made. See appendix A for frequency codes.

General Description - Turbidity is an expression of the optical property of water that causes light to be scattered and absorbed rather than transmitted in straight lines. It is caused by the presence of a wide variety of suspended matter, such as clay, silt, finely divided organic and inorganic matter, plankton, and other microscopic organisms. It is usually measured in terms of milligrams per liter, Jackson turbidity units (JTU), or nephelometric units (NTU). 
$\frac{500}{\text { IN SR }}$

MANDATORY

No

PICTURE $X(1)$
COLOR

COMPONENT NAME

KEY No

DATA TYPE

Char

LARGEST VALUE

1 character

Data Values - A 1-character alphabetic code in this component indicates the frequency with which color determinations are made. See appendix A for frequency codes.

General Description - Color in water can be caused by the presence of plankton, aquatic vegetation, decaying organic matter, natural metaliic ions, industrial wastes, and sewage. A distinction is made between "true color" (the color of a water sample after turbidity has been removed by filtration) and "apparent color" (the color of an untreated water sample). "True color" is usually measured by comparing the color of a water sample to that of a fixed standard. Color is expressed in terms of "color units" where one color unit is the difference in tint produced by one milligram per liter of the chloroplatinate ion. 
$\frac{500}{\text { IN SR }}$

MANDA TORY

No

PICTURE $\quad \mathrm{X}(1)$
ODOR

COMPONENT NAME
505

COMPONENT NUMBER

DATA TYPE Char

LARGEST VALUE

1 character

Data Values - A 1-character alphabetic code in this component indicates the frequency with which odor determinations are made. See appendix $A$ for frequency codes.

General Description - Odors from water can be caused by a variety of materials, both natural and foreign, in the water body. Odor tests are made by using the human sense of smell. A panel of "testers," in turn, each sniff various dilutions of a water sample. until that dilution with the least, but definitely perceptible, odor to all on the panel is determined. 
500

$\overline{\text { IN SR }}$

MANDA TORY

No

PICTURE $\mathrm{X}(1)$
$\mathrm{pH}$

COMPONENT NAME
506

COMPONENT NUMBER

DATA TYPE Char

KEY No

Data Values - A 1-character alphabetic code in this component indicates the frequency with which $\mathrm{pH}$ determinations are made. See appendix $A$ for frequency codes.

General Description - pH stands for "parts hydrogen" and is a term used almost universaliy to express the intensity of the acid or alkaline condition of a solution. It is the logarithm of the reciprocal of hydrogen-ion, concentration, or more precisely, the hydrogen-ion activity expressed in moles per liter. The practical pH scale (in standard units) ranges from 0 to 14 . A pH of 7.0 indicates that the water sample solution is neutral while readings progressively lower than 7.0 denote increasing acidity and those progressively higher than 7.0 denote increasing alkalinity. 
500

IN SR

MANDATORY

No
SUSPD SOLIDS

COMPONENT NAME
507

COMPONENT NUMBER

PICTURE $\quad \mathrm{X}(1)$

KEY

No

DATA TYPE

Char

LARGEST VALUE

1 character

Data Values - A 1-character alphabetic code in this component indicates the frequency with which suspended solids determinations are made. See appendix A for frequency codes.

General Description - Suspended solids include colloidal and particulate matter, such as sand, clay, finely divided organic material, bacteria, and plankton that are suspended in the water body.

The term "suspended solids" is synonymous with "suspended sediment concentration" (component 602), however, it is generally used by sanitary engineers in connection with water treatment facilities, while "suspended sediment" is generally used by civil or hydraulic engineers in connection with sediment transport studies, and the data are reported accordingly. 
500

IN SR

MANDA TORY No

KEY

No

DATA TYPE

Char

COMPONENT NUMBER

PHY RECMD MTHDS

COMPONENT NAME

PICTURE $\quad \mathrm{X}(1)$

LARGEST VALUE

1 character

Data Values - The Physical Recommended Methods component is valued with a " $Y$ " if the C500 data record describes data collected according to recommended records. If not, the component is valued with an " $\mathrm{N}$ ".

General Description - In 1977, the Office of Water Data Coordination published the National Handbook of Recommended Methods for Water Data Acquisition. Another reference for recommended methods is the USGS's Techniques of Water-Resources Investigations (TWRI). 
$\frac{500}{\text { IN SR }}$

MANDA TORY No

KEY No
PHY BEGIN YR

COMPONENT NAME
540

COMPONENT NUMBER

DATA TYPE Integer

PICTURE $9(4)$

Data Values - The Physical Data Collection Begin Year component contains a 4-digit numeric value identifying the year that physical data were first collected at the site, for example, 1910 .

General Description - This component identifies the calendar year in which the acquisition of physical data was first begun at a site, regardless of the types of physical data that were collected. This date will never change even though physical data collection may be deactivated and reactivated several times during a site's history. 
PHY END YR

COMPONENT NAME
541

COMPONENT NUMBER

MANDATORY No

KEY

No

DATA TYPE Integer

PICTURE 9(4)

LARGEST VALUE

current year

Data Values - The Physical Data Collection End Year component contains a 4-digit numeric value identifying the year that all physical data collection activities were ceased at the site. If the organization is currently collecting any physical data at the site, this component is not valued.

General Description - This component Identifies the calendar year in which all physical data collection activities at a site were discontinued. If at a later date, the collection of any of the physical parameters is resumed, the former end date is deleted. 
500

IN SR

MANDA TORY

Yes

PICTURE $9(4)$

KEY

No

DATA TYPE Integer

PHY LST UPDATE

COMPONENT NAME

LARGEST VALUE

Current YYMM

Data Values - This component contains the year and the month ( $Y Y / M M)$ in which the 6500 data record was last updated. This date is generated by the computer.

General Description - An update is defined as any transaction that adds, deletes, or changes data values in the MWDI data base. 
500

$\overline{\text { IN SR }}$

MANDA TORY

No

KEY

No

DATA TYPE Char

PICTURE $\quad \mathrm{X}(1)$

LARGEST VALUE

1 character

Data Values - This component contains a 1-character code indicating the type(s) of storage media (document, computer readable, etc.) on which the physical data are stored and available to potential users of the data. See appendix B for data storage codes.

General Description - Organizations collect hydrologic data and record and store the information on a variety of storage media ranging from original field notes to computer storage devices. Media is used as a general term encompassing all means of storing and disseminating the data. 
500

IN SR

MANDATORY

N/A

N/A

PICTURE
PHY MODIF IERS

COMPONENT NAME
570

COMPONENT NUMBER

KEY

N/A

DATA TYPE

SR

LARGEST VALUE

N/A

A schema record containing codes that indicate the external file that contains the data indexed in the C500 data record. The MWDI indexes data in the Envi ronmental Protection Agency's Storage and Retrieval (STORET) System, the U.S. Geological Survey's National Water Data Storage and Retrieval System (WATSTORE), and the Texas Natural Resources Information System (TNRIS) by means of software interfaces. Multiple occurrences of C570 may exist for each $\mathrm{C} 500$ data record having data indexed from more than one external file. 
570

$\overline{\text { IN SR }}$

MANDATORY

No

KEY

No

PHY POINTER

COMPONENT NAME
571

COMPONENT NUMBER

PICTURE X(4)

LARGEST VALUE 4 characters

DATA TYPE Char

Data Values - This component contains a 4-character code that indicates an external file from which data have been indexed in the C500 schema record. The codes assigned at time of interfacing, are described below:

Code

STOR

TNRS

WATD

WATG

WATP

WATS

\section{Description}

Data have been indexed from EPA's STORET.

Data have been indexed from the Texas Natural

Resources Information System (TNRIS).

Data have been indexed from the WATSTORE Daily Values.

Data have been indexed from the WATSTORE Ground-water Site Inventory (GWSI) data base.

Data have been indexed from the WATSTORE Peak Flow file.

Data have been indexed from the WATSTORE data base but exact file unknown.

General Description - Physical data at the time of interfacing with the major water data bases have the physical pointer component (C571) automatically set and stored to indicate the appropriate major water data base. Use of this component simplifies the retrieval of data from the appropriate data base. 
570

IN SR

MANDA TORY No

PICTURE X(1)
PHY_MOD_FILE

COMPONENT NAME
572

COMPONENT NUMBER

KEY No

DATA TYPE

Char

LARGEST VALUE

1 character

Data Values - This component contains a 1-character code to indicate the WATSTORE Ground Water Site Inventory (GWSI) data base subset from which the data were indexed.

\begin{tabular}{|c|c|}
\hline Code & Subset \\
\hline $\mathrm{N}$ & Northeast Region \\
\hline $\mathbf{S}$ & Southeast Region \\
\hline C & Central Region \\
\hline $\mathbf{W}$ & We stern Region \\
\hline
\end{tabular}

General Description - This component is set automatically to one of the above codes to Indicate the GWSI subset in which the data resides at the time of interfacing with the GWSI. 
MANDA TORY

N/A

KEY N/A

DATA TYPE

SR

PICTURE

N/A

LARGEST VALUE

N/A

A schema record containing data values indicating the types of sediment data collection activities performed, the frequency at which the observations and/or determinations are made, and the media on which sediment data for the site is avallable.

Sediment is the solid particles of inorganic or organic fragmental material, usually derived from disintegrated rocks or other earth material that have been or are being transported laterally or vertically from one or more places of origin by air or water. All references to sediment in this database pertain to fluvial sediment only--that is, sediment which is transported by, suspended in, or deposited by water. 
600

IN SR

MANDATORY No
BED_LOAD

COMPONENT NAME
601

COMPONENT NUMBER

PICTURE

KEY

No

DATA TYPE

Char

Data Values - This component contains a 1-character alphabetic code that indicates the intervals of time for which records of bedload are avallable. See appendix $A$ for frequency codes.

General Description - Bedload is the sediment mixture moving on or near the streambed by rolling, sliding, and making brief excursions into the flow, a few diameters above the bed. The term "diameter" is defined as the diameter of a sphere of the same volume as the given particle. Bedload discharge is the amount (weight, mass, or volume) of bedload passing through any cross section of a stream during a unit of time. 
$\frac{600}{\text { IN SR }}$

MANDA TORY

No
CNCNTRTN SUS

COMPONENT NAME
602

COMPONENT NUMBER

PICTURE $\mathrm{X}(1)$

KEY

No

DATA TYPE

Char

LARGEST VALUE

1 character

Data Values - A 1-character alphabetic code in this component indicates the frequency with which concentration determinations are made. See appendix A for frequency codes.

General Description - Suspended sediment is the sediment mixture that is carried in suspension in the main body flow of a stream for appreciable lengths of time, being kept in this state by the upward components of the turbulence of flow or by colloidal suspension.

The term for component 602 (suspended-sediment concentration) is synonymous with the term for component 507 (suspended solids). However, "suspended-sediment concentration" is generally used by civil or hydraulic engineers in connection with sediment transport studies, while "suspended solids" is generally used by sanitary engineers in connection with water treatment facilities. The data are reported accordingly.

Suspended-sediment concentration is the velocity-weighted (representative) concentration of suspended sediment in the sampled zone (taken from the water surface to a point approximately $0.3 \mathrm{ft}$. above the bed) and is usually expressed as milligrams of dry solids per liter of water-sediment mixture. 
$\frac{600}{\text { IN SR }}$

MANDA TORY

No

$\mathrm{X}(1)$

PICTURE $\mathrm{X}(1)$
CNCNTRTN TOT

COMPONENT NAME
603

COMPONENT NUMBER

KEY

No

DATA TYPE

Char

-

LARGEST VALUE

1 character

Data Values - A 1-character alphabetic code in this component indicates the frequency with which total sediment concentrations are determined. See appendix A for frequency codes.

General Description - Total sediment concentration is the concentration of all the sediment passing through a given cross-section in a stream expressed in milligrams per liter or as parts per million. This is possible only at a total-1oad measuring section where physical circumstances cause all of the sediment particles being transported to be thrown into a fairly uniform suspension throughout the total depth by natural or artificial turbulence. 
600

$\overline{\text { IN SR }}$

MANDA TORY

No

$\mathrm{X}(1)$

PICTURE
PART_SIZ_SUS

COMPONENT NAME
604

COMPONENT NUMBER

KEY

No

DATA TYPE Char

LARGEST VALUE

1 character

Data Values - A 1-character alphabetic code in this component indicates the frequency with which suspended particle-size determinations are made. See appendix $A$ for frequency codes.

General Description - The particle-size of suspended sediment is the diameter, usually expressed in millimeters, of a particle measured by settling, sieving, micrometric, or direct measurement methods. Particle-size data are usually expressed as a distribution showing the relative amount, in terms of percent of total weight, of a sediment sample having a specific size finer than a given size, 
600

IN SR

MANDA TORY

No

PICTURE $\quad \mathrm{X}(1)$
PART_SIZ_BED

COMPONENT NAME

KEY No

DATA TYPE

Char

LARGEST VALUE

605

COMPONENT NUMBER

Data Values - A 1-character alphabetic code in this component indicates the frequency with which bed material particle-size determinations are made. See appendix $A$ for frequency codes.

General Description - The particle size of bed-material sediment is the diameter, usually expressed in millimeters, of a particle measured by settling, sieving, micrometric, or direct measurement methods. Particle-size data are usually expressed as a distribution showing the relative amount, in terms of percentage of total weight, of a sediment sample having a specific size finer than a given size. 
$\frac{600}{\text { IN SR }}$

MANDATORY

No

PICTURE $\mathrm{X}(1)$
SED_DIS_SUS

COMPONENT NAME
606

COMPONENT NUMBER

KEY No

DATA TYPE Char

Data Values - A 1-character alphabetic code in this component indicates the intervals of time for which suspended-sediment discharge records are available. See appendix A for frequency codes.

General Description - Sediment discharge (suspended) is the rate of transport of suspended sediment passing through a given cross-section of a stream expressed in tons per day. It is computed from the measured suspended-sediment concentration (instantaneous sediment discharge), or from the mean-daily suspended-sediment concentration (daily sediment discharge). 
600

$\overline{\text { IN SR }}$

MANDA TORY

No

KEY

No

DATA TYPE

Char

PICTURE $\quad X(1)$

LARGEST VALUE

1 character

Data Values - A 1-character alphabetic code in this component indicates the Intervals of time for which sediment-discharge (total) records are available. See appendix A for frequency codes.

General Description - Sediment discharge (tota1) is the rate of transport of all the sediment passing through a given cross-section in a stream expressed in tons per day. It is computed from the measured sediment concentration (Instantaneous) at a total-1oad measuring section (see component 603) only, or from computed mean daily total sediment concentration (daily) based on samples. 
$\frac{600}{\text { IN SR }}$

MANDATORY No

PICTURE $\quad \mathrm{X}(1)$
SED RECMD MTHDS

COMPONENT NAME
630

COMPONENT NUMBER

KEY

No

DATA TYPE

Char

Data Values - The Sediment Recommended Methods component is valued with a " $Y$ " if the $\mathrm{C} 600$ data record describes data collected according to recommended methods. If not, the component is valued with an " $\mathrm{N}$ ".

General Description - In 1977, the Office of Water Data Coordination published the National Handbook of Recommended Methods for Water Data Acquisition. Another reference for recommended methods is the USGS's Techniques of Water-Resources Investigations (TWRI). 
600

IN SR

MANDATORY

Yes

KEY

No

COMPONENT NAME

640

COMPONENT NUMBER

PICTURE 9(4)

LARGEST VALUE

current year

Data Values - The Sediment Data Collection Begin Year component contains a 4-digit numeric value identifying the year that sediment data were first collected.

General Description - This component identifies the calendar year in which the acquisition of sediment data first began at a site regardless of the types of sediment data that were collected. This date will never change even though sediment data collection may be deactivated and reactivated several times during a site's history. 
$\frac{600}{\text { IN SR }}$

MANDA TORY

No
SED END YR

COMPONENT NAME
641

COMPONENT NUMBER

PICTURE

KEY

No

DATA TYPE Integer

LARGEST VALUE

current year

Data Values - The Sediment data collection end year component contains a 4digit numeric value identifying the year that all sediment data collection activities were ceased at the site. If the organization is currently collecting sediment data at the site, this component is not valued.

General Description - This component identifies the calendar year in which all sediment data-collection activities at the site were discontinued. If at a later date, the collection of any of the sediment parameters is resumed, the end date is deleted. 
$\frac{600}{\text { IN SR }}$

MANDATORY

Yes

PICTURE 9(4)
SED LST UPDATE

COMPONENT NAME

KEY No

DATA TYPE Integer

LARGEST VALUE

Current YYMM

Data Values - This component contains the year and the month (YY/MM) in which the C600 data record was last updated. This date is generated by the computer.

General Description - An update is defined as any transaction that adds, deletes, or changes data values in the MWDI data base. 
600

$\overline{\text { IN SR }}$

MANDATORY

No

PICTURE $\mathrm{X}(1)$
SEDIMENT MED

COMPONENT NAME
646

COMPONENT NUMBER

KEY No

DATA TYPE Char

LARGEST VALUE

1 character

Data Values - This component contains a 1-character code indicating the type(s) of storage media (document, computer readable, etc.) on which the sediment data are stored and available to potential users of the data. See appendix B for data storage codes.

General Description - Organizations collect hydrologic data and record and store the information on a variety of storage media ranging from original field notes to computer storage devices. Media is used as a general term encompassing all means of storing and disseminating the data. 
600

$\overline{\text { IN SR }}$

MANDATORY

N/A
PICTURE N/A
SED_MODIF IERS

COMPONENT NAME

KEY N/A

SR

670
DATA TYPE

COMPONENT NUMBER

N/A

A schema record containing codes that indicate the external file that contains the data indexed in the 6600 data record. The MWDI indexes data from the Environmental Protection Agency's Storage and Retrieval (STORET) System, the U.S. Geological Survey's National Water Data Storage and Retrieval System (WATSTORE), and the Texas Natural Resources Information System (TNRIS) by means of software interfaces. Multiple occurrences of 6670 may exist for each 6600 data record having data indexed from more than one external file. 
$\frac{670}{\text { IN SR }}$

MANDATORY

No

KEY

No
671

COMPONENT NUMBER

PICTURE X(4)

LARGEST VALUE

DATA TYPE

Char

$\mathrm{X}(4)$

SED POINTER

COMPONENT NAME

Data Values - This component contains a 4-character code that indicates an external file from which data have been indexed in the 6600 schema record. The codes, assigned at time of interfacing, are described below:

Code

STOR

TNRS

WATD

WATG

WATP

WATS
Description

Data have been indexed from EPA's STORET

Data have been indexed from the Texas Natural Resources Information System (TNRIS)

Data have been indexed from the USGS's WATSTORE Daily Values File

Data have been indexed from the USGS's WATSTORE Ground-water Site Inventory (GWSI) data base.

Data have been indexed from the USGS's WATSTORE Peak Flow file

Data have been indexed from the WATSTORE data base, but exact file unknown.

General Description - Sediment data indexed at the time of interfacing with the major water data bases have the Sediment Pointer component (671) automatically set and stored to indicate the appropriate major water data base. Use of this component simplifies the retrieval of data from the appropriate data base. 
670

IN SR

MANDATORY No

KEY

No

COMPONENT NUMBER

DATA TYPE Char

PICTURE $\mathrm{X}(1)$

LARGEST VALUE 1 character

Data Values - This component contains a 1-character code to indicate the WATSTORE Ground-Water-Site-Inventory (GWSI) data base subset from which the data were indexed.

Code

Subset

N

S

C

W
Subset

Northeast Region

Southeast Region

Central Region

Western Region

General Description - This component is set automatically to one of the above codes to Indicate the GWSI subset in which the data resides at the time of interfacing with the GWSI. 
$\frac{300}{\text { IN SR }}$

MANDA TORY

N/A

N/A

PICTURE
CHEMICAL QW

COMPONENT NAME

KEY N/A

DATA TYPE

SR

700

LARGEST VALUE

N/A

COMPONENT NUMBER

A schema record containing data values indicating the types of chemical-water quality data-collection activities performed, the frequency at which the observations and/or determinations are made, and the media on which the chemical water-quality data for the site is available.

Chemical water quality parameters are those which pertain to the chemical constituents and properties of substances present in water. 
MANDATORY No

KEY No

DATA TYPE Char

PICTURE $\mathrm{X}(1)$

Data Values - A 1-character alphabetic code in this component indicates the frequency with which dissolved solids determinations are made. See appendix $A$ for frequency codes.

General Description - Dissolved solids in water consist mainly of inorganic salts and small amounts of organic matter. A general working definition of "dissolved" (as compared to suspended) solids is anything which will pass through a 0.45 -micron filter. 
700

IN SR

MANDATORY No

KEY

No

DATA TYPE

Char
702

COMPONENT NUMBER

PICTURE X(1)

LARGEST VALUE

1 character

Data Values - A 1-character alphabetic code in this component indicates the frequency with which major ion determinations are made. See appendix A for frequency codes.

General Description - Major ions include elements which are (or could be) in fairly high concentration in most natural waters, such as calcium, magnesium, sodium, potassium, bicarbonate, carbonate, sulfate, and chloride. 
700

IN SR

MANDATORY No

KEY

No

DATA TYPE

PICTURE $X(1)$

LARGEST VALUE

1 character

Data Values - A 1-character alphabetic code in this component indicates the frequency with which hardness determinations are made. See appendix A for frequency codes.

General Description - Hardness has historically been defined as a measure of the ability of water to precipitate soap, and, in natural waters, is primarily a function of the presence of calcium and magnesium ions. Other constituents, such as iron, manganese, aluminum, barium, strontium, zinc, and free acid also cause hardness but they are not usually present in quantities large enough to have any objectionable effect.

Hardness is normally expressed in terms of calcium carbonate ( $\mathrm{CaC03}$ ) and is often reported as "carbonate hardness," "noncarbonate hardness," and "total hardness." 
700

IN SR

MANDATORY

No

KEY

No
DATA TYPE

Char

PICTURE X(1)

LARGEST VALUE 1 character

Data Values - A-character alphabetic code in this component indicates the frequency with which silica determinations are made. See appendix $A$ for frequency codes.

General Description - Silica $\left(\mathrm{SiO}_{2}\right)$ is the term widely used in referring to the presence of silicon, in soluble and colloidal forms, in natural waters. Amounts of silica are commonly reported as tons per day or milligrams per liter of $\mathrm{SiO}_{2}$. 
700

$\overline{\text { IN SR }}$

PICTURE $\quad \mathrm{X}(1)$
PHOSPHORUS

COMPONENT NAME
706

COMPONENT NUMBER
MANDATORY No

KEY

No
DATA TYPE

Char

Data Values - A 1-character alphabetic code in this component indicates the frequency with which total phosphorus determinations are made. See appendix A for frequency codes.

General Description - This component pertains only to the gross measurement (tota1) of the element phosphorus without regard to individual species. The measurement is usually expressed in milligrams per liter. 
700

IN SR

MANDATORY

No

PICTURE $\mathrm{X}(1)$

PHOS SPECIES

COMPONENT NAME
707

COMPONENT NUMBER

PICTURE $\mathrm{X}(1)$

KEY

No

DATA TYPE

Char

LARGEST VALUE

1 character

Data Values - A 1-character alphabetic code in this component indicates the frequency with which species determinations of the element phosphorus are made. See appendix A for frequency codes.

General Description - This component pertains to the measurement of any species of the element phosphorus commonly found in water, for example, organic phosphorus, or orthophosphate. 
.700

IN SR

MANDATORY

No

PICTURE $\mathrm{X}(1)$
NITROGEN

COMPONENT NAME

KEY No

DATA TYPE

Char

LARGEST VALUE

1 character

Data Values - A 1-character alphabetic code in this component indicates the frequency with which total nitrogen determinations are made. See appendix $A$ for frequency codes.

General Description - This component pertains only to the gross measurement (total) of the element nitrogen without regard to individual species. The measurement is usually expressed in milligrams per 1iter. Nitrogen in water in the form of nitrogen gas will be reported in component 721 (OTHER_DIS_GAS). 
700

IN SR

MANDA TORY No

PICTURE
N SPECIES

COMPONENT NAME
709

COMPONENT NUMBER

KEY No

DATA TYPE

Char

LARGEST VALUE

1 character

Data Values - A 1-character alphabetic code in this component indicates the frequency with which species determinations of the element nitrogen are made. See appendix A for frequency codes.

General Description - This component pertains to the measurement of any species of the element nitrogen commonly found in water, for example, nitrate, nitrite, or ammonia. 
700

IN SR

MANDA TORY No

PICTURE $\quad \mathrm{X}(1)$

PICTURE
DETERGENTS

COMPONENT NAME
710

COMPONENT NUMBER

KEY

No

DATA TYPE

Char

LARGEST VALUE

1 character

Data Values - A 1-character alphabetic code in this component indicates the frequency with which detergent determinations are made. See appendix $A$ for frequency codes.

General Description - The term "detergent" is applied to a wide variety of cleansing agents used to wash clothes, dishes, and other articles. Generally, detergents are organic materials that are surfactants in aqueous solutions. Detergents are reported in terms of milligrams per liter or as a visual observation, that is, suds on water in terms of severity values. 
700

IN SR

MANDATORY No

KEY

No
711

COMPONENT NUMBER
COMPONENT NAME

DATA TYPE

Char

PICTURE $\mathrm{X}(1)$

LARGEST VALUE

1 character

Data Values - A 1-character alphabetic code in this component indicates the frequency with which Other Minor Inorganic Constitutent determinations are made. See appendix $A$ for frequency codes.

General Description - Other minor inorganic constituents are those not included in any of the other components of the 700 series, such as the halides (flouride, bromite, lodide), the rare earths, and the transition metals (iron, manganese, etc.). 
700

$\overline{\text { IN SR }}$

MANDA TORY No

PICTURE $\mathrm{X}(1)$
RADIOACTIVITY

COMPONENT NAME
712

COMPONENT NUMBER

KEY No

DATA TYPE

Char

Data Values - A 1-character alphabetic code in this component indicates the frequency with which gross radiation determinations are made. See appendix $A$ for frequency codes.

General Description - This component is concerned with only the gross measurement of radioactivity (alpha, beta, gamma) without regard to the radiochemical species that produces the radiation. 
700

IN SR

MANDATORY

No

KEY

No

RCHM SPEC IES

COMPONENT NAME

713

COMPONENT NUMBER

PICTURE $\mathrm{X}(1)$

LARGEST VALUE

1 character

Data Values - A 1-character alphabetic code in this component indicates the frequency with which radiochemical species determinations are made. See appendix A for frequency codes.

General Description - Radiochemical species refers to the individual radioactive elements that produce radioactivity such as: radium 226, cobalt 60 , strontium 90 , and tritium. 
700

IN SR

MANDATORY

No

PICTURE X(1)
CARBON

COMPONENT NAME

KEY No

DATA TYPE

Char

LARGEST VALUE 1 character

Data Values - A 1-character al phabetic code in this component ind icates the frequency with which total carbon determinations are made. See append ix A for frequency codes.

General Description - The Carbon component pertains only to the gross measurement of all of the carbon present without regard to groups or species. 
700

$\overline{\text { IN SR }}$

MANDATORY

No

$x(1)$

PICTURE
ORG GROUPS

COMPONENT NAME
715

COMPONENT NUMBER

KEY

No

DATA TYPE

Char

Data Values - A 1-character al phabetic code in this component ind icates the frequency with which organic group determinations are made. See append ix A for frequency codes.

General Description - This component refers to the reporting of the presence of organic groups, such as the phenols or the methols, rather than of specific organic molecules, such as chloroform or DDT. Such results are obtained from the application of analytic techniques such as mass spectrometry, NMR (Nuclear Magnetic Resonance) and IR (Infrared Spectroscopy). 
700

IN SR

PEST SPECIES

COMPONENT NAME

716

COMPONENT NUMBER

MANDATORY No

KEY No

DATA TYPE

Char

PICTURE $\mathrm{X}(1)$

LARGEST VALUE

1 character

Data Values - A 1-character al phabetic code in this component indicates the frequency with which pesticide-species determinations are made. See appendix A for frequency codes.

General Description - The Pesticide.-Species component incl ud es insecticides, herbicides, fungicides, rodendricides, etc. Examples are: chlordane, DDT, $2,4,5-T$, and silvex. 
700

$\overline{\text { IN SR }}$

MANDATORY No

PICTURE

$\mathrm{X}(1)$
OTH_ORG_SPECIES

COMPONENT NAME
717

COMPONENT NUMBER

DATA TYPE

Char

KEY No

LARGEST VALUE

1 character

Data Values - A 1-character alphabetic code in this component indicates the frequency with which determinations of other organic species are made. See appendix $A$ for frequency codes.

General Description - This component refers to the reporting of the presence of specific organic species, other than pesticides, such as chloroform, PCBs (Polychlorinated Biphenyls), and formaldehyde. 
700

$\overline{\text { IN SR }}$

MANDATORY

No

PICTURE $\quad \mathrm{X}(1)$

PICTURE
BIOCHM_OX_DMND

COMPONENT NAME
718

COMPONENT NUMBER

KEY

No

DATA TYPE

Char

(1)

-

LARGEST VALUE

1 character

Data Values - A 1-character al phabetic code in this component indicates the frequency with which biochemical-oxygen-d emand determinations are made. See append ix A for frequency codes.

General Description - Biochemical-oxygen-demand (BOD) is a measure of the quantity of dissolved oxygen, in milligrams per liter, required to stabilize the demand for oxygen in a water sample, usually resulting from the process of microorganisms consuming organic matter and utilizing the available dissolved oxygen in the oxidation process. 
700

$\overline{\text { IN SR }}$

MANDATORY

No

$\mathrm{x}(1)$

PICTURE
CHM OX DMND

COMPONENT NAME
719

COMPONENT NUMBER

KEY

No

DATA TYPE

Char

Data Values - A 1-character al phabetic code in this component indicates the frequency with which chemical-oxygen-demand determinations are made. See append ix A for frequency codes.

General Description - Chemical-oxygen-demand (COD) determinations provide a measure of the oxygen equivalent of that portion of the organic matter in a water sample that can be oxidized by a strong chemical-oxidizing agent. 
700

IN SR

MANDATORY

No

PICTURE $\quad \mathrm{X}(1)$
DISSOLVED OX

COMPONENT NAME
720

COMPONENT NUMBER

KEY No

DATA TYPE

Char

LARGEST VALUE

1 character

Data Values - A 1-character alphabetic code in this component indicates the frequency with which dissolved oxygen determinations are made. See appendix A for frequency codes.

General Description - Dissolved oxygen (DO) in water is expressed in milligrams per liter and the amount present reflects chemical, physical, and biological activities in the water body. It can only be increased by aeration and the photosynthetic processes of aquatic plants. 
700

$\overline{\text { IN SR }}$

MANDATORY

No

PICTURE $\quad \mathrm{X}(1)$
OTHER DIS GAS

COMPONENT NAME
721

COMPONENT NUMBER

KEY

No

DATA TYPE

Char

LARGEST VALUE

1 character

Data Values - A 1-character alphabetic code in this component indicates the frequency with which other dissolved-gases determinations are made. See appendix $A$ for frequency codes.

General Description - Other dissolved gases include all gases except oxygen, which is accounted for in component number 720. Examples are: nitrogen, hydrogen sulfide, and methane. 
700

$\overline{\text { IN SR }}$

MANDATORY

No

$\mathrm{X}(1)$

PICTURE
CHM RECMD MTHDS

COMPONENT NAME
730

COMPONENT NUMBER

KEY

No

DATA TYPE

Char

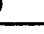

LARGEST VALUE

1 character

Data Values - The Chemical Recommended Methods component is valued with a "Y" If the C700 data record describes data collected and analyzed according to recommended methods. If not, the component is valued with a "N".

General Description - In 1977, the Office of Water Data Coordination published the National Handbook of Recommended Methods for Water Data Acquisition. Another reference for recommended methods is the USGS's Techniques of WaterResources Investigation (TWRI). 
700

$\overline{\text { IN SR }}$

MANDATORY Yes
CHM BEGIN_YR

COMPONENT NAME
740

COMPONENT NUMBER

KEY

No

DATA TYPE

Integer

PICTURE $9(4)$

LARGEST VALUE

current year

Data Values - The Chemical Data-Collection Begin-Year component contains a 4-digit numeric value identifying the year that chemical data were first collected.

General Description - This component identifies the calendar year in which the acquisition of chemical data first began at a site regardless of the types of chemical data that were collected. This date will never change even though chemical data collection may be deactivated and reactivated several times during a site's history. 
700

IN SR

MANDATORY

No

PICTURE 9(4)
CHM_END_YR

COMPONENT NAME

KEY

No

DATA TYPE

Integer
741

COMPONENT NUMBER

LARGEST VALUE current year

Data Values - The Chemical Data-Collection End-Year component contains a 4-digit numeric value identifying the year that all chemical data-collection activities were ceased at the site. If the organization is currently collecting chemical data at the site, this component is not valued.

General Description - This component identifies the calendar year in which all chemical data-collection activities at the site were discontinued. If at a 1 ater date, the collection of any of the chemical parameters is resumed, the end date is deleted. 
700

$\overline{\text { IN SR }}$

MANDATORY

Yes

KEY

No

ST UPDATE

COMPONENT NAME

744

COMPONENT NUMBER

DATA TYPE Integer

PICTURE $9(4)$

LARGEST VALUE current YYMM

Data Values - This component contains the year and the month ( $Y Y / M M)$, in which the C700 data record was 1 ast updated. This date is generated by the computer.

General Description - An update is defined as any transaction that adds, deletes, or changes data values in the MWDI data base. 
700

$\overline{\text { IN SR }}$

PICTURE X(1)
CHEMICAL_MED

COMPONENT NAME
746

COMPONENT NUMBER
MANDATORY No

KEY

No
DATA TYPE

Char

Data Values - This component contains a 1-character code ind icating the type(8) of storage media (document, computer readable, etc.) on which the data values for chemical parameters are stored and avallable to potential users of the data. See appendix B for Data Storage codes and al so see component number 700 (CHEMICAL) for the definition of chemical.

General Description - Organizations collect hyd rologic data and record and store the information on a variety of storage media ranging from original field notes to computer storage devices. Media is used as a general term encompassing all means of storing and disseminating the data. 
700

IN SR

MANDATORY N/A

PICTURE

N/A
CHM MODIFIERS

COMPONENT NAME
770

COMPONENT NUMBER
DATA TYPE SR
KEY N/A

$\mathrm{N} / \mathrm{A}$

N/A

A schema record containing codes that indicate the external file that contains the data ind exed in the 6700 data record. The MWDI indexes data in Environmental Protection Agency's Storage and Retrieval (STORET) System, U.S. Geological Survey's National Water Data Storage and Retrieval System (WATSTORE), and the Texas Natural Resources Information System (TNRIS), by means of software interfaces. Multiple occurrences of $\mathrm{C770}$ may exist for each $\mathrm{C700}$ data record having data indexed from more than one external file. 
770

$\overline{\text { IN SR }}$

PICTURE

$x(4)$
CHM POINTER

COMPONENT NAME
771

COMPONENT NUMBER
MANDATORY No

KEY

No

DATA TYPE Char

DATA TYPE Char
4 characters

Data Values - This component contains a 4-character code that indicates an external file from which data have been indexed in the C700 schema record. The codes, assigned at time of interfacing, are described below:

Code

STOR

TNRS

WATD

WATG

WATP

WATS

\section{Description}

Data have been indexed from EPA's STORET.

Data have been indexed from the Texas Natural Resources Information System (TNRIS).

Data have been indexed from the WATSTORE Da11y Values.

Data have been indexed from the WATSTORE Ground-water Site Inventory (GWSI) data base.

Data have been indexed from the WATSTORE Peak Flow File.

Data have been indexed from the WATSTORE data base but exact file unknown.

General Description - Chemical data at the time of interface with the major water data bases have the chemical pointer component (C771) automatically set and stored to indicate the appropriate major water data base. Use of this component simplifies the retrieval of data from the appropriate data base. 
770

$\overline{\text { IN SR }}$

MANDATORY

No

PICTURE X(1)
CHM MOD FILE

COMPONENT NAME

KEY No

DATA TYPE

Char
772

COMPONENT NUMBER

LARGEST VALUE

1 character

Data Values - This component contains a 1-character code to ind icate the WATSTORE Ground-Water-Site-Inventory (GWSI) data base subset from which the data were Ind exed.

$\begin{array}{cc}\text { Code } & \text { Subset } \\ \text { N } & \text { Northeast Region } \\ \mathrm{S} & \text { Southeast Region } \\ \mathrm{C} & \text { Central Region } \\ \mathrm{W} & \text { We stern Region }\end{array}$

General Description - This component is set automatically to one of the above codes to indicate the GWSI subset in which the data resides at the time of interfacing with the GWSI. 
$\frac{0}{\text { IN SR }}$

MANDATORY N/A

PICTURE N/A
PROJECTS

COMPONENT NAME $\frac{800}{\text { COMPONENT NUMBER }}$

DATA TYPE

SR

LARGEST VALUE

N/A

A schema record identifying hyd rologic projects, associated with the data collection station, that are conducted by the Water Resources Division of the U.S. Geological Survey. In some instances more than one project will be associated with a particular station. 
800

$\overline{\text { IN SR }}$

MANDATORY

No
WRD_PROJ_NO

COMPONENT NAME

801

COMPONENT NUMBER

PICTURE $\mathrm{X}(5)$

KEY No

DATA TYPE Char

LARGEST VALUE

5 characters

Data Values - The WRD Project Number is 5 characters in 1 ength. The first 2 characters contain a meaningful al phabetic code and the remaining 3 characters contain a numeric serial number.

General Description - The WRD Project Number is assigned by the Water Resources Division and pertains only to U.S. Geological Survey operations. It uniquely identifies a specific work effort in a given program and provides the funding basis for hydrologic data collection activities. One project usually provides the funding support (wholly or partially) for many sites. The project is set up as follows:

State - A 2-character al phabetic abbreviation designating the district, region, or division headquarters office from which the project is programmed and supervised. For district offices, the al phabetic FIPS code of the state in which the office is located is used. All others have a meaningful abbreviation of the organizational name (WR = Western Region, WD = WRD (national) head quarters, etc.)).

Serial Number - A 3-digit sequence number of a project activated within a given jurisdiction (right justified, for example, 017). Serial numbers 001 through 009 are reserved for dedicated projects as follows:

$\begin{array}{ll}001 & \text { Surface Water Stations } \\ 002 & \text { Ground Water Stations } \\ 003 & \text { Water Qual ity Stations (SW and GW) } \\ 004 & \text { Sediment Stations } \\ 005 & \text { Precipitation Stations } \\ 006 & \text { HUD Flood Insurance Stud ies } \\ 007 & \text { Water Use Studies } \\ 008-009 & \text { May be assigned at a later date }\end{array}$


$\frac{0}{\text { IN SR }}$

MANDATORY

N/A

KEY N/A

DATA TYPE

SR
NETWORKS

COMPONENT NAME $\frac{900}{\text { COMPONENT NUMBER }}$

PICTURE N/A

LARGEST VALUE

N/A

A schema record identifying and containing information about networks that the site is a member of. 
$\frac{900}{\text { IN SR }}$

MANDATORY No

PICTURE $\mathrm{X}(4)$
NETWORK CODE

COMPONENT NAME

KEY Yes
901

COMPONENT NUMBER

DATA TYPE Char

LARGEST VALUE

4 characters

Data Values - If applicable, this component will contain a 4-character network code indicating that the site is a member of one or more networks. Possible codes are:

Code

Meaning

ADAS

Automatic Data Acquisition System - This system, operated by Tennessee Valley Authority's Data Services Branch in support of the Reservoir Operations Branch, is used to collect real-time precipitation and stream elevation data for the daily operation of the TVA reservoir system. The system is currently composed of 125 precipitation gages and 6 stream elevation gages which are interrogated by a master computer using the dial telephone network. The network, when complete, will include 185 precipitation gages and 32 stream elevation gages. The system is scheduled for completion in fiscal year 1985 .

BRFW Blue Ridge Flood Warning System - This system, operated by TVA, will be lused by the Reservoir Operations Branch to monitor dam safety at the Blue Ridge Dam. The system will be composed of 6 precipitation gages, 2 stream elevation gages, and 1 headwater gage at the Blue Ridge Dam. These gages will report to the ADAS computer by means of the GOES satellite and a direct readout ground station.

COOP

The U.S. Geological Survey maintains data for some sites for which the collection of data was not funded by the U.S. Geological Survey. These sites should not have C1000 (FUNDING) data record existing and component C35 (WRD-ACCT) should contain a "N". This code is applicable only for sites identified as USGS sites.

CORE

National Ambient Water Monitoring Network - A network operated by the Environmental Protection Agency of approximately 1000 ambient water quality monitoring stations, composed primarily of a minimum core network of State stations selected as a subset of stations supporting ongoing State programs and national trend assessments. 


\begin{abstract}
Code Meaning
CQMI The California Surface Water Quality Monitoring Inventory is maintained by the California Water Resources Control Board. This is an inventory of all water-quality sites in California with which the Water Resources Control Board has jurisdiction, or make use, of the data collected as a part of their programs.

DAEW Department of Agriculture Experimental Watershed.

FLGQ The Florida Groundwater Quality Monitoring Network established and operated by the Water Resources Division of the U.S. Geological Survey and the Florida State Department of Environmenta1 Regulation.

NSQN The National Stream Quality Accounting Network (NASQAN) is a group of interrelated sites established and operated by the Water Resources Division of the U.S. Geological Survey at which systematic and continuing measurements are made to determine long-term trends in the physical, chemical, and biological characteristics of the Nation's surface waters.

NWQS The National Water Quality Surveillance System is a group of interrelated sites monitored by the U.S. Environmental Protection Agency as a part of their program to monitor pollutants on a national basis.
\end{abstract}

NWSF River gages used by the National Weather Service for river and flood forecasting.

NWSP River gages that the National Weather Service plans to use in river or water-supply forecasting.

NWSS River gages used by the National Weather Service for water-supply forecasting only.

RCWP Soil Conservation Services sites where both water quantity and quality are measured as part of the Rural Clean Water Program to monitor the effects of conservation and farming practices on water quality.

SCSF River gages used by the Soil Conservation Service for water supply forecasting.

SCSR River gages used by the Soll Conservation Service reservoir operation.

General Description - The network code identifles sites as being members of a network of interrelated sites where data are collected for specific purpose programs. 
$\frac{0}{\text { IN SR }}$

MANDATORY N/A

PICTURE N/A
SITE FUNDING

COMPONENT NAME

\section{COMPONENT NUMBER}

KEY N/A

DATA TYPE

SR

LARGEST VALUE

N/A

A schema record identifying the total amount of funding for the current fiscal year associated with the station if it is identifled as a U.S. Geological Survey data-collection site. 
MANDATOR No

KEY No

DATA TYPE Integer

PICTURE $9(6)$

Data Values - This component contains up to 6 numeric characters to represent the total funds in dollars required for operating this site. This component is valued for U.S. Geological Survey sites only.

General Description - This component contains the total funds, in dollars, required for operating USGS sites only if component C35 (WRD-ACCT) is valued with a "Y". Additiona11y, if this component is valued and component C1004 (DOLLARS) is valued, then the corresponding percentage (C1002) will be computed from $\mathrm{C1004}$ and $\mathrm{C} 991$. 
990

IN SR

MANDATORY

No

PICTURE $\quad 9(2)$
SITE FISCAL YR

COMPONENT NAME

COMPONENT NUMBER

DATA TYPE

Integer

LARGEST VALUE

99

Data Values - This component contains a 2-digit number which is the last two digits of the fiscal year for which the funding applies.

General Description - This component represents the current fiscal year for which the total funding in dollars has been stored in component TOTAL DOLLARS (C991)

for U.S. Geological Survey operated sites. The fiscal year begins on October 1 . 
$\frac{0}{\text { IN SR }}$

MANDATORY N/A

PICTURE

$\mathrm{N}(\mathrm{A})$
FUNDING

COMPONENT NAME
1000

COMPONENT NUMBER

DATA TYPE

SR

KEY N/A

A schema record containing information about supportive funding, which will only be valued for sites operated by the Water Resources Division of the U.S. Geological Survey. It is possible that there will be multiple occurrences of funding support for one site, each one in dollars, representing a separate customer, hydrologic discipline, funding in dollars, and percentage of funds combination. If the USGS provides no funding for the operation of the site and the site is identified as a USGS site (C4=USGS) then component C35 (WRD-ACCT) should contain a " $N$ " and C901 (NETWORK-CODE) should equal "COOP". 
$\frac{1000}{\text { IN SR }}$

MANDATORY

No

PICTURE $\mathrm{X}(4)$
KEY No $\frac{1001}{\text { COMPONENT NUMBER }}$

DATA TYPE Char

Data Values - The customer number is a 4-character al pha-numeric value. It is only valued for U.S. Geological Survey sites.

General Description - A customer number is a unique code identifying organizations that provide funding in support of Geological Survey project and site activities. The Finance and Fiscal Analysis Section, Water Resources Division, serves as 1 iaison with the Branch of Finanacial Management in coordination of the assignment of customer numbers, and a 1 ist is maintained for internal use only. 
1000

$\overline{\text { IN SR }}$

MANDATORY

No
1002

COMPONENT NAME
COMPONENT NUMBER

PICTURE $9(3)$

LARGEST VALUE 100

Data Values - The percentage component will contain up to 3 numeric characters indicating the percentages of the site's operating funds supplied by a customer (see component 1001) for activities associated with a particular discipline (see component 1003). This component is valued for U.S. Geological Surveyoperated sites only.

General Description - The Percentage component indicates the proportionate share of total station funds that each supporting organization allocates to each type of data (discipline activity) collected at the site. The figures are shown to the nearest 5 percent and computed by using the site operating fund total as the base figure. When added, the percentage figures will equal 100 percent for the site regardless of the number of customers or discipline activities involved. 
1000

$\overline{\text { IN SR }}$

MANDATORY No

PICTURE $\mathrm{X}(2)$

\section{PICTURE $X(2)$}

DISC IPLINE

COMPONENT NAME
1003

COMPONENT NUMBER

KEY No

DATA TYPE Char

Data Values - The Discipline component will contain a two-character alphabetic abbreviation as follows:

\begin{tabular}{|c|c|}
\hline Code & Meaning \\
\hline SW & Surface Water \\
\hline GW & Ground Water \\
\hline QW & Water Quality \\
\hline SD & Sediment \\
\hline PR & Precipitation \\
\hline
\end{tabular}

General Description - Discipline indicates the type of hydrologic data collection activities being funded by supporting organizations (customers). It indicates the discipline for which customer (component 1001) supplies a percentage (component 1002) of the operating funds for the site. 
1000

$\overline{\text { IN SR }}$

MANDATORY

No

PICTURE
DOLLARS

COMPONENT NAME
1004

COMPONENT NUMBER
KEY No
DATA TYPE Integer

Data Values - This component contains up to 6 digits that indicate, in dollars, the amount of the site's operating funds supplied by a customer for activities associated with a particular discipline. This component is valued for U.S. Geological Survey-operated sites only.

General Description - The dollars component indicates, in dollars, the amount of station funds each supporting organization allocates to each type of data (discipline activity) collected at the site. 
1000

$\overline{\text { IN SR }}$

MANDATORY

No

PICTURE
FISCAL YR

COMPONENT NAME

KEY No

DATA TYPE

Integer

Data Values - This component contains a 2-digit number which is the last two digits of the fiscal year for which the funding information applies. This component is valued for U.S. Geological Survey operated sites only.

General Description - This component represents the fiscal year for which the station funding, by each supportive organization, applies. The fiscal year begins on October 1 . 
1000

$\overline{\text { IN SR }}$

MANDATORY

Yes

KEY No

DATA TYPE Integer

Data Values - This component contains the year and the month ( $Y Y / M M)$ in which the C1000 data record was last updated. This date is generated by the computer.

General Description - An update is defined as any transaction that adds, deletes, or changes data values in the MWDI data base. 


$\frac{0}{\text { IN SR }}$

MANDATORY

N/A

N/A
OTHR SRC

COMPONENT NAME

KEY N/A

DATA TYPE

SR

LARGEST VALUE

N/A

The "Other Source" schema record identifies organizations, other than, or in addition to, the operating organization cited in component 4 (NAWDEX_AGCY), that store and make water data avallable for the site. 
1100

IN SR

MANDATORY No
OT_SRC_AGCY

COMPONENT NAME
1101

COMPONENT NUMBER
KEY No

DATA TYPE

Char

Data Values - The Other Source Agency component will contain a NAWDEX Agency code. The NAWDEX Agency code varies in length from three to five characters. For Federal organizations, it will be US followed by an up to three-character abbreviation of the organization's name. Non-Federal organizations whose activities are contained within a given state boundary will have a 2-character alphabetic state code followed by an arbitrary sequence number. Alphabetic state codes are contained in the Federal Information Processing Standards (FIPS) Publication 5-1, dated June 15, 1970. Non-Federal organizations having activities at the multistate or national level will have a three to five character abbreviation of the organization name (the characters US will not appear in the first two character positions).

NAWDEX Agency codes are presented in the publication entitled "Identification Codes for Organizations Listed in Computerized Data Systems of the U.S. Geological Survey" which may be obtained from the National Water Data Exchange, U.S. Geological Survey, 421 National Center, Reston, Virginia 22092.

General Description - The Other Source Agency component will contain the NAWDEX Agency code of any organization, other than the operating organization cited in component number 4, that also is a source of data collected at the site. The NAWDEX Agency code is assigned by the NAWDEX Program office and is the unique organization identifier for the participating Federal and non-Federal organizations that actively collect and/or store water data. Non-Federal organizations State, county, and municipal organizations, as well as intergovernmental compacts, private organizations, universities, and any local organizations at other than the county or municipal level. 
0

$\overline{\text { IN SR }}$

MANDATORY

N/A

KEY N/A

DATA TYPE

SR

SOURCE INFORMATION

COMPONENT NAME
1200

COMPONENT NUMBER

PICTURE N/A

LARGEST VALUE

N/A

A schema record containing codes indicating the data base which is the source in which some or all of the data collected at the site reside and the organization code utilized by the data base source to indicate the organization operating the site. More than one schema record may exist for each site if data have been stored in more than one data base. 
1200

IN SR

MANDATORY

NO

PICTURE $\mathrm{X}(4)$
SOURCE_FILE_ID

COMPONENT NAME

1201

COMPONENT NUMBER

KEY NO

DATA TYPE Char

LARGEST VALUE 4 characters

Data Values - The Source File ID contains a 4-character code identifying the data base in which some or all of the data for the indexed site is stored.

General Description - The NAWDEX Program office has developed interfaces with major water-data base systems of other organizations to directly index the data stored in the system in the MWDI data base. Presently, the three major data bases the MWDI is interfaced with are:

Code

STOR

TNRI

WATS
Data base

U.S. Environmental Protection Agency's Storage and Retrieval (STORET) System

Texas Natural Resources Information System (TNRIS)

U.S. Geological Survey's National Water Data Storage and Retrieval System (WATSTORE). 
1200

$\overline{\text { IN SR }}$

MANDATORY

NO

KEY

No

DATA TYPE Char

PICTURE $8(\mathrm{X})$

LARGEST VALUE

8 characters

Data Values - This component contains the organization (agency) code utilized in the source water data base identified in component number 1201 (SOURCE FILE ID) to identify the operating organization of the site.

General Description - Organizations having large data bases for storing water data use organization (agency) codes that may differ from those assigned by NAWDEX. This code is often necessary to accomplish the retrieval of water data for a site from data bases of other organizations. 
0

$\overline{\text { IN SR }}$

MANDATORY

N/A

KEY N/A
METEOROLOGICAL

COMPONENT NAME
1300

COMPONENT NUMBER

PICTURE N/A

LARGEST VALUE

N/A

DATA TYPE SR

A schema record containing values indicating the types of meteorological data collection activities performed, the years in which these activities took place, and the media on which meteorological data for the sites are stored. 
1300

IN SR

MANDATORY

Yes

KEY No

DATA TYPE

Integer
MET_BEGIN_YR

COMPONENT NAME

1301

COMPONENT NUMBER

LARGEST VALUE

current year

Data Values - The Meteorological Data-Collection Begin Year component contains a 4-digit numeric value identifying the year that meteorological data were first collected at the site, for example, 1910 .

General Description - This component identifies the calendar year in which the acquisition of meteorological data first began at a site, regardless of the types of meteorological data that were collected. This date will never change even though meteorological data collection may be deactivated and reactivated several times during a site's history. 
1300

$\overline{\text { IN SR }}$

MANDATORY

No

PICTURE $\quad 9(4)$

PICTURE 9(4)
MET END YR

COMPONENT NAME
1302

COMPONENT NUMBER

DATA TYPE_ Integer

KEY No

current year

Data Values - The Meteorological Data Collection End Year component contains a 4-digit numeric value identifying the year that all meteorological data collection activities were ceased at the site. If the organization is currently collecting meteorological data at the site, this component is not valued.

General Description - This component identifies the calendar year in which all meteorological data collection activities at the site were discontinued. If at a later date, the collection of any of the meteorological parameters is resumed, the end date is deleted. 
1300

IN SR

MANDATORY

No

PICTURE $\mathrm{X}(1)$
MET_INTERRUPTED

COMPONENT NAME
1303

COMPONENT NUMBER

DATA TYPE Char

KEY No

Data Values - The Meteorological Interrupted component contains a value of "Y" if the collection of meteorological parameters has been discontinued (for more than one year) and later resumed one or more times in the history of the site. If meteorological data collection has not been discontinued at any time, the component is not valued.

General Description - The presence of a value of "Y" for this component indicates one or more interruptions in the period of record of meteorological data acquisition during the period beginning with MET BEGIN YR (component 1301) through the present time (if currently active), or ending with MET_END_YR (component 1302). 
1300

IN SR

MANDATORY

No

PICTURE

$\mathrm{X}(1)$
MET RAINFALL

COMPONENT NAME
1310

COMPONENT NUMBER
KEY No

DATA TYPE Char

Data Values - A 1-character code in this component indicates the frequency with which rainfall observations or instrument recorded rainfall determinations are made at this site. See appendix A for frequency codes.

General Description - Rainfall is the quantity of water that falls as rain only and is not synonymous with precipitation. 
1300

IN SR

MANDATORY

No

PICTURE $\quad X(1)$
MET_UNIT_RAINFALL

COMPONENT NAME

KEY No

DATA TYPE Char

Data Values - The Unit Rainfall component if applicable is valued with a 1-character code as follows:

\begin{tabular}{|c|c|c|}
\hline Code & Recording Interval & Readings Per Day \\
\hline A & $0.5 \mathrm{~min}(30 \mathrm{sec})$ & 2880 \\
\hline B & $1 \mathrm{~min}$. & 1440 \\
\hline C & $2 \mathrm{~min}$. & 720 \\
\hline D & $3 \mathrm{~min}$. & 480 \\
\hline E & $4 \mathrm{~min}$. & 360 \\
\hline $\mathbf{F}$ & 5 min. & 288 \\
\hline G & 6 min. & 240 \\
\hline $\mathrm{H}$ & 10 min. & 144 \\
\hline I & 15 min. & 96 \\
\hline $\mathrm{J}$ & 30 min. & 48 \\
\hline $\mathrm{K}$ & $45 \mathrm{~min}$. & 32 \\
\hline L & $1 \mathrm{hr}$ & 24 \\
\hline $\mathbf{M}$ & $2 \mathrm{hr}$ & 12 \\
\hline $\mathbf{N}$ & $3 \mathrm{hr}$ & 8 \\
\hline 0 & $4 \mathrm{hr}$ & 6 \\
\hline
\end{tabular}




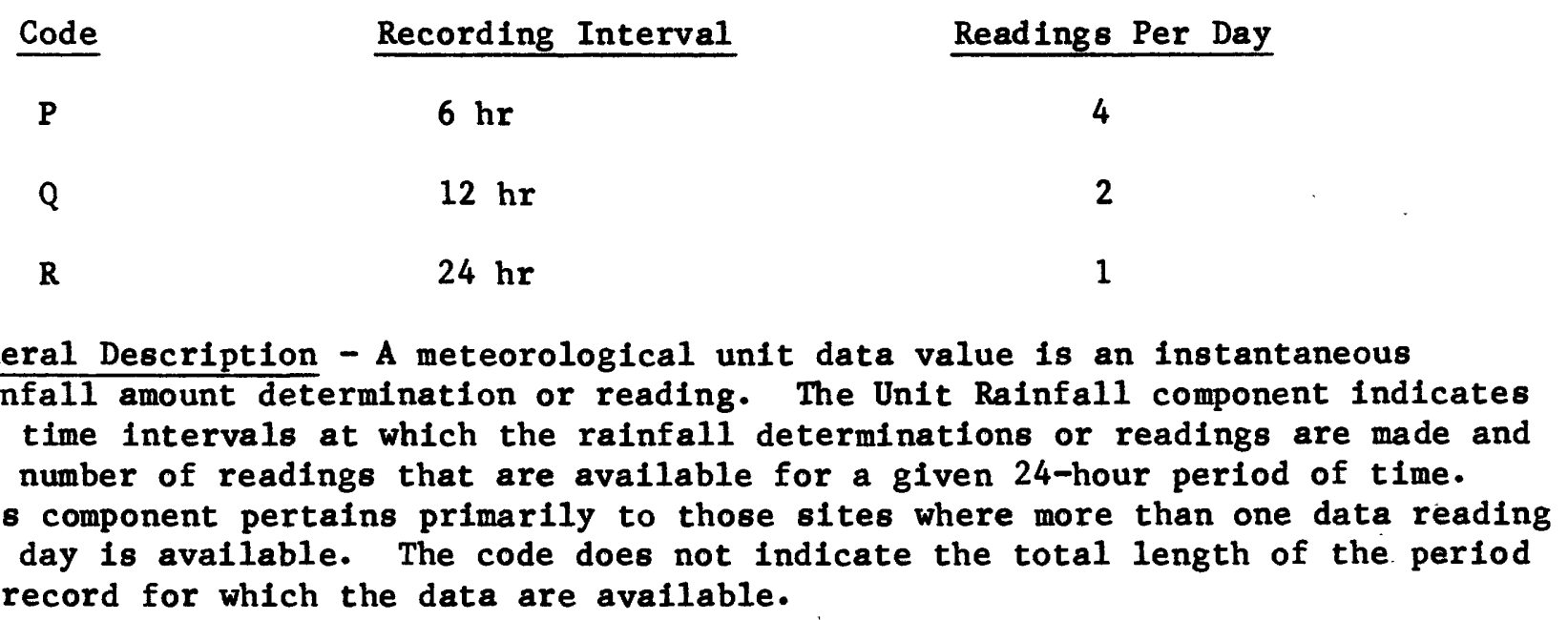


1300

$\overline{\text { IN SR }}$

MANDATORY

No

PICTURE $\mathrm{X}(1)$

PICTURE $\mathrm{X}(1)$

MET_AIR_TEMPERATURE

COMPONENT NAME
1312

COMPONENT NUMBER

KEY No

DATA TYPE

Char

Data Values - A 1-character alphabetic code in this component indicates the frequency with which observed or instrument recorded air temperature data are collected. See appendix A for frequency codes.

General Description - Air temperature is a measure of the intensity aspect of heat energy present in the atmosphere. 
1300

$\overline{\text { IN SR }}$

MANDATORY

No

KEY No

DATA TYPE Char
MET_RSVD1

COMPONENT NAME

1313

COMPONENT NUMBER

PICTURE $\quad \mathrm{X}(1)$

LARGEST VALUE

1 character

Data Values - This component is reserved for future use. 
1300

$\overline{\text { IN SR }}$

MANDATORY

No

PICTURE
MET WIND VELOCITY

COMPONENT NAME
1314

COMPONENT NUMBER

DATA TYPE Char

KEY No

LARGEST VALUE

1 character

Data Values - A 1-character code in this component indicates the frequency with which wind velocity observation or instrument recorded wind velocity determinations are made at this site. See appendix $A$ for frequency codes.

General Description - Wind velocity is the velocity of the natural movement of air parallel to the Earth's surface. 
1300

$\overline{\text { IN SR }}$

MANDATORY

No

KEY No

DATA TYPE

Char

PICTURE $\quad X(1)$

LARGEST VALUE

1 character

Data Values - This component is reserved for future use. 
1300

$\overline{\text { IN SR }}$

MANDATORY

No

KEY No

DATA TYPE Char
MET RSVD3

COMPONENT NAME

1316

COMPONENT NUMBER

PICTURE

$X(1)$

LARGEST VALUE

1 character

Data Values - This component is reserved for future use. 
1300

$\overline{\text { IN SR }}$

MANDATORY

No

KEY No

DATA TYPE

Char
MET_RECMD_MTHDS

COMPONENT NAME

1330

COMPONENT NUMBER

PICTURE $X(1)$

LARGEST VALUE

1 character

Data Values - The Meteorological Recommended Methods component is valued with a " $\mathrm{Y}$ " if the $\mathrm{C} 1300$ data record describes data collected according to recomnended methods. If not, the component is valued with a "N".

General Description - In 1977, the Office of Water Data Coordination published the National Handbook of Recommended Methods for Water Data Acquisition. Another reference for recommended methods is the USGS's Techniques of Water-Resources Investigations (TWRI). 
1300

$\overline{\text { IN SR }}$

MANDATORY No

DATA TYPE Char
KEY No

MET OTHER

COMPONENT NAME

PICTURE $\quad \mathrm{X}(6)$

1340

COMPONENT NUMBER

LARGEST VALUE 6 characters

Data Values - This component is reserved for future use. 
1300

$\overline{\text { IN SR }}$

MANDATORY

No

PICTURE $9(1)$
MET TELEMETRY

COMPONENT NAME
1343

COMPONENT NUMBER

KEY No

DATA TYPE

Integer

9

Data Values - The Meteorological Telemetry code is a 1-digit numeric code Identifying, if applicable, the type of telemetry system in use at the sites:

Code $\quad \underline{\text { Meaning }}$

1 Telemeter-land line - A telemetry system that uses electrical current conducting wires (telephone, etc.) to transmit data from a site to a distant receiving site.

2 Telemeter-radio network - A telemetry system that uses terrestrial line of sight radios (wireless transmission of electric impulses) to transmit data from a site to a distant receiving site.

3 Landsat - A satellite telemetry system used to relay data two or more times dally from in situ sensors.

4 GOES (Geostationary Operational Environmental Satellite) - A satellite telemetry system used to relay data, normally once every three hours, from in situ sensors.

5 DARDC (Device for Automatic Remote Data Collection) - A telemetry system interface used to enter in situ sensor data into a landline, line of sight radio, or satellite telemetry system.

6 Other - Other telemetry systems.

7 Two or more of the above telemetry systems are in use.

8 Telemetry equipment used but type not specified.

General Description - A telemeter is an electrical apparatus for measuring quantity (for example, State data) and transmitting the value to a distant recelving site, and there indicating or recording the quantity measured. The meteorological telemetry component identifies the type of system or equipment being used to transmit meteorological information from the data-collection site to a central-recelving site. 
1300

IN SR

MANDATORY

Yes

KEY

No

MET_LST_UPDATE

COMPONENT NAME

1344

COMPONENT NUMBER

PICTURE 9(4)

LARGEST VALUE Current YYMM

Data Values - This component contains the year and month ( $Y Y / M M$ ) in which the C1300 data record was last updated. This date is generated by the computer.

General Description - An update is defined as any transaction that adds, deletes, or changes data values in the MWDI data base. 
1300

$\overline{\text { IN SR }}$

MANDATORY

No

KEY No

DATA TYPE

Char
MET MEDIA

COMPONENT NAME
1346

COMPONENT NUMBER

PICTURE $\quad \mathrm{X}(1)$

LARGEST VALUE

1 character

Data Values - This component contains a 1-character code indicating the type(s) of storage media (document, computer readable, etc.) on which the meteorological data values are stored and available to potential users of the data. See appendix B for Data Storage codes.

General Description - Organizations collect meteorological data and record and store the information on a variety of storage media ranging from original field notes to computer storage devices. Media is used as a general term encompassing all means of storing and disseminating the data. 
1300

IN SR

MANDATORY No

\section{PICTURE $X(1)$}

MET RECORDER TYPE

COMPONENT NAME
1347

COMPONENT NUMBER

KEY No

DATA TYPE

Char

Data Values - The Meteorological Recorder Type component is valued with a 1character code to indicate the type of recorder used to collect the water data.

Code

A

B

\section{Meaning}

Digital Recorder - Records data at intervals throughout the day by storing the values on paper tape or magnetic recording devices.

LARGEST VALUE 1 character

Graphic Recorder - Supplies a continuous trace of parameter value with respect to time on a chart.

General Description - A recorder is an automatic (self-acting or self-regulating) device that registers and stores data values without human intervention. Telemetry equipment, which is used to transmit data to points distant from the data collection site, is separately accounted for in component 1343 (MET TELEMETRY). 
$\frac{1300}{\text { IN SR }}$

MANDATORY

No

KEY No

DATA TYPE

Char
COMPONENT NAME

COMPONENT NUMBER
MET RECORDER FREQ

LARGEST VALUE

1 character

Data Values - This component contains a 1-character code to indicate the frequency at which data are being recorded at site.

Code

A

B

C

D

E

F

G

H

I

$J$

K

L

M

N

0
Recording Interval

$0.5 \mathrm{~min}(30 \mathrm{sec})$

1 min.

2 min.

3 min.

4 min.

5 min.

6 min.

$10 \mathrm{~min}$.

15 min.

$30 \mathrm{~min}$.

$45 \mathrm{~min}$.

$1 \mathrm{hr}$

$2 \mathrm{hr}$

$3 \mathrm{hr}$

$4 \mathrm{hr}$
Read Ings Per Day

2880

1440

720

480

360

288

240

144

96

48

32

24

12

8

6 


\begin{tabular}{lcc} 
Code & Recording Interval & Readings Per Day \\
\cline { 2 - 3 } P & $6 \mathrm{hr}$ & 4 \\
$\mathrm{Q}$ & $12 \mathrm{hr}$ & 2 \\
$\mathrm{R}$ & $24 \mathrm{hr}$ & 1 \\
$\mathrm{~S}$ & Continuous & - \\
$\mathrm{T}$ & Periodic & -
\end{tabular}

General Description - This component pertains to the frequency at which the data are recorded. The code does not indicate the total length of the period of record for which the data are available. 
1300

IN SR

MANDATORY No
MET_PN_CODE

COMPONENT NAME
1349

COMPONENT NUMBER

PICTURE $\quad X(1)$

KEY No

DATA TYPE

Char

LARGEST VALUE 1 character

Data Values - For sites which are in the plannng stage, the Meteorological Planned or Needed component contains a 1-character code as follows:

B Plan to establish - The establishment of a new site is planned.

$R \quad$ Plan to reestablish - The reestablishment of a discontinued site is planned.

D Plan to discontinue - An active site is planned to be discontinued.

C Plan to change - A change in the parameter types or frequency of data collection at an active site is planned.

1 Need to establish - There is a need for the establishment of a new site.

2 Need to reestablish - There is a need for the reestablishment of a discontinued site.

3 Need to discontinue - There is a need for discontinuing an active site.

4 Need to change - A change in the parameter types or frequency of data collection at an active site is needed.

General Description - The Office of Water Data Coordination (OWDC) is responsible for coordinating Federal agency needs and plans for long-term site activities for obtaining data on stage, flow, and quality of surface waters and quality of ground waters. "Planned" activities are those for which funds have been budgeted. "Needed" activities are those that are planned but do not yet have funds budgeted for them. 
1300

IN SR

MANDATORY

N/A

KEY N/A

COMPONENT NAME

1370

COMPONENT NUMBER

DATA TYPE

SR

PICTURE N/A

LARGEST VALUE

N/A

A schema record containing codes that indicate the external file that contains the data indexed in the C1300 data record. The MWDI indexes data in the Environmental Protection Agency's Storage and Retrieval (STORET) System, the U.S. Geological Survey's National Water Data Storage and Retrieval System (WATSTORE), and the Texas Natural Resources Information System (TNRIS) by means of software interfaces. Multiple occurrences of $\mathrm{C} 1370$ may exist for each $\mathrm{Cl} 300$ data record having data indexed from more than one external file. 
1370

$\overline{\text { IN SR }}$

MANDATORY

No

PICTURE X(4)

Data Values - This component contains a 4-character code that indicates an external file from which data have been indexed in the $\mathrm{Cl} 300$ data record. The codes, assigned at time of interfacing, are described below:

$\begin{array}{ll}\text { Code } & \text { Description } \\ \text { STOR } & \text { Data have been indexed from EPA's STORET. } \\ \text { TNRS } & \begin{array}{l}\text { Data have been indexed from the Texas Natural Resources } \\ \text { Information System (TNRIS). }\end{array} \\ \text { WATD } & \text { Data have been indexed from the WATSTORE Daily Values } \\ \text { File. } & \text { Data have been indexed from the WATSTORE Groundwater } \\ \text { WATG } & \text { Site Inventory (GWS). } \\ \text { WATP } & \text { File. } \\ \text { WATS } & \text { Data have been indexed from the WATSTORE data base } \\ & \text { but exact file unknown. }\end{array}$

General Description - Meteorological data indexed at the time of interfacing with the major water data bases have the Meteorological Pointer component (C1371) automatically set and stored to indicate the retrieval of data from the appropriate major water data base. Use of this component simplifies the retrieval of data from the appropriate data base. 
1370

$\overline{\text { IN SR }}$

MANDATORY

No

$\mathrm{KEY}$

No

DATA TYPE

Char
MET MOD FILE

COMPONENT NAME
1372

COMPONENT NUMBER

PICTURE X(1)

LARGEST VALUE 1 character

This component is reserved for future use. 


\section{SELECTED REFERENCES}

American Public Health Association, American Water Works Association, and Water Pollution Control Federation, 1975, Standard methods for the examination of water and wastewater: Washington, D.C., American Public Health Association, 14 th edition, $1,193 \mathrm{p}$.

Baker, C. H. Jr., and Foulk, D. G., 1980, National Water Data Storage and Retrieval System (WATSTORE)--Instructions for preparation and submission of ground-water data: U.S. Geological Survey Open-File Report 75-589 (revised), $173 \mathrm{p}$.

Bates, R. L., and Jackson, J. A., editors, 1980, Glossary of geology: Falls Church, Va., American Geological Institute, 749 p.

Benson, M. A., and Dalrymple, Tate, 1967, General fleld and office procedures for indirect discharge measurements: U.S. Geological Survey Techniques of Water Resources Investigations, book 3, chap. Al, 30 p.

Buchanan, T. J., and Somers, W. P. 1968, Stage measurements at gaging stations: U.S. Geological Survey Techniques of Water Resources Investigations, book 3, chap. A7, 28 p.

Buchanan, T. J., and Somers, W. P., 1969, Discharge measurements at gaging stations: U.S. Geological Survey Techniques of Water Resources Investigations, book 3, chap. A8, 65 p.

Carter, R. W., and Davidian, Jacob, 1968, General procedure for gaging streams: U.S. Geological Survey Techniques of Water Resources Investigations, book 3, chap A6, $13 \mathrm{p}$.

Clark, G. L., 1966, Elements of ecology: New York, London, Sydney, John Wiley \& Sons, Inc., 2nd ed., $560 \mathrm{p}$.

Edwards, M. D., 1977, The National Water Data Exchange (NAWDEX): U.S. Geological Survey Open-File Report 77--259, 5 p.

Edwards, M. D., and Myers, B. M., 1981, Identification codes for organizations listed in computerized data systems of the U.S. Geological Survey:

U.S. Geological Survey Open-File Report 81-904, 102 p.

Fair, G. M., Geyer, J. C., Okun, D. A., 1966, Water and wastewater engineering-Vol. 1, Water supply and wastewater removal: New York, London, Sydney, John Wiley \& Sons, Inc., $505 \mathrm{p}$.

, 1968, Water and wastewater engineering--Vol. 2. Water purification and wastewater treatment and disposal: New York, London, Sydney, John Wiley \& Sons, Inc., $659 \mathrm{p}$. 
Ficke, J. F., and Hawkinson, R. 0., 1975, The National Stream Quality Accounting Network (NASQAN) - Some questions and answers: U.S. Geological Survey Circular $719,23 \mathrm{p}$.

Greeson, P. E., Ehlke, T. A., Irwin, G. A., and others, editors, 1977, Methods for collection and analysis of aquatic biological and microblological samples: U.S. Geological Survey Techniques of Water Resources Investigations, book 5, chap. A4, $332 \mathrm{p}$.

Guy, H. P., 1970, F1uvial sediment concepts: U.S. Geological Survey Techniques of Water Resources Investigations, book 3, chap. $\mathrm{Cl}, 55 \mathrm{p}$.

Guy, H. P., and Norman, V. W., 1970, Field methods for measurement of fluvial sediment: U.S. Geological Survey Techniques of Water Resources Investigations, book 3, chap. C2, 59 p.

Hem, J. D., 1970, Study and interpretation of the chemical characteristics of natural water: U.S. Geological Survey Water-Supply Paper 1473, 2nd ed., $363 \mathrm{p}$.

Hutchinson, N. E., compiler, 1975, WATSTORE--National Water Data Storage and Retrieval System of the U.S. Geological Survey--User's guide: U.S. Geological Survey Open-File Report 75-426, 791 p.

Knecht, W. A., and Edwards, M. D., 1980, Definitions of Components of the Water Data Sources Directory Maintained by the National Water Data Exchange: U.S. Geological Survey Open-File Report 79-1541, 106 p.

Langbein, W. B., and Iseri, K. T., 1960, General introduction and hydrologic definitions: U.S. Geological Survey Water-Supply Paper 1541-A, 29 p.

Lohman, S. W., 1972a, Definitions of selected ground-water terms--Revisions and conceptual refinements: U.S. Geological Survey Water-Supply Paper 1988, $21 \mathrm{p}$.

1972b, Ground-water hydraulics: U.S. Geological Survey Professional Paper 213, 70 p.

Meinzer, 0. E., 1923, Outline of ground-water hydrology with definitions: U.S. Geological Survey Water-Supply Paper 494, 71 p. , ed., 1949, Hydrology: New York, Dover Publications, Inc., 712 p.

MRI Systems Corporation, 1972, General Information manual: Austin, Texas, 23 p. , 1973, SYSTEM 2000 reference manual: Austin, Texas, 180 p.

Poland, J. F., and Davis, G. H., 1969, Land subsidence due to withdrawal of fluids: Geological Society of America, 269 p. 
Porterfield, George, 1972, Computation of fluvial-sediment discharge:

U.S. Geological Survey Techniques of Water Resources Investigations, book 3, chap. C3, $66 \mathrm{p}$.

Ruttner, Franz, 1963, Fundamentals of 1imnology: Toronto, University of Toronto Press, 295 p.

Sawyer, C. N., and McCarty, P. L., 1967, Chemistry for sanitary engineers: New York, McGraw-Hill Book Co., 2nd ed., 518 p.

Skougstad, M. W., and others, editors, 1979, Methods for determination of inorganic substances in water and fluvial sediments: U.S. Geological Survey Techniques of Water Resources Investigations, book 5, chap. A1, 626 pages.

United Nations Educational, Scientific and Cultural Organization, World Me teorological Organization, 1974, International glossary of hydrology: WMO/OMM/BMO - No. 385, 393 p.

U.S. Department of Commerce, National Bureau of Standards, 1970, States and outlying areas of the United States: Federal Information Processing Standards Publication 5-1, 4 p.

, 1976, Countries, dependencies, and areas of special sovereignty:

Federal Information Processing Standards Publication 10-2, 25 p.

, 1979, Counties and county equivalents of the States of the United States and the District of Columbia: Federal Information Processing Standards Publication 6-3, 35 p. 

APPENDIX A

DATA COLLECTION

FREQUENCY CODES

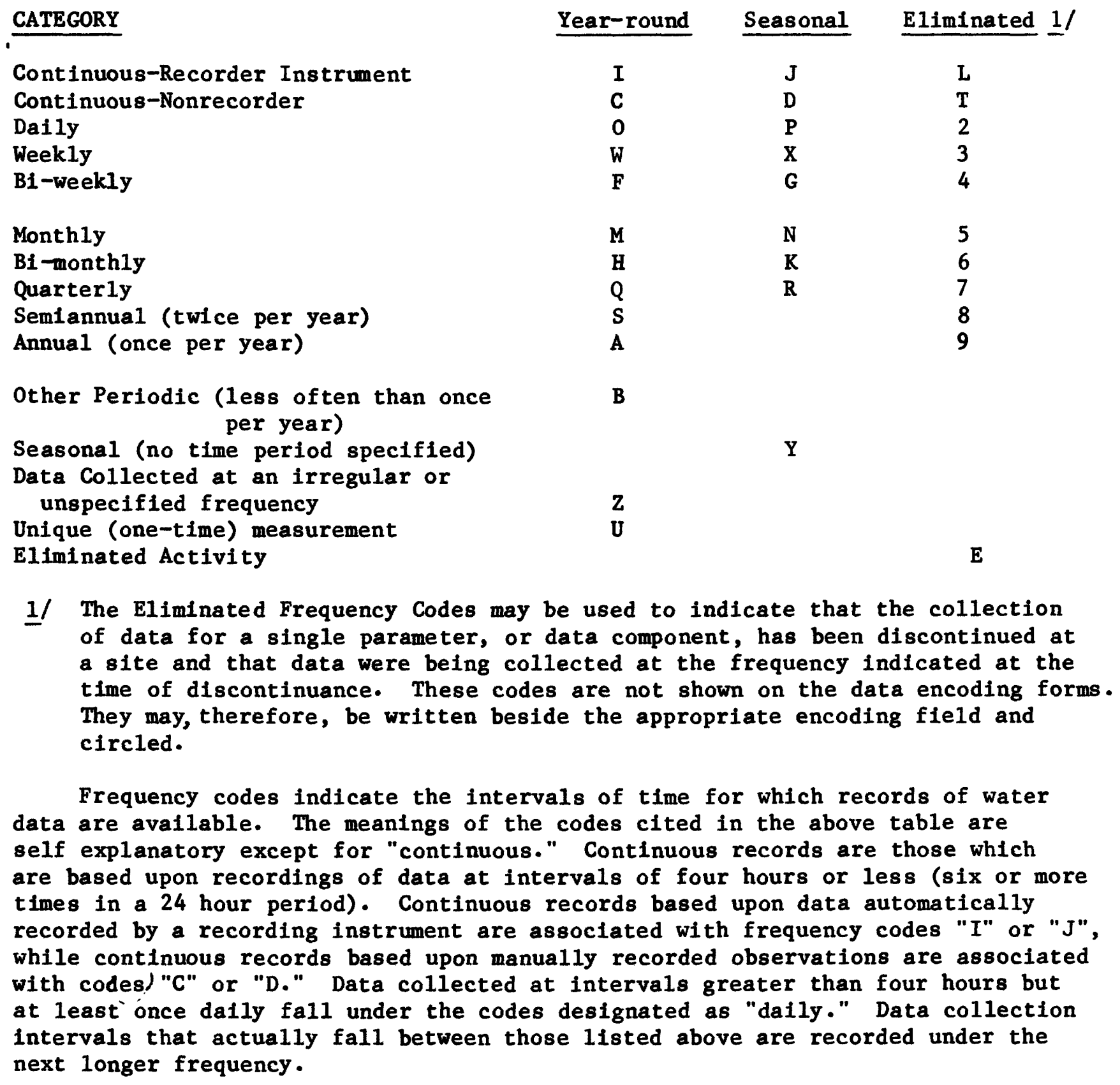


APPENDIX B

DATA STORAGE CODES

Code
P $\begin{gathered}\text { Meaning } \\ \text { Published - Includes methods of data dissemination such as } \\ \text { documents (work sheets, etc.) which may be copied or } \\ \text { communicated over the telephone, as well as formal } \\ \text { publications. }\end{gathered}$
C
Computer recognizable format - Includes data stored in
digital form in punched paper tapes, punched cards,
magnetic tapes, magnetic disks, etc., that potential-
ly can be transmitted to computer terminals and dis-
played on cathode-ray tube screens, printed out on
paper, or copied to another digital recording medium.
M
Microform - Includes data that has been recorded on micro-
film or microfiche.
D
C and P - Computer recognizable format and published.
F $\quad$ C, P, and M - Computer recognizable format, published, and
microform.




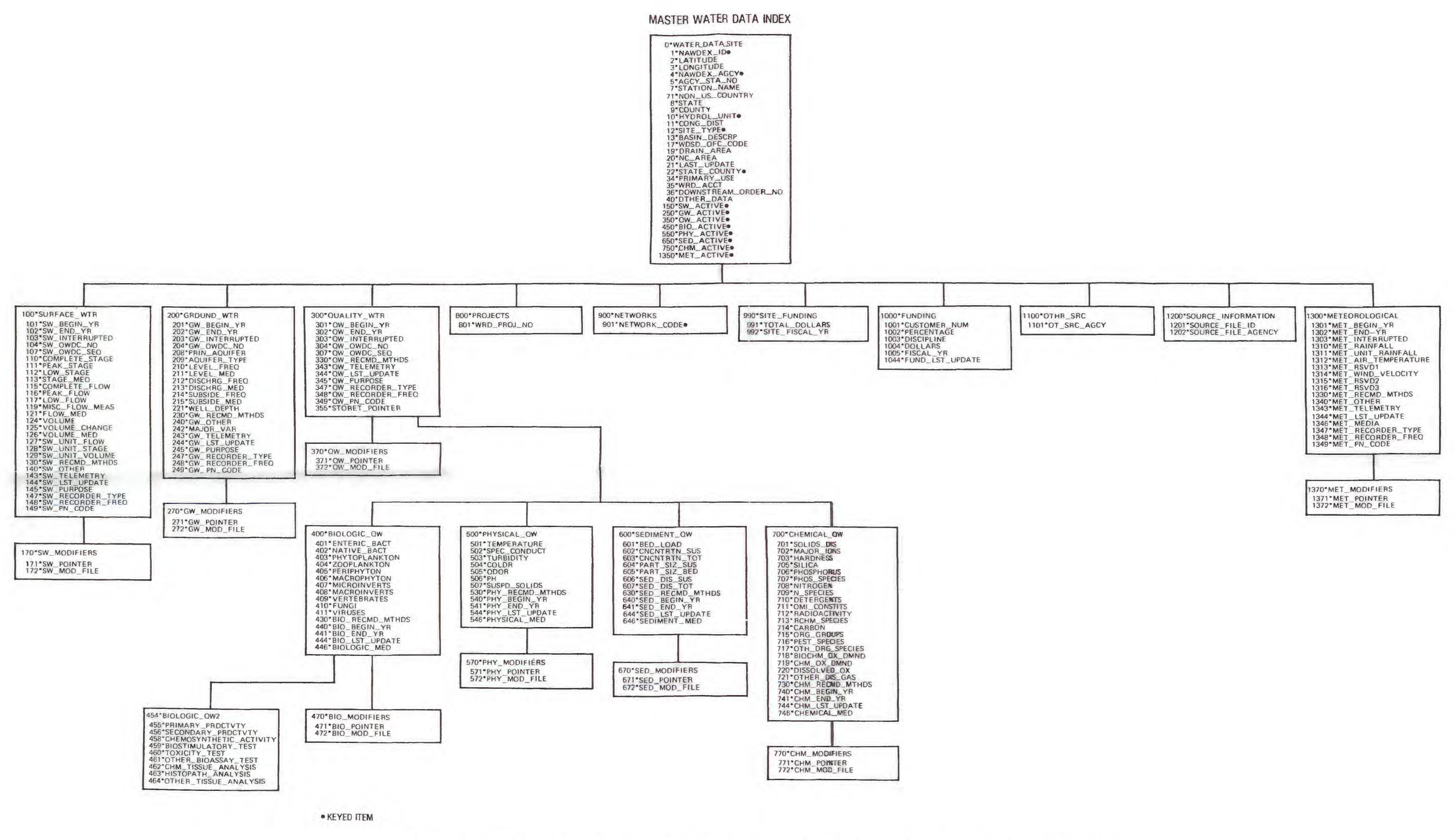

Figure 1.--Hierarchical structure and contents of the Master Water Data Index data base. 


